\section{Las relaciones económicas de Bolivia con Alemania 1880-1920}

COLLOQUIUM VERLAG

\author{
BERLIN
}

Basado en la consulta de la correspondencia consular que se encuentra en los repositorios de diversos archivos de la República Federal de Alemania, la investigación permite compenetrarse en el interés del Imperio Alemán por las riquezas naturales y por la modernización de la infraestructura de Bolivia, en los intentos por atraer capitales alemanes para fomentar la explotación de la goma, en la importancia que adquirió el comercio germano-boliviano con anterioridad.a la Primera Guerra Mundial así como en las razones determinantes del éxito y de las limitaciones del Imperio Alemán en sus relaciones con el país andino. Aparte del carácter novedoso e informativo que este material pueda tener y de la contribución que aporte a los estudios sobre las relaciones entre Alemania y países suramericanos, puede servir también para ampliar y profundizar la investigación sobre las relaciones germano-bolivianas y para emprender estudios de carácter comparativo, sea sobre las relaciones de Alemania con países de América Latina, sea sobre los vínculos de otras naciones altamente desarrolladas con Bolivia.

De su investigación el autor deriva tres conclusiones básicas: 1ra) Las relaciones económicas germano-bolivianas fueron producto de la confluencia de intereses entre una nación urgida por encontrar esferas de expansión e 



(c) 


\section{B I B L I O T H E C A I B E R O-A M E R I C A N A}

Veröffentlichungen des Ibero-Amerikanischen Instituts

Preußischer Kulturbesitz

Herausgegeben von Wilhelm Stegmann

Band 31 
B I B L I O T H E C A I B ER O-A M E R I C A N A

LEÓN ENRIQUE BIEBER

\section{Las relaciones económicas de Bolivia con Alemania 1880-1920}

COLLOQUIUM VERLAG BERLIN 1984 
CIP-Kurztitelaufnahme der Deutschen Bibliothek

Bieber, León Enrique

Las relaciones económicas de Bolivia con Alema-

nia 1880-1920/León Enrique Bieber. - Berlin:

Colloquium Verlag, 1984.

(Bibliotheca Ibero-Americana; Bd. 31)

ISBN 3-7678-0605-3

NE: GT

(C) 1984 Colloquium Verlag $\mathrm{GmbH}$

Satz: Gleißberg \& Wittstock, Berlin

Druck: Color-Druck, Berlin

Schrift: Garamont

Printed in Germany 


\section{PALABRAS DE AGRADECIMIENTO}

El presente trabajo se ha elaborado en el marco de un contrato de trabajo que por siete meses me otorgó el Instituto Ibero-Americano de Berlín Occidental. Agradezco de manera especial al Director de este Instituto, el Dr. Wilhelm Stegmann, por su interés en que se realice la investigación y por su empeño en obtener los fondos para el contrato de la Fundación del Patrimonio Cultural Prusiano. Agradezco, a su vez, al personal del Instituto, que se ha tomado el trabajo de revisar y corregir los manuscritos, así como a aquellos miembros de esta institución que de una u otra manera han colaborado con mi esfuerzo. El fácil acceso a la valiosa Biblioteca del Instituto Ibero-Americano y el cordial ambiente de trabajo que he encontrado en este Instituto han sido valiosos estímulos.

Mis reconocimientos los hago extensivos a mi esposa, Elisabeth, quien mostró gran paciencia y comprensión. 



\section{I $\cdot$ PRÓLOGO}

Los trabajos sobre las relaciones económicas entre países altamente desarrollados y la República de Bolivia son exiguos. Una revisión de los dos voluminosos tomos de bibliografía boliviana de A. Costa de la Torre, que abarcan los años comprendidos entre 1900 y 1963, ${ }^{1}$ de la Bio-Bibliografía Boliviana, que desde 1962 publica anualmente W. Guttentag ${ }^{2}$ o de la historiografía comentada de $\mathrm{Ch}$. W. Arnade sobre la Bolivia colonial y moder$\mathrm{na}^{3}$ permite cercionarse sobre el particular. Ch. W. Arnade publicó con anterioridad a su historiografía comentada una bibliografía selecta sobre Bolivia. Mientras que en el acápite sobre historia no se registra un solo estudio concerniente a las relaciones económicas de este país con naciones desarrolladas, la parte correspondiente a "Miscellanea" incluye únicamente dos trabajos vinculados a esta temática. ${ }^{4}$ Entre las Obras Generales y las obras correspondientes a la Epoca Nacional incluidas en la bibliografía selecta de J. Siles Guevara no figura una sola ficha sobre el tema en cuestión. ${ }^{5}$

De la bibliografía revisada se desprende que de los vínculos financieros y comerciales sustentados por Bolivia con países de fuerte desarrollo industrial solamente aquellos con Gran Bretaña y con los Estados Unidos han sido objeto de análisis. Sobre las relaciones económicas anglo-bolivianas la mayor parte de la literatura se refiere a la fracasada inversión británica en Potosí entre 1825 y 1827. Ella ha sido investigada por Humphreys, Ovando-Sanz y, posteriormente, por Tandeter. ${ }^{6} \mathrm{~J}$. F. Rippy ha hecho un escueto recuento de las inversiones inglesas en Bolivia entre 1873 y $1946 .{ }^{7}$ El libro de R. Querejazu Calvo "Bolivia y los ingleses" es un trabajo sobre la historia de las relaciones diplomáticas entre ambos países que no incursiona en el campo de la economía. ${ }^{8}$ En el marco de una serie de investigaciones financiadas por "The American Fund for Public Service" para examinar el rol del capital de los Estados Unidos en América Latina, M. A. Marsh publicó en 1928 su estudio sobre las inversiones de este país en Bolivia. Descartando la tesis de grado de N. Ness, que no ha podido ser consultada, ese estudio probablemente constituye la investigación más ampliamente documentada que existe hasta el presente sobre la penetración económica norteamericana en Bolivia con anterioridad a la revolución acaecida en este país en 1952. ${ }^{10}$ Análisis sobre las relaciones económicas entre los dos países en la 
fase posterior a 1952 se encuentran sobre todo en trabajos que examinan en un contexto general el desarrollo de Bolivia a partir de aquel año. ${ }^{11}$

Datos estadísticos y referencias de carácter general sobre los nexos financieros y comerciales de Bolivia con potencias extranjeras, sobre todo con Gran Bretaña y los Estados Unidos, se encuentran dispersos en libros y artículos de autores bolivianos que han analizado aspectos relativos al desarrollo de la explotación de materias primas, la economía, las finanzas, la banca y el comercio de su país. En estos trabajos se pueden encontrar alusiones esporádicas a las vinculaciones mantenidas con Alemania.

El complejo de las relaciones económicas entre Bolivia y el Imperio Alemán fundado por Bismarck en 1871 no ha sido estudiado todavía en forma sistemática. Referencias sobre estas relaciones se encuentran tanto en publicaciones alemanas como en publicaciones bolivianas de índole histórica y económica. Una parte substancial de aquellas y varias de éstas se citan a lo largo de este trabajo.

El presente estudio no pretende ser un análisis exhaustivo de las relaciones económicas entre Alemania y Bolivia en el período comprendido entre 1880 y 1920. En él se examina en capítulos separados la ingerencia que tuvo el Imperio Alemán en la explotación de materias primas, en el desarrollo del sistema de transportes y comunicaciones y en el comercio exterior del país andino. Cada uno de estos capítulos peca de claras insuficiencias. Ellas son el resultado de los factores que se explicitan a continuación.

La investigación fue proyectada a partir de la consulta de la correspondencia consular sobre Bolivia que se encuentra en los repositorios de diversos archivos de la República Federal de Alemania. Si bien el material consultado ha permitido desentrañar esferas importantes del conjunto de las relaciones de índole económica entre los dos países y, a su vez, ha hecho posible esclarecer, en diverso grado, pormenores sobre ellas, él no permite disipar una serie de interrogantes; algunas de ellas de importancia medular. En algunos casos la literatura secundaria revisada ha sido de suma utilidad para enfocar aspectos globales del desarrollo de la economía y la infraestructura de Bolivia. En este sentido ella ha facilitado llegar a una percepción más cabal del contexto y trasfondo histórico en los cuales se gestaron y desarrollaron las relaciones germano-bolivianas. Ejemplos al respecto se pueden apreciar en los acápites sobre la extracción de la goma, la construcción de la red ferroviaria y el desarrollo del comercio exterior boliviano. Sin embargo, una gran parte de aquella literatura contiene datos poco fiables. Fechas, cifras o estadísticas pertinentes a una misma cuestión varían, a 
veces de manera pronunciada, de un trabajo a otro y/o están en contradicción con los datos respectivos que contiene el material documental. Una parte apreciable de las obras consultadas, entre ellas varias consideradas clásicas en su materia, carecen de rigidez estructural y de rigor científico. No ha sido posible encontrar un solo trabajo que aborde concienzudamente el problema de las inversiones foráneas realizadas en Bolivia, o un trabajo que analice con amplitud el desarrollo del comercio exterior de este país entre 1880 y $1920 .{ }^{12}$ La literatura dispersa que existe sobre estas cuestiones no permite esclarecer aspectos fundamentales sobre ellas. Hasta el presente no existe un solo trabajo sobre la instalación de las primeras estaciones radiotelegráficas en Bolivia.

Para aclarar las interrogantes que suscitó el estudio del material de archivos y de la literatura secundaria hubiese sido necesario consultar fuentes documentales en otros países, sobre todo en Bolivia. Para ello no existían los medios ni el tiempo necesarios. Como se ha señalado en las Palabras de Agradecimiento, esta investigación contó con apoyo financiero durante 7 meses. Este lapso escasamente fue suficiente para asimilar la bibliografía y redactar los tres capítulos centrales. La recopilación del material documental fue realizada con anterioridad, la parte introductoria y las conclusiones fueron escritas posteriormente.

Desde la perspectiva del autor son las limitaciones expuestas las que básicamente explican las deficiencias que el lector va a encontrar en los siguientes capítulos. Ellas son numerosas y conviene explicitar por lo menos algunas importantes. Si bien parece evidente que hasta 1920 inversiones de capital alemán no jugaron ningún papel importante en la economía boliviana, ha sido imposible establecer su grado de ingerencia en la esfera extractiva. No se ha logrado discernir la probable vinculación de capitales del Imperio Alemán con importantes compañías mineras establecidas por alemanes arraigados en Bolivia, o con la empresa del magnate del estaño Simón Patiño, quien durante la segunda década del presente siglo tuvo nexos financieros con Alemania. Tampoco se pudo establecer de manera definitiva sí y, en su caso, en qué medida capitales de este país incursionaron en la extracción de la goma boliviana. La vinculación que llegaron a tener capitales procedentes del Imperio Alemán con la economía boliviana a través de las poderosas casas comerciales que inmigrantes germanos levantaron en todos los centros importantes del país andino, es otra de las interrogantes que deja abierto este estudio. El material estadístico recopilado sobre el intercambio comercial germano-boliviano es incompleto. Abarca sólo algunos años y su desagregación por rubros es fragmentaria. Aunque las 
estadísticas permitan establecer el carácter estructural del intercambio y apreciar, por ejemplo, el importante impacto que en determinados años tuvo la construcción ferroviaria en Bolivia para las exportaciones de material rodante realizadas por Alemania a este país, no se ha logrado elaborar un cuadro relativamente completo de la composición del comercio entre ambos países para todo el período analizado. Los datos sobre el establecimiento de estaciones radiotelegráficas en Bolivia entre 1915 y 1925 han sido tomadas de la única fuente bibliográfica que se ha encontrado al respecto en la Biblioteca del Instituto Ibero-Americano de Berlín. Durante una breve estadía en la ciudad de La Paz, posterior a la redacción final del trabajo, el autor ha revisado en la Biblioteca Central de la Universidad Mayor de San Andrés los Informes Anuales de la Dirección General de Correos y Telégrafos de Bolivia disponibles para los años de interés. De acuerdo al Informe de 1914-1915, las estaciones de D’Orbigni y de Balliván no fueron instaladas por la Marconi, como se desprende de la fuente consultada en Berlín, sino por la compañía Telefunken. ${ }^{13}$ Esta diversidad de datos hace necesario advertir que el Cuadro III. 5 (Estaciones radiotelegráficas de Bolivia 1925) de este trabajo está sujeto a cuestionamiento.

A parte de las limitaciones señaladas existen interrogantes de carácter puntual. Así, por ejemplo, las siguientes: ¿Por qué a comienzos de la última década del siglo XIX el empresario cauchero boliviano Antonio Vaca Diez no logró obtener créditos en Alemania?; ¿ por qué el Banco Alemán Transatlántico no llegó a recibir la concesión otorgada en 1909 por el gobierno chileno para la construcción del ferrocarril Arica-El Alto de La Paz?; ¿fueron capitales provenientes del Imperio Alemán o capitales de alemanes establecidos en Bolivia los que contribuyeron a la construcción de tranvías eléctricos entre 1910 y 1913 en el valle de Cochabamba?

Si bien las respuestas a este tipo de preguntas no ayudarían a disipar de manera definitiva cuestiones fundamentales sobre las relaciones económicas entre el Imperio Alemán y Bolivia, probablemente su aclaración hubiese permitido precisar las consideraciones que sobre ellas se hacen a lo largo de este estudio.

Con sus deficiencias, los capítulos que siguen permiten compenetrarse en el interés de Alemania por riquezas naturales y por el desarrollo de la infraestructura en Bolivia, en los esfuerzos por atraer capitales de aquel país para la explotación de la goma boliviana, en la importancia que adquirió el comercio germano-boliviano con anterioridad a la Primera Guerra Mundial y en los éxitos y las limitaciones del Imperio Alemán en sus relaciones con el país andino. Aparte del carácter novedoso e informativo que este 
material pueda tener y de la contribución que él aporte a los estudios sobre las relaciones entre Alemania y países suramericanos, puede servir también para ampliar y profundizar la investigación sobre las relaciones germanobolivianas y para emprender estudios de carácter comparativo, sea sobre las relaciones de Alemania con países de América Latina, ${ }^{14}$ sea sobre los vínculos de otras naciones altamente desarrolladas con Bolivia.

Cada uno de los temas abordados comienza con una descripción del desarrollo que a partir de 1880 tuvo en Bolivia el sector en cuestión. A partir de esta descripción, la cual refleja el proceso de integración del país al mercado mundial, se analiza la ingerencia del Imperio Alemán en este desarrollo. Los capítulos contienen un breve balance que incluye intentos de explicar las razones que posibilitaron, dificultaron o impidieron la penetración alemana en los sectores tratados. Una excepción de esta estructuración se presenta en el capítulo sobre el establecimiento de estaciones radiotelegráficas en Bolivia. Debido a la falta de literatura secundaria sobre el particular, la temática se analiza partiendo de una exposición, basada en material documental alemán, sobre la rivalidad que a nivel mundial surgió a comienzos del siglo XX entre la compañía británica Marconi y la compañía alemana Telefunken por establecer sistemas propios de telegrafía sin hilos.

En la medida que ello ha sido factible, y sobre todo en materia de cifras y estadísticas, se ha optado por tomar datos de bibliografía alemana y no boliviana. Esta preferencia parte del razonamiento de que a diferencia de la literatura boliviana utilizada, los documentos, artículos de prensa y libros alemanes consultados son poco asequibles y hasta el presente no han tenido ninguna o solamente una restricta difusión. Al presentar al lector datos prácticamente desconocidos, él tiene la posibilidad de compararlos con aquellos que sin mayores dificultades están a su alcance. De este modo puede persuadirse de las discrepancias, a veces notorias, que entre ellos existe. Algunas de estas discrepancias han sido realzadas a lo largo del trabajo. De la bibliografía alemana citada no sólo los documentos, sino también la mayor parte de los artículos de prensa y libros son contemporáneos al período que abarca este estudio.

La última observación se refiere al período analizado. Inicialmente existió el propósito de extender el análisis hasta 1933, año a partir del cual se producen profundas transformaciones en Alemania a consecuencia del ascenso del Nacional Socialismo al poder. A medida que adelantaba la revisión y selección del material documental, y debido al limitado tiempo disponible, se optó por no avanzar más allá de 1920. Varias razones hacen plausible la 
circunscripción del estudio al período transcurrido entre 1880 y 1920. A partir de aquel año Bolivia empieza a integrarse aceleradamente en el mercado mundial en calidad de productor de materias primas. Elevados índices de producción, rápida modernización de la infraestructura, fuerte incremento del comercio exterior, bonanza económica y una notable estabilidad política caracterizan el desarrollo del país durante esta época, que se cierra definitivamente con la revolución de julio de 1920. Después de su unificación política en 1871, Alemania conoció un inusitado desarrollo industrial, primero en el sector de la industria pesada, luego en el de la industria química y electrónica. La red ferroviaria y la flota mercantil expandieron a ritmo acelerado. Paralelo a la rápida formación de sociedades anónimas y a la formación de sindicatos, carteles, trusts y monopolios, se produjo una vertiginosa concentración de capitales y la fusión de capital industrial con capital bancario. En el campo de la tecnología se dieron importantes innovaciones. Su dinámica económica convirtió al Imperio Alemán en una potencia mundial de primer orden con marcadas ambiciones imperialistas. Esta etapa del desarrollo de la historia alemana termina en 1918 con la derrota sufrida en la Primera Guerra Mundial y la transformación del Imperio en una República.

El presente trabajo abarca, entonces, períodos claramente definidos de la historia de ambos países. Para Bolivia se trata del período que va desde los inicios hasta los primeros síntomas de crisis del orden neocolonial; para Alemania el que se extiende del ascenso a potencia mundial hasta el debacle experimentado durante la primera gran conflagración mundial. Inicio y conclusión de este ciclo se reflejan claramente en las relaciones entre los dos países. A partir de los años 80 del siglo pasado empezaron a expandir sus relaciones comerciales. Corolario de esta expansión fue el establecimiento de relaciones diplomáticas en 1902. En 1917 Bolivia rompió estas relaciones. En aquel año el intercambio comercial germano-boliviano había perdido toda importancia debido a las repercusiones de la Primera Guerra Mundial. 


\section{II · LA EXPLOTACIÓN DE MATERIAS PRIMAS EN BOLIVIA Y EL IMPERIO ALEMĀN}

Entre el último cuarto del siglo XIX y la segunda década del siglo XX Bolivia conoció un impetuoso desarrollo de la producción minera y un auge de la explotación de la goma natural. La extracción de este producto, así como la de la plata y posteriomente del estaño, constituyeron el eje alrededor del cual giró la economía boliviana.

En los dos acápites siguientes se expondrán detalles sobre este particular y se analizará la ingerencia que Alemania buscó o logró obtener en el desarollo de la explotación de las principales materias primas bolivianas. El capítulo cierra con una evaluación sobre la influencia que tuvo el Imperio Alemán en el sector extractivo del país andino.

\section{El caso de la producción minera}

Bolivia en el primer cuarto siglo de vida independiente, vale decir de 1825 a 1850 , atravesó por una fase de profunda decadencia de la producción minera. Sólo después de 1850 se reiniciaron labores de cateo de escala más o menos apreciable en centros mineros ya explotados durante la época colonial. Sin embargo, recién el último cuarto del sigloXIX fue un período de verdadera expansión de la minería debido al resurgimiento de la extracción argentífera en vasta escala. ${ }^{1}$ A partir de entonces el desarollo del sector minero fue colosal. A este hecho contribuyeron básicamente la explotación de la plata y del estaño.

La producción de la plata se elevó de 13.5 millones de onzas en el quinquenio 1870-1874 a 76.5 millones de onzas en el lustro 1890-1894; es decir que ella llegó más que a quintuplicarse en el correr de dos decenios. Con casi 20 millones de onzas la producción llegó a su cenit en 1895. De ahí en adelante la explotación argentífera sufrió un notorio deterioro y empezó a perder cada vez mayor importancia como producto de exportación. ${ }^{2}$ Pfannenschmidt estima que hacia 191310.000 minas de plata estaban abandonadas. ${ }^{3}$ Durante los últimos tres decenios del siglo XIX el desarollo de la minería de la plata permitió a Bolivia acrecentar su participación en la producción argentífera mundial. Esta participación se elevó de aproximadamente un 
Mapa II.1

Bolivia: Depósitos Minerales en el Macizo Boliviano

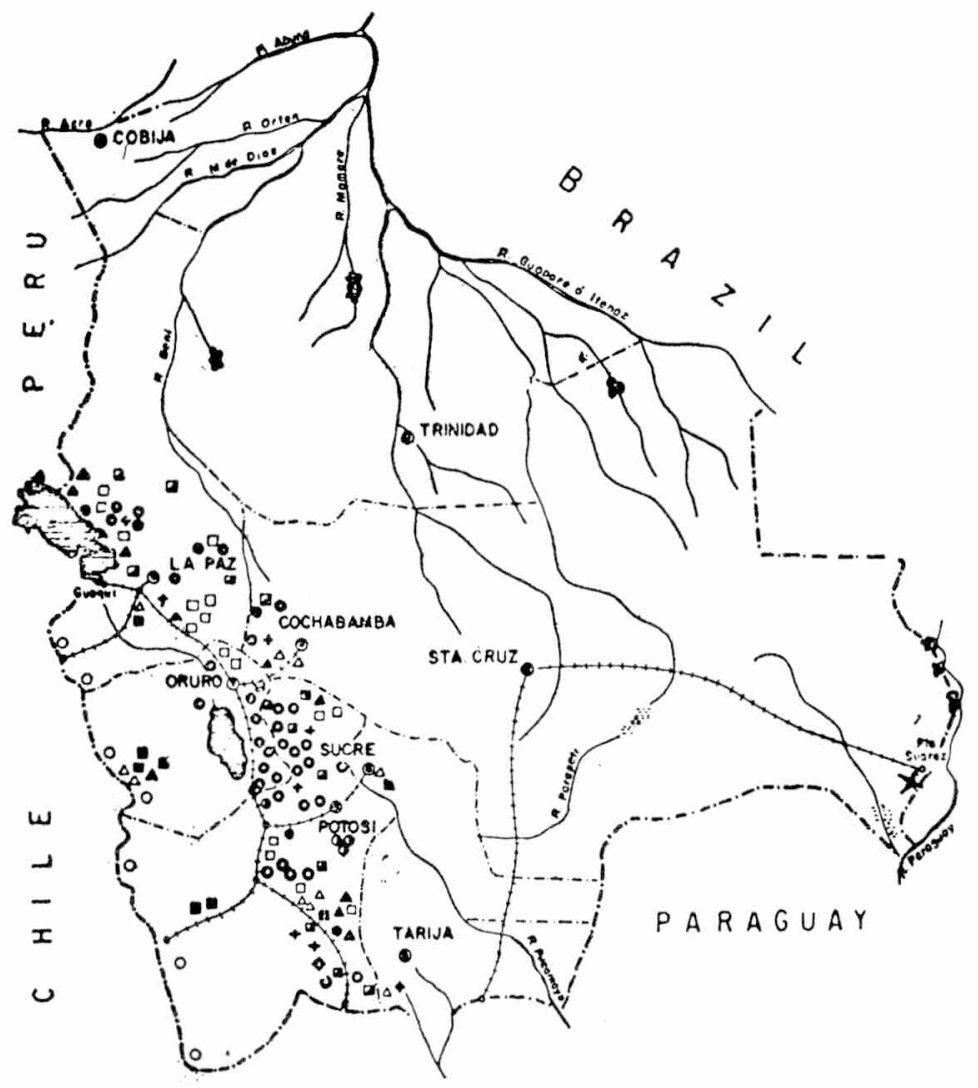

REFERENCIA

Escand $\ldots \ldots \ldots \ldots \ldots \ldots . . . . . .6$

Plate y Estrino ..............

Wolftum .................

Plenmo y Zine ............

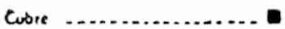

Ma1, ....................

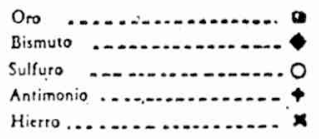


Cuadro II.1

Producción de plata en Bolivia

(en onzas)

\begin{tabular}{l|r|r|r|r|r}
\hline Año & Anual & Quinquenal & Año & Anual & Quinquenal \\
\hline 1870 & 2.672 .000 & & 1890 & 13.216 .000 & \\
1871 & 2.355 .000 & & 1891 & 13.743 .000 & \\
1872 & 2.689 .000 & & 1892 & 17.229 .000 & \\
1873 & 2.895 .000 & & 1893 & 14.893 .000 & \\
1874 & 2.910 .000 & $\ldots 13.521 .000$ & 1894 & 17.487 .000 & $\ldots .76 .568 .000$ \\
1875 & 3.245 .000 & & 1895 & 19.912 .000 & \\
1876 & 4.707 .000 & & 1896 & 12.115 .000 & \\
1877 & 5.938 .000 & & 1897 & 13.232 .000 & \\
1878 & 7.548 .000 & & 1898 & 10.432 .000 & \\
1879 & 7.834 .000 & $\ldots 29.270 .000$ & 1899 & 9.545 .000 & $\ldots .65 .236 .000$ \\
1880 & 10.150 .000 & & 1900 & 13.469 .000 & \\
1881 & 8.231 .000 & & 1901 & 8.975 .000 & \\
1882 & 11.871 .000 & & 1902 & 8.294 .000 & \\
1883 & 11.254 .000 & & 1903 & 5.516 .000 & \\
1884 & 10.976 .000 & $\ldots 52.482 .000$ & 1904 & 3.203 .000 & $\ldots 39.457 .000$ \\
1885 & 10.801 .000 & & & & \\
1886 & 12.085 .000 & & & & \\
1887 & 11.708 .000 & & & & \\
1888 & 12.449 .000 & & & & \\
1889 & 12.340 .000 & $\ldots 59.383 .000$ & & & \\
\hline
\end{tabular}

Fuente: Antonio Mitre, The Economic and Social Structure of Silver Mining in XIX Century in Bolivia, Ann Arbor 1981 (reprint Ph.D. Columbia University 1977), pp. 278-279.

\section{Cuadro II.2}

Participación por países en la producción mundial de la plata (millones de onzas)

\begin{tabular}{l|c|c|c|c}
\hline Años & México & $\begin{array}{l}\text { Estados } \\
\text { Unidos }\end{array}$ & Bolivia & Total \\
\hline $1861-1870$ & 160 & 78 & 20 & 408 \\
$1871-1880$ & 190 & 279 & 40 & 710 \\
$1881-1890$ & 270 & 414 & 110 & 1.000 \\
$1891-1900$ & 480 & 567 & 130 & 1.600 \\
$1901-1910$ & 640 & 557 & 40 & 1.800 \\
\hline
\end{tabular}

Fuente: A. Mitre, op. cit., p. 277. 
Gráfico II.1

Participación por países en la producción mundial de la plata

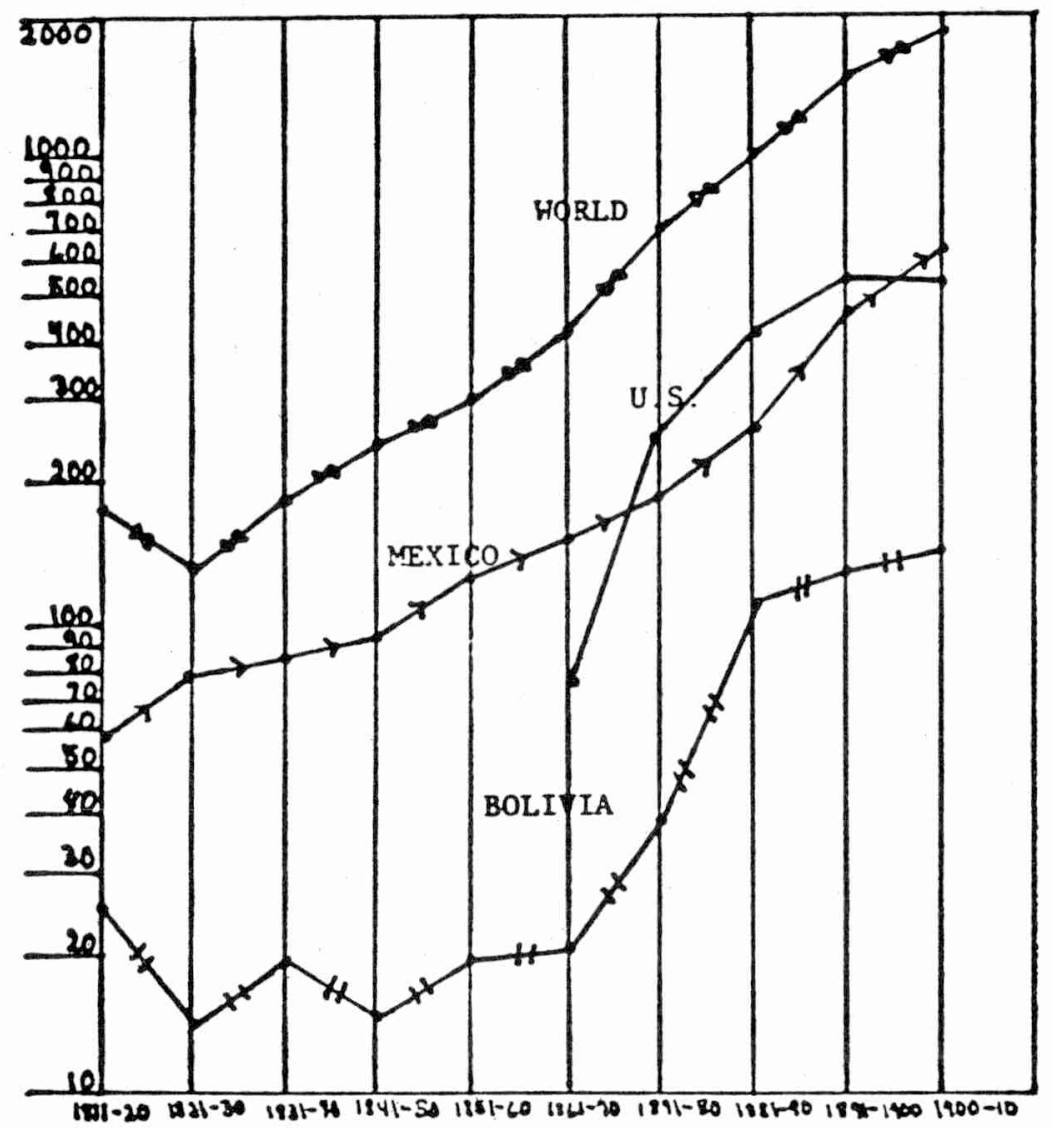

Fuente: A. Mitre, op. cit., p. 29.

$5 \%$ entre 1861 y 1870 a casi $7 \%$ en la década siguiente. Entre 1881 y 1890 alcanzó un promedio de $11 \%$ para descender a algo más del $8 \%$ en el último decenio del siglo pasado. A comienzos del presente siglo ella llegó escasamente a algo más del $2 \%$ (veáse Cuadro II. 2). 


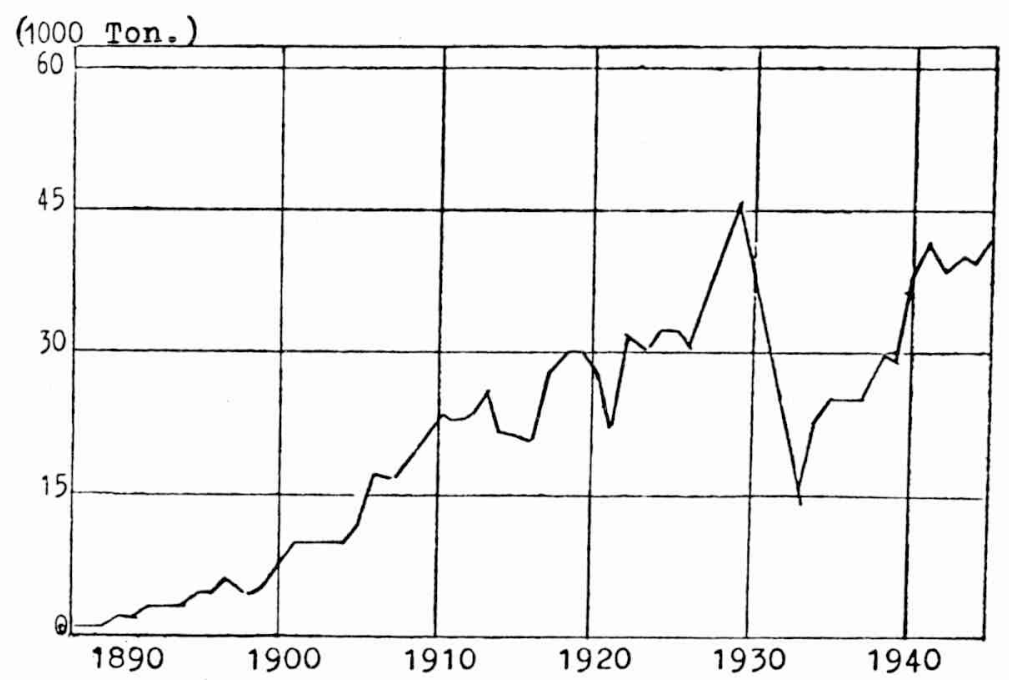

Fuente: Eduardo Klein Koch, Grundzüge der geschicbtlichen Entwicklung des Exportsektors und des Staates in Bolivien (1545-1952), Marburg/Lahn (Inaugural-Dissertation) 1978 , p. 305.

Si bien durante el período considerado el aporte de Bolivia a la producción mundial de la plata fue marcademente inferior a la de los Estados Unidos y a la de México, una comparación con este último país muestra que entre 1871 y 1890 el incremento porcentual de la participación boliviana fue manifiestamente mayor. De 1860 a 1890 la disparidad que había existido anteriormente en el aporte de los dos países llegó a reducirse notoriamente (veáse gráfico II. 1)

De manera prácticamente paralela al ocaso de la producción argentífera comenzó en Bolivia la explotación masiva del estaño. El monto de la producción estañífera se elevó de algo menos de 3.000 toneladas finas en 1892 a casi 10.000 en 1900 para seguir ascendiendo a aproximadamente 18.000 en 1908 y llegar a las 30.000 toneladas finas al cerrarse la segunda década del presente siglo. 
Cuadro II.3

Producción del estaño en Bolivia

(toneladas finas)

\begin{tabular}{l|c|c|c}
\hline Año & Monto & Año & Monto \\
\hline 1892 & 2819 & 1900 & 9740 \\
1893 & 2909 & 1901 & 13149 \\
1894 & 3482 & 1902 & 10564 \\
1895 & 4097 & 1903 & 13280 \\
1896 & 3892 & 1904 & 12927 \\
1897 & 4298 & 1905 & 16603 \\
1898 & 3464 & 1906 & 17624 \\
1899 & 3940 & 1907 & 16608 \\
& & 1908 & 17962 \\
\hline
\end{tabular}

Fuente: Julius Uzarski, Bolivia. Natur und wirtschaftliche Verbältnisse, Bonn (Inaugural-Dissertation) 1911, p. 78.

Una comparación del Cuadro II. 3 con el Cuadro II. 4 muestra que prácticamente toda la producción de estaño era destinada a la exportación. Entre 1900 y 1920 el valor comercial de la exportación del estaño casi se decuplicó. Mientras que en aquel año arrojó una suma de 14.6 millones de bolivianos llegó a 112.2 millones de bolivianos en 1920 .

Como en el caso de la plata en las postrimerías del siglo XIX, aunque de manera más pronunciada todavía, la expansión de la minería del estaño permitió una mayor participación de Bolivia en la producción mundial de minerales. El aporte boliviano de estaño al total de la producción mundial de este metal se elevó de un promedio de $0.41 \%$ entre 1851 y 1875 a un promedio de $3.12 \%$ entre 1876 y 1900 , alcanzando un término medio de $18.51 \%$ en el primer cuarto del siglo $\mathrm{XX}^{4}$

Con el auge de la producción de la plata y a partir de 1900 con la del estaño Bolivia pasó definitivamente a ser un país exportador de materia prima mineral. De 1900 a 1920 (con excepción de 1916) no se registra año alguno en el cual el total de la participación deestos dos productos en las exportacio- 


\section{Cuadro II.4}

Exportación de estaño de Bolivia

(volúmenes y valores)

\begin{tabular}{|c|c|c|c|c|}
\hline Año & $\begin{array}{l}\text { Peso bruto } \\
\text { Ton. mét. }\end{array}$ & $\begin{array}{l}\text { Peso fino } \\
\text { Ton. mét. }\end{array}$ & $\begin{array}{c}\text { Valor com. } \\
\text { Bs. }\end{array}$ & $\begin{array}{c}\text { Promedio de } \\
\text { cotizac. } £\end{array}$ \\
\hline $1900 \ldots$ & 16.230 & 9.739 & 14.608.080.- & 131.11.- \\
\hline $1901 \ldots$ & 21.910 & 13.146 & 17.532.720.- & 118.12.- \\
\hline $1902 \ldots$ & 17.610 & 10.566 & 15.847.470.- & 120.14.- \\
\hline $1903 \ldots$ & 20.930 & 12.558 & 19.540.320.- & 127.06.- \\
\hline $1904 \ldots$ & 21.550 & 12.930 & 17.064.190.- & 126.14.- \\
\hline $1905 \ldots$ & 27.690 & 16.614 & 26.250.370.- & 149.19.- \\
\hline $1906 \ldots$ & 29.370 & 17.622 & 35.248.250.- & 179.12.- \\
\hline $1907 \ldots$ & 27.680 & 16.608 & 29.892.000.- & 173.15.- \\
\hline $1908 \ldots$ & 29.940 & 17.964 & 30.928.800.- & 132.17.- \\
\hline $1909 \ldots$ & 35.570 & 21.342 & 31.654.110.- & 134.08.- \\
\hline $1910 \ldots$ & 38.550 & 23.130 & 37.006.500.- & 154.10.- \\
\hline $1911 \ldots$ & 37.070 & 22.242 & 52.639.600.- & 192.05.- \\
\hline $1912 \ldots$ & 38.610 & 23.166 & 60.238.200.- & 208.14.- \\
\hline $1913 \ldots$ & 44.590 & 26.754 & 67.784.370.- & 202.18.- \\
\hline $1914 \ldots$ & 37.260 & 22.356 & $42.479 .890 .-$ & 156.06.- \\
\hline $1915 \ldots$ & 36.490 & 21.894 & 44.885.450.- & 163.10.- \\
\hline $1916 \ldots$ & 35.540 & 21.324 & $42.652 .260 .-$ & 182.01.- \\
\hline $1917 \ldots$ & 46.430 & 27.858 & 85.258.480.- & 237.06.- \\
\hline $1918 \ldots$ & 48.800 & 29.280 & 129.611.140.- & 329.11.- \\
\hline $1919 \ldots$ & 48.500 & 29.100 & 99.924.440.- & 257.06.- \\
\hline $1920 \ldots$ & 47.050 & 28.230 & 112.282.400.- & 295.09.- \\
\hline
\end{tabular}

Fuente: Luis Peñaloza, Historia Económica de Bolivia, t. II, La Paz 1954, pp. 233-234. ${ }^{5}$

nes del país llegó a descender a menos del 50\%. Su promedio de participación anual fue del $66.63 \%$ y del $67.3 \%$ entre 1900 y 1910 y entre 1911 y 1920 respectivamente. A partir de 1903 la plata, que un año antes constituyó todavía el $42 \%$ del total exportado, dejó de ser un producto de importancia en el comercio exterior. De aquel año en adelante el estaño se convirtió en el producto de exportación absolutamente preeminente. 


\section{Cuadro II.5}

Bolivia: Participación porcentual del estaño $y$ de la plata en el total de las exportaciones

\begin{tabular}{|c|c|c|c|c|}
\hline Año & Estaño & Plata & Total & $\begin{array}{l}\text { Promedio } \\
\text { anual }\end{array}$ \\
\hline 1900 & 24,0 & 36,6 & 60.6 & \multirow{15}{*}{66.63} \\
\hline 1901 & 25,0 & 30,3 & 55.3 & \\
\hline 1902 & 31,3 & 42,0 & 73.3 & \\
\hline 1903 & 77,3 & & & \\
\hline 1904 & 54,2 & 12,3 & 66.5 & \\
\hline 1905 & 62,8 & 9,2 & 72.0 & \\
\hline 1906 & 63,3 & 8,6 & 71.9 & \\
\hline 1907 & 59,4 & 12,9 & 72.3 & \\
\hline 1908 & 63,2 & 16,5 & 79.7 & \\
\hline 1909 & 49,6 & 9,0 & 58.6 & \\
\hline 1910 & 48,9 & 7,2 & 56.1 & \\
\hline 1911 & 63,7 & 5,5 & 69.2 & \\
\hline 1912 & 66,8 & 4,8 & 71.6 & \\
\hline 1913 & 72,3 & 3,0 & 75.3 & \\
\hline 1914 & $\cdot$ & $\cdot$ & & \\
\hline 1915 & 47,2 & 3,1 & 50.3 & \multirow[t]{6}{*}{67.3} \\
\hline 1916 & 42,0 & 4,4 & 46.4 & \\
\hline 1917 & 54,0 & 3,6 & 57.6 & \\
\hline 1918 & 71,0 & 4,1 & 75.1 & \\
\hline 1919 & 69,3 & 8,6 & 77.9 & \\
\hline 1920 & 72,0 & 10,3 & 82.3 & \\
\hline
\end{tabular}

Fuente: E. Klein Koch, op. cit., p. 307. Las cifras del Total y del Promedio Anual han sido calculadas por L.B.

Dado que Bolivia no sólo exportaba plata y estaño sino también varios otros minerales, los porcentajes anuales de la participación de la minería en el comercio exterior del país eran todavía más elevados que los registrados en el Cuadro II.5. Así, por ejemplo, en 1902 el sector minero contribuyó con el $78.75 \%$ al total exportado (22.083.653 bolivianos sobre un total exportado de 28.041 .578 bolivianos) $^{6}$ y en 1903 con más del $80 \%$ (21.674.629 bolivianos sobre un total de 25.169.148). ${ }^{7}$ Del total de las exportaciones que realizó el país en 1907 y en 1908 el $80 \%$ y el $83 \%$ respectivamente provinieron de la venta de minerales. ${ }^{8}$ Aparte de plata y estaño Boli- 


\section{Cuadro II.6}

Bolivia: Exportación de minerales en el quinquenio anterior a la Primera Guerra Mundial

\begin{tabular}{|c|c|c|c|c|c|}
\hline & \multicolumn{5}{|c|}{ Kilogramos } \\
\hline Estaño & 35566415 & 38548441 & 37073148 & 38614228 & 44594749 \\
\hline Plata & 155360 & 142977 & 127900 & 123939 & 81289 \\
\hline Cobre & 3096605 & 3211987 & 2950023 & 4707188 & 4019635 \\
\hline Bismuto & 236762 & 311060 & 414598 & 477748 & 422484 \\
\hline Tungsteno & 152600 & 210061 & 297272 & 474640 & 282597 \\
\hline Zinc & 602000 & 11897000 & 9798125 & 8961352 & 7367463 \\
\hline Plomo & 7000 & 30485 & 443188 & 1074887 & 1765296 \\
\hline Antimonio & 494440 & 524878 & 311715 & 91350 & 62050 \\
\hline Oro en barras & 42 & - & 55 & 78 & 93 \\
\hline Oro sellado & - & - & - & 898 & 98 \\
\hline \multirow[t]{3}{*}{ Plata sellada } & - & - & - & 10491 & 5084 \\
\hline & 1909 & 1910 & 1911 & 1912 & 1913 \\
\hline & \multicolumn{5}{|c|}{ Pesos bolivianos } \\
\hline Estaño & 31654109 & 37006503 & 52639603 & 60238196 & 67784377 \\
\hline Plata & 5721915 & 5476597 & 4587745 & 4308329 & 2784354 \\
\hline Cobre & 1641201 & 1786952 & 1426942 & 3389175 & 2773546 \\
\hline Bismuto & 1451075 & 1923417 & 2106162 & 2150042 & 2092925 \\
\hline Tungsteno & 97691 & 141629 & 231187 & 519705 & 415417 \\
\hline Zinc & 26325 & 435008 & 372490 & 329995 & 223150 \\
\hline Plomo & 152 & 700 & 23546 & 214977 & 553059 \\
\hline Antimonio & 51260 & 97080 & 68418 & 22837 & 12410 \\
\hline Oro en barras & 57306 & - & 94906 & 144275 & 163900 \\
\hline Oro sellado & - & 7187 & - & 1297375 & 153750 \\
\hline Plata sellada & - & 5501 & 791507 & 432400 & 212431 \\
\hline Totales & 40701034 & 46880574 & 62342506 & 73047306 & 77169319 \\
\hline
\end{tabular}

Fuente: E. Pfannenschmidt, Boliviens Land- und Volkswirtschaft, Berlin 1916, p. 52.

via producía cobre, bismuto, tungsteno, zinc, plomo, antimonio y oro. De estos metales sólo los dos nombrados en primer orden tenían una apreciable gravitación económica. Si bien la importancia del cobre y del bismuto quedó muy por debajo de la que tenía el estaño, hacia 1913 el valor de la producción de cada uno de ellos llegó casi a igualar al de la plata. 
En una conferencia pronunciada en 1916 en Buenos Aires ante la Asociación Alemana de Ingenieros, R. Stappenbeck expuso con toda claridad el grado de dependencia externa que Alemania había alcanzado en 1910 respecto al suministro de productos minerales. Exceptuando el carbón, el zinc y el vanadio, del cual el país se abasteció a través de su colonia Deutsch-Südwest-Afrika, el resto del consumo mineral debía ser cubierto, en mayor o menor escala, con importaciones. La producción nacional de pirita sólo cubría $1 / 6$, la de plata $1 / 5$, la de plomo $1 / 3$ y la de hierro $3 / 5$ del consumo interno. Las 34.900 toneladas de cobre y las 100 de tungsteno extraídas en el país en aquel año obligaron a importar 181.500 toneladas de aquel y 2.491 de este metal. Hubo que introducir oro por valor de 243 millones de marcos mientras que su exportación escasamente llegó a 38 millones de marcos. Casi todo el bismuto, estaño, tungsteno, manganeso y petróleo y todo el antimonio, mercurio, platino, cerio y torio (estos últimos de vital importancia para la industria eléctrica) tuvieron que importarse. Elevado era también el porcentaje de importación de sales minerales como el salitre y el bórax. ${ }^{9}$

Enfrentado a esta falta de recursos naturales para cubrir su demanda interna, el Imperio Alemán ya a fines del siglo XIX importaba materia prima mineral de Bolivia. Ella constituía el grueso absoluto de las compras que realizaba de este país. Los datos siguientes reflejan este hecho. En 1893 el $97.5 \%$ de las exportaciones bolivianas destinadas a Alemania fueron minerales. ${ }^{10}$ El año 1901 Alemania, de acuerdo con datos recopilados por Sievers, importó de Bolivia mercaderías por valor de 66 millones de marcos, de los cuales aproximadamente 48.5 millones fueron entregados por concepto de venta de productos del sector minero. La adquisición de plata por valor de 25.5 millones de marcos fue de lejos la más significativa. A ella siguieron en orden de importancia la de estaño (16.4 millones), bismuto (2.6 millones), cobre ( 2 millones), oro (aproximadamente 1 millón) y antimonio (approximadamente 1 millón). ${ }^{11}$ Es decir que del total de las exportaciones realizadas por Bolivia a Alemania en 1901, el $73.48 \%$ fueron minerales. Este porcentaje descendió a un $65.7 \%$ en $1904^{12}$ para elevarse nuevamente y llegar al $87.89 \%$ en 1908. En este último año no fue más la plata sino el estaño el producto más importante de las exportaciones de Bolivia a Alemania. Sobre un total de 15.7 millones de marcos aquel metal contribuyó con sólo 400.000 marcos, mientras que el valor de éste ascendió a 11.9 millones de marcos, es decir que conformaba el $75.79 \%$ del total de las ventas realizadas. ${ }^{13}$ En el correr de la primera década del presente siglo, un 80 a un $85 \%$ del estaño que consumía Alemania provino de las minas bolivianas. ${ }^{14}$ Según Stappenbeck, Alemania en 1910 importó de Bolivia 17.347 
toneladas de estaño por un valor de 26.709 .000 de marcos. ${ }^{15}$ De acuerdo con las cifras detalladas en el Cuadro II.4, la exportación de estaño en aquel año ascendió a 23.130 toneladas finas. De ser correctas ambas cifras, Alemania habría importado el $74.99 \%$ de la producción estañífera boliviana de 1910. El mencionado autor señala a su vez que las 12.4 toneladas de plata que Bolivia exportó en 1912 fueron enviadas en su totalidad a Alemania. ${ }^{16}$

El Imperio Alemán, a pesar de haberse convertido en una nación altamente dependiente de la importación de minerales, a pesar de su afán por obtener esferas de influencia para asegurarse el aprovisionamiento con materias primas del subsuelo y a pesar de la importancia que para él habían llegado a adquirir las importaciones bolivianas de plata, bismuto y particularmente las del estaño, no logró incursionar de manera notoria en la explotación minera de Bolivia. En cualquier caso la importancia del capital alemán en la minería de este país fue muy reducida si se la compara con los intereses que Gran Bretaña y, en época posterior, los Estados Unidos tuvieron en este sector.

Las primeras inversiones extranjeras apreciables que se realizaron en Bolivia después de 1850 se concentraron en la región desértica del Litoral. Ellas fueron consecuencia de bizarras licencias de explotación que se otorgaron durante el gobierno de Melgarejo (1864-1871) a empresarios y compañías extranjeras, sobre todo para la explotación de cobre y de yacimientos de salitre y de guano. Hasta 1880, año en el cual Bolivia, como consecuencia de la Guerra del Pacífico, tuvo que ceder su litoral a Chile, empresarios brasileros (Pedro López Gama), franceses (Luciano Armand) y, sobre todo, empresarios y compañías chilenas, británicas y estadounidenses ("Sociedad Explotadora del Desierto de Atacama", "Melbourne Clark and Company", "Compañía de Salitres y Ferrocarril de Antofagasta") explotaron las riquezas naturales de aquella región. ${ }^{17}$

A diferencia de lo ocurrido en la costa boliviana, donde desde un principio capitales extranjeros controlaron la explotación, el resurgimiento de la minería en el interior del país se organizó a base de capitales nacionales. ${ }^{18}$ Sólo a partir de 1875 aproximadamente empezaron a afluir inversiones foráneas al sector minero de la región altiplánica. Dos hechos determinaron este desarollo: por un lado la patente debilidad de los empresarios nacionales para realizar costosas obras de modernización, tanto en el campo de la explotación como de la refinación de minerales, por el otro, la creciente demanda por productos mineros bolivianos en el mercado mundial. Sin embargo, hasta los inicios de la explotación del estaño en vasta escala a comienzos del presente siglo, la incursión de capitales extranjeros 
no alcanzó grados significativos y fue insignificante en términos comparativos latinoamericanos. Uno de los primeros grandes pioneros de la minería boliviana, José Avelino Aramayo, ha destacado esta situación a mediados de la década del 70 del siglo pasado cuando, refiriéndose a las reservas británicas de invertir capital en Bolivia, escribió: „Les ofrecemos la mitad de todo un Potosí, en cambio de un poco de ciencia y de dinero para remover aquellas riquezas y nos dicen secamente que no quieren tesoros en Bolivia: les presentamos informes positivos sobre nuestros productos vegetales y minerales, con planos levantados por ingenieros ingleses, y no nos escuchan, ... En suma, todo cuanto tiene contacto con el nombre de Bolivia, es rechazado con desdén en el mercado inglés. ${ }^{\text {19 }}{ }^{\text {En efecto, Gran }}$ Bretaña, el único país que en el siglo XIX realizó cuantiosas inversiones en la minería latinoamericana, apenas mostró interés alguno por la minería boliviana. Hasta 1890 aquel país invirtió 8.540.000 de libras esterlinas en la producción minera mexicana y 2.910.000 en la colombiana. Las inversiones británicas en el sector minero boliviano en aquel mismo año llegaron escasamente a las 520.000 libras esterlinas, suma que estaba incluso por debajo del capital que Londres tenía invertido en la Argentina (570.000 libras esterlinas), país mucho más pobre que Bolivia en recursos minerales. ${ }^{20} \mathrm{~A}$ pesar del interés relativamente restrictivo del capital foráneo por la minería boliviana, no cabe duda que él jugó un rol fundamental en el proceso de concentración y centralización de la producción minera y que obtuvo un control altamente significativo en la industria extractiva del país altiplánico. Como ya se ha insinuado, el capital que incursionó en la industria extractiva boliviana fue básicamente inglés $y$, posteriormente, norteamericano.

La Compañía Huanchaca, que después de 1870 se convirtió en la empresa argentífera más grande de Bolivia y en segunda productora mundial de plata, fue organizada en 1832 por empresarios mineros bolivianos. Debido a la falta de capital, tuvo que ser reorganizada en 1873, hecho que determinó un predominio de capitales chilenos en la empresa.

A partir de 1880 la creciente necesidad de nuevos aportes financieros para realizar costosas obras de modernización que tenían por finalidad racionalizar y elevar la producción obligaron a contratar nuevos empréstitos. Un consiguiente endeudamiento llevó a la disolución de la empresa en 1891 para dar paso a la fundación de una nueva compañía que con un capital inicial de 1.6 millones de libras esterlinas quedó dominada por intereses británicos. Créditos tomados a fines de siglo de la CasaJ.H. Schroeder de Londres, así como la caída del volumen y el valor de la producción, obligaron a 


\section{Cuadro II.7}

List of Sharebolders of the

Huanchaca Company, 1874

\begin{tabular}{lr} 
Bolivia & \\
Arce & 1.000 \\
$\quad$ Sub-Total & 1.000 \\
Chile & \\
Dorado & 611 \\
Peró & 600 \\
Concha y Toro & 365 \\
Balmaceda & 70 \\
Others & 281 \\
Sub-Total & 1.927 \\
Europeans & 73 \\
Total & 3.000 \\
\hline
\end{tabular}

Fuente: Compañía Huanchaca de Bolivia. Primera Memoria del Directorio e Informe del Administrador General, Valparaiso 1874, apéndice 1, en: A. Mitre, op. cit., p. 293.

la nueva compañía en 1899 a entablar negociaciones con la Guggenheim Brothers de Nueva York, la cual asumió el control de la empresa en 1901. ${ }^{21}$ La historia de la Compañía Huanchaca, vale decir su transformación de una empresa controlada por empresarios bolivianos en una empresa dominada primero por capitales ingleses y luego norteamericanos, fue típica para prácticamente todas las grandes empresas mineras que surgieron en Bolivia después de 1850. En 1857 José A. Aramayo organizó la Compañía del Real Socavón con la finalidad de reiniciar labores mineras en el Real Socavón del Cerro Rico de Potosí. Tres décadas más tarde, en 1886, esta empresa quedó dominada por capitales británicos constituyéndose una nueva sociedad, "The Royal Silver Mines of Potosi, Bolivia Limited", en Londres con un capital de 300.000 libras esterlinas. ${ }^{22}$ A partir de 1866 José A. Aramayo y su hijo Félix emprendieron actividades mineras de mucho mayor importancia que las del Real Socavón. En aquel año el subprefecto de la provincia de Chichas (departamento de Potosí) les otorgó derechos de cateo en el Cerro Grande del Chorolque y en los cantones ubicados entre Cotaigata y Portugalete. Para iniciar los trabajos en aquellas regiones, los 
Aramayo formaron la Sociedad Minera y Mercantil Aramayo y Co. La explotación de plata, bismuto y, a partir de la última década del siglo XIX, de estaño, aseguró el ascenso económico de estos empresarios. Como en el caso de la Compañía Huanchaca y debido a exactamente las mismas razones (necesidad de créditos y consecuente endeudamiento), el capital de la empresa se internacionalizó rápidamente. Las principales oficinas de la compañía pasaron a establecerse en Londres. En 1916 una reorganización llevó a la formación de la Compagnie Aramayo de Mines en Bolivie con un capital de 25 millones de francos y sede central en Ginebra. En la década siguiente, la Guggenheim Brothers de Estados Unidos adquirió por un valor de 2.5 millones de libras esterlinas 1/3 del capital de esta compañía, pasando a controlar su dirección y casi toda su sección administrativa. ${ }^{23}$ Los ejemplos señalados muestran cómo, a partir de inicios del presente siglo, capitales británicos empezaron a ser desplazados por intereses norteamericanos. Evidentemente en la historia de la minería boliviana la transición de la época de la explotación de la plata a la época de la explotación del estaño fue acompañada de un relevo de la influencia británica por la norteamericana. En la tercera década del siglo XX los Estados Unidos controlaban o tenían una fuerte influencia en las siguientes empresas estañíferas de Bolivia: Caracoles Tin Company (subsidiaria de la Guggenheim Brothers), International Mining Company (subsidiaria de la W.R. Grace and Company), Berenguela Tin Mines Ltd. (adquirida de Gran Bretaña en 1924), Compañía General de Minas en Bolivia, Andes Tin Corporation y la pequeña Bolivia Tin Corporation. Además, aquel país en 1924 adquirió una parte importante de las propiedades de Simón Patiño, quien en base a trabajos realizados desde comienzos del siglo había logrado levantar la empresa minera privada más grande que conoció Bolivia y quien para aquel entonces ya controlaba una serie de empresas que tuvieron su fase de esplendor durante el auge de la plata entre 1870 y 1890 . En el mencionado año se unificaron en una sola empresa las minas de Llallagua y Uncía y el ferrocarril Machacamarca-Uncía; todas propiedades de Patiño. De esta fusión surgió una nueva empresa con fuerte participación norteamericana, la Patiño Mines and Enterprises Consolidated con sede en Delaware. ${ }^{24}$ Con esta participación los Estados Unidos llegaron a controlar aproximadamente $2 / 3$ partes de la producción estañífera de Bolivia. ${ }^{25}$ Capitales norteamericanos también estaban presentes en la extracción de oro, plomo, plata y tungsteno. A partir de 1920 ellos obtuvieron importantes concesiones para la exploración petrolera. De acuerdo con M. A. Marsh, a fines de 1924, del total de las inversiones mineras realizadas en Bolivia, 2/3 partes provenían del extranjero. Sin lugar a dudas, agrega Marsh, "the lion's share 
of the seventy million dollars of foreign capital invested in Bolivian mines is concentrated largely in American, British and Chilean hands." ${ }^{26}$

Es sumamente dificultoso encontrar información, aún parcializada, sobre la participación que tuvieron capitales del Imperio Alemán en la industria extractiva boliviana.

En todo caso, y a contrapunto del caso británico y estadounidense, no es conocida ninguna inversión considerable por parte de este país. Sin embargo, algunos autores destacan que Alemania sí tuvo una participación relativamente importante en la explotación de minas bolivianas. Así, por ejemplo, Stappenbeck al mencionar que Bolivia hacia 1910 constituía la fuente principal de suministro de estaño para Alemania denota que ello "debería ser para nosotros (los alemanes, L.B.) un estímulo hacia una participación aún mayor en la minería estañífera boliviana." ${ }^{27} \mathrm{Y}$ al referirse a las exportaciones argentíferas de Bolivia en 1912 señala que "el capital alemán ya participa con más fuerza en la minería boliviana; ...”. ${ }^{28}$ Kübler cita la Sociedad Minera de Oro del ingeniero Gedlmayr, a Otto Philipp Braun y sobre todo a la empresa Böttiger, Trepp \& Co. así como a Moritz Hochschild como testimonios de la presencia alemana en la minería boliviana. ${ }^{29} \mathrm{Al}$ respecto es menester señalar que en todos estos casos no se trata de empresas levantadas a base de empréstitos tomados en Alemania, sino de empresas de raigambre nacional, desarrolladas por inmigrantes o súbditos alemanes residentes en Bolivia. Si bien ellas pueden haber tenido ciertos vínculos económicos y financieros con Alemania, no cabe duda que su capital provino básicamente de fortunas personales y que sus negocios no se cimentaron en la banca o la industria alemana.

Las pocas informaciones y los escasos datos que existen sobre la participación de capital alemán en la esfera de la explotación minera boliviana dan lugar a presumir que ella se reducía fundamentalmente a inversiones realizadas por alemanes residentes en Bolivia. Pero aún estas inversiones - si se deja de lado a M. Hochschild, cuyos intereses mineros fueron de verdadera importancia pero corresponden a una época posterior eran de importancia marginal en el conjunto de la expandiente minería boliviana y en muchos casos pasaron a formar parte de empresas controladas por capital británico o norteamericano. O.P. Braun adquirió propiedades mineras en la rica región cuprífera de Corocoro a finales de los años 40 del siglo pasado y poseía, además, una mina de plata en los Yungas (departamento de La Paz). Ya en 1860 él vendió sus pertenencias de Corocoro. ${ }^{30}$ En las décadas siguientes la minería del cobre de esta región pasó a ser controlada por un consorcio chileno y por la British United Copper Mines. ${ }^{31}$ De acuerdo con 
M.J. de Vacano, la mina de Chuquiaguillo en las cercanías de la ciudad de la $\mathrm{Paz}$ - se trata probablemente de una propiedad perteneciente a la mencionada Sociedad Minera de Oro de Gedlmayr - "ha sido trabajada antes por una compañía alemana, habiendo pasado ahora a otras manos." ${ }^{32}$

Tanto en el caso de Gedlmayr como en el de Braun o deE. Mossbach, quien en la década del 60 junto a otros dos alemanes se asoció a una compañía argentífera en los Yungas, ${ }^{33}$ se trata de pequeñas empresas personales o de pocos socios que probablemente no conocieron ningún tipo de financiamiento externo. Aquellos hombres eran pioneros mineros o aventureros alemanes en tierras bolivianas, pero no representantes de intereses económicos y financieros de Alemania en Bolivia.

También la Böttiger, Trepp \& Co. fue establecida por inmigrantes alemanes. Hasta el ascenso de M. Hochschild a magnate minero, esta fue la empresa minera más importante organizada por alemanes en Bolivia y no puede descartarse que capitales procedentes de Alemania hayan tenido participación en ella. Entre varias otras propiedas era dueña de Araca, una de las minas de estaño más grandes del país y la de mayor producción en el departamento de La Paz. ${ }^{34}$ Esta mina fue adquirida por S. Patiño en 1925. ${ }^{35}$ Un caso - probablemente uno de los pocos - en el cual capital del Imperio Alemán intervino en la minería boliviana se ha registrado con la empresa Patiño años antes de que los Estados Unidos pasaran a tener influencia decisiva en ella. A comienzos de la segunda década del presente siglo, la Deutsche Überseeische Bank, así como las empresas industriales SiemensSchuckert y Orenstein \& Koppel proveyeron créditos a Patiño, permitiéndole modernizar sus complejos mineros y establecer un sistema de comercialización directa en Europa. ${ }^{36}$

La vinculación de alemanes con la minería boliviana no se circunscribió al campo de la explotación. En la década del 80 del siglo pasado ya existían casas comerciales establecidas por inmigrantes alemanes que poseían concesiones del gobierno para rescatar minerales de plata. Entre ellas destacan la casa de Enrique Rosenbluth, con licencia para comercializar plata en diversas provincias del departamento de Potosí, y la de Otto Richter en Potosí y Oruro. ${ }^{37}$ Estas casas comerciales, así como la de Germán Fricke \& Co. jugaron un papel importante tanto en la comercialización de productos minerales como en el financiamiento de pequeñas y medianas empresas mineras. Patiño en la fase inicial de sus labores de cateo en la mina La Salvadora, que fue la base de su futuro imperio minero, trabajó con créditos otorgados por Germán Fricke \& Co. en Oruro.

Importante fue también el aporte que prestaron alemanes en el campo de la 
exploración minerealógica y de las innovaciones tecnológicas. José A. Aramayo contrató a los ingenieros y técnicos mineros Hugo Reck, Carlos y Ernesto Francke y Otto Rück. Este último, graduado en la famosa Escuela de Minería de Clausthal-Zellerfeld, aparte de sus trabajos como técnico tanto en la empresa de los Aramayo como en la Huanchaca, contribuyó al reconocimiento de las riquezas del subsuelo boliviano al realizar múltiples estudios sobre los recursos minerealógicos del país. Los hermanos Francke desarrollaron una técnica de amalgamación que contribuyó a elevar significativamente el nivel de la producción argentífera. Rück fue director de la Escuela de Minas de Potosí y varios alemanes presidieron la Escuela de Minas de Oruro. En época posterior Augusto Stumpf exploró regiones de Caupolicán en el noreste del departamento de la Paz para establecer la existencia de yacimientos minerales. ${ }^{38}$

A pesar del mencionado crédito que recibió Patiño de bancos y empresas industriales alemanas y si bien queda todavía por ser investigada la participación que capitales provenientes de Alemania tuvieron en la minería boliviana, es necesario desechar las afirmaciones vertidas por Stappenbeck y Kübler que aquella participación tuvo una importante gravitación. El aporte de alemanes que pasaron a residir en Bolivia e intervinieron en la exploración, explotación, innovación tecnológica y comercialización minera no puede ser considerado, como subrepticiamente sugieren aquellos autores, parte de la influencia económica que tuvo el Imperio Alemán en Bolivia. Para Alemania el desarrollo minero de Bolivia tuvo más bien un efecto importante a otro nivel: en el terreno de las exportaciones de aquel a este país. Como se desarollará con amplitud en el subsiguiente capítulo, Alemania jugó un rol descollante en las importaciones bolivianas. Estas fueron posibles debido fundamentalmente al desarrollo de la minería. Este permitió a Alemania ampliar sus ventas a Bolivia y proveer al país no sólo con insumos para la industria extractiva sino también con maquinaria pesada. Las empresas Orenstein \& Koppel, Siemens-Schuckert, Borsig, Krupp, Demag, Pholig, Mercedes Benz y MAN-Dieselmotoren vendieron a Bolivia ferrovías para las minas, concentradoras para el enriquecimiento del mineral, ferrocarriles funiculares, material para construcción de caminos, camiones y otras maquinarias. ${ }^{39}$ Con el crédito que Patiño obtuvo de Alemania adquirió maquinaria moderna en Europa, entre ésta un ferrocarril funicular alemán por valor de 1.5 millones de libras esterlinas. ${ }^{40}$ En materia de inversiones de capital, Alemania en el campo de la minería boliviana no llegó a rivalizar ni con Gran Bretaña ni con los Estados Unidos. Stappenbeck, al resumir en su mencionada conferencia de 1916 la influencia foránea 
en la minería suramericana, puntualizó: "Vemos a los ingleses en posiciones firmes, a los franceses perdiendo terreno, $y$ a los norteamericanos avanzando sistemática y enérgicamente. Pues bien déjennos imitar el ejemplo de los norteamericanos! ... no puede ser nuestro interés ceder a otros pueblos un campo tan rico como Suramérica, por eso debe ser considerada como necesaria una participación mayor del capital alemán en la minería suramericana." ${ }^{41}$ Exactamente dos décadas más tarde Kübler observaba que en el sector minero de Bolivia "norteamericanos, el magnate minero Simón Patiño e ingleses se dividen el predominio, mientras que la otrora fuerte participación alemana ha sido eliminada temporalmente por completo." ${ }^{42}$ Hablar de una fuerte participación alemana en la minería boliviana es afirmación por demás exagerada. El resto de su aseveración ya era una realidad al cerrarse el primer cuarto del siglo XX.

\section{El caso de la goma natural}

En comparación con la minería, la producción agrícola siempre fue de importancia secundaria para las exportaciones bolivianas. En realidad, el único producto vegetal importante que Bolivia exportó entre 1880 y 1920 fue la goma. Cifras recogidas por Pfannenschmidt para el quinquenio 1909-1913 muestran la abrumadora importancia de este producto en el marco de las exportaciones agrícolas.

La importancia que adquirió la goma en la economía boliviana prácticamente a partir de finales del siglo XIX fue resultado de la creciente demanda de este producto en el mercado internacional. Con el descubrimiento del proceso de vulcanización por Charles Goodyear en 1839, la goma natural alcanzó a tener enorme importancia industrial. Su uso, destinado entre otros a la fabricación de calzados, impermeables, juguetes y correas de transmisión, se incrementó de manera exorbitante después de que Thomson, en 1869, hizo funcionar el primer automóvil con ruedas de caucho vulcanizado en Edimburgo. La creciente demanda de goma en los países de rápida industrialización repercutió en aquella efímera y tormentosa prosperidad cauchera que conocieron regiones de la Amazonía brasileña, boliviana, colombiana, ecuatoriana, peruana y venezolana entre aproximadamente el último cuarto del siglo pasado y la segunda década del présente siglo. Hasta el inicio de la explotación masiva en plantaciones del Asia Oriental después de 1910 la Cuenca Amazónica fue la región gomera más importante del mundo. De acuerdo con cálculos hechos a comienzos del siglo por E. Ule, A. Kahler y P. Reintgen, se puede estimar que durante tres 


\section{Cuadro II.8}

Volumen y valor de las exportaciones agricolas de Bolivia

\begin{tabular}{|c|c|c|c|c|c|}
\hline & \multicolumn{5}{|c|}{ Kilogramos } \\
\hline Goma & 3052453 & 3117650 & 3645551 & 4079828 & 5143214 \\
\hline Coca & 125593 & 196458 & 252276 & 385828 & 352067 \\
\hline Quina cort. & 39157 & 41732 & 42534 & 52186 & 51517 \\
\hline Café & 2832 & 7976 & 4917 & 5619 & 3473 \\
\hline \multirow[t]{3}{*}{ Mático } & 2017 & 1621 & 3254 & 838 & 5553 \\
\hline & 1909 & 1910 & 1911 & 1912 & 1913 \\
\hline & \multicolumn{5}{|c|}{ Pesos bolivianos } \\
\hline Goma & 21947138 & 27653355 & 18921192 & 15508721 & 14651647 \\
\hline Coca & 292681 & 420105 & 511051 & 736290 & 682192 \\
\hline Quina cort. & 17011 & 24577 & 40473 & 46967 & 41183 \\
\hline Café & 3465 & 6862 & 5463 & 5338 & 4319 \\
\hline Mático & 1740 & 2320 & 3076 & 963 & 5829 \\
\hline
\end{tabular}

Fuente: E. Pfannenschmidt, op. cit., p. 25.

décadas aquella cuenca proveyó a los países altamente industrializados con 18.000 toneladas anuales de caucho. ${ }^{43}$

Es difícil estimar con exactitud la participación que Bolivia tuvo en el auge gomero amazónico. Pfannenschmidt evalúa que en 1910 el país contribuyó con un $20 \%$ a la producción mundial; ${ }^{44}$ Uzarski, para el mismo año, valora el aporte en tan sólo un 3\%. ${ }^{45}$ Las estimaciones de Reintgen y Tambs, de acuerdo con las cuales entre un 60 y $70 \%$ de la goma extraída en la Amazonía entre 1877 y 1903 provenía de la región boliviana del Acre, ${ }^{46}$ parecen sobrevaloradas si se consideran las cifras de Sievers sobre los aportes regionales en los años de 1900 y 1901 (véase nota 43 del presente capítulo). En todo caso, la producción de Bolivia llegó más que a decuplicarse entre 1890 y 1900, pasando de 294.000 a casi 3.5 millones de kilogramos. El abrupto descenso registrado entre 1902 y 1908 está vinculado sobre todo a la pérdida del territorio del Acre. De 1908 en adelante, la producción se volvió a elevar rápidamente para alcanzar más de 5.000 toneladas en 1913. Altos valores de producción se registraron en el quinquenio 1909-1913. 


\section{Cuadro II.9}

Producción de goma boliviana

\begin{tabular}{l|c|c|c|c|c}
\hline Año & Kilos & $\begin{array}{c}\text { Pesos } \\
\text { bolvs. }\end{array}$ & Año & Kilos & \multicolumn{1}{c}{$\begin{array}{c}\text { Pesos } \\
\text { bolvs. }\end{array}$} \\
\hline 1890 & 294000 & 1260000 & 1902 & 1902993 & 5910334 \\
1891 & 345000 & 1350000 & 1903 & 1321034 & 2977819 \\
1892 & 363400 & 1422000 & 1904 & 1569628 & 4175328 \\
1893 & 394818 & 1504940 & 1905 & 1677796 & 7341165 \\
1894 & 632500 & 2475000 & 1906 & 1929608 & 10612848 \\
1895 & 820400 & 3070000 & 1907 & 1830513 & 8841380 \\
1896 & 1140712 & 4852560 & 1908 & 2606591 & 11286541 \\
1897 & 1674216 & 6551280 & 1909 & 3052453 & 21947138 \\
1898 & 3155955 & 13556593 & 1910 & 3117650 & 27653555 \\
1899 & 2140000 & 8210000 & 1911 & 3645551 & 18921192 \\
1900 & 3496240 & 10403959 & 1912 & 4079828 & 15508721 \\
1901 & 3465063 & 9151823 & 1913 & 5143214 & 14651647 \\
\hline
\end{tabular}

Fuente: E. Pfannenschmidt, op. cit., p. 35.

\section{Cuadro II.10}

Participación porcentual de la goma en el total de las exportaciones bolivianas

\begin{tabular}{l|c|c|c}
\hline Año & $\%$ & Año & $\%$ \\
\hline 1900 & 29.2 & 1911 & 22.9 \\
1901 & 24.3 & 1912 & 17.2 \\
1902 & 21.1 & 1913 & 15.6 \\
1903 & 13.9 & 1914 & - \\
1904 & 25.0 & 1915 & 11.3 \\
1905 & 17.6 & 1916 & 13.1 \\
1906 & 19.1 & 1917 & 9.8 \\
1907 & 17.6 & 1918 & 6.0 \\
1908 & 11.0 & 1919 & 7.4 \\
1909 & 34.4 & 1920 & 4.9 \\
1910 & 36.6 & & \\
\hline
\end{tabular}

Fuente: Die Wirtschaft des Auslandes. 1928, Berlin 1929, en: E. Klein, op. cit., p. 307. 
La participación de la goma en el total de las exportaciones fue significativa sobre todo a finales del siglo XIX. En 1896 ella llegó al 20\%, en 1897 al $30 \%$ y un año más tarde incluso al $49 \% .{ }^{47} \mathrm{~A}$ partir de entonces, debido al auge de la minería del estaño, a la pérdida del Acre y, después de 1910, a la producción del Asia Oriental, la goma empezó a perder importancia en el comercio exterior boliviano. Entre 1900 y 1910 su contribución promedia anual al total de las ventas realizadas al extranjero fue del $22 \%$ aproximadamente. En la década siguiente descendió al 12\% para seguir bajando en años posteriores.

Con la creciente demanda mundial de caucho natural comenzó la explotación de gomales en cuatro regiones bolivianas. De ellas, la zona ubicada en el norte y este del departamento de Santa Cruz y la que comprendía los bosques de Caupolicán y Yungas en el departamento de La Paz eran las de menor importancia. La tercera región, ubicada en los llanos del Beni, abarcaba tierras comprendidas entre los ríos Madidi, Beni, Madre de Dios, Ortón, Manuripi, Tahuamanu y Mamoré. Al norte de esta tercera se situaba la cuarta región que englobaba los bosques del territorio del Acre. Fue en estas dos últimas regiones, las cuales por vías fluviales se comunicaban a través del Brasil con el océano Atlántico, donde la producción adquirió enorme importancia.

Al igual de lo ocurrido con su litoral sobre el océano Pacífico, Bolivia siempre tuvo dificultades en establecer un efectivo control demográfico y político en la parte septentrional del país. ${ }^{48}$ A finales de los años 70 del siglo pasado, escasamente unas 200 personas trabajaban en los gomales de los llanos del Beni. Esta situación empezó a cambiar después de que Edwin Heath, en octubre de 1880, logró establecer la vinculación entre los ríos Beni y Mamoré, hecho que facilitó enormemente el transporte de las bolachas de goma hacia el río Amazonas. A partir de entonces, empresarios bolivianos empezaron a explotar gomales en zonas comprendidas entre el Tahuamanu y el Mamoré. Debido a la falta de mano de obra local, ellos fomentaron la migración de trabajadores, especialmente del departamento de Santa Cruz, a los llanos del Beni, permitiendo de este modo una integración relativamente sólida y estable de la région al territorio nacional. ${ }^{49}$ Muy diferente fue, sin embargo, la situación en el Acre. A partir de mediados del siglo XIX, este territorio empezó a poblarse con ciudadanos brasileros que se desplazaron por los ríos Madera y Purus en busca de gomales. El avance geográfico de siringueros, comerciantes y aventureros del Brasil tomó masivo impulso después de la sequía que azotó al estado de Ceará en 1878. 


\section{Mapa II.2}

Bolivia: Región Norte y Central

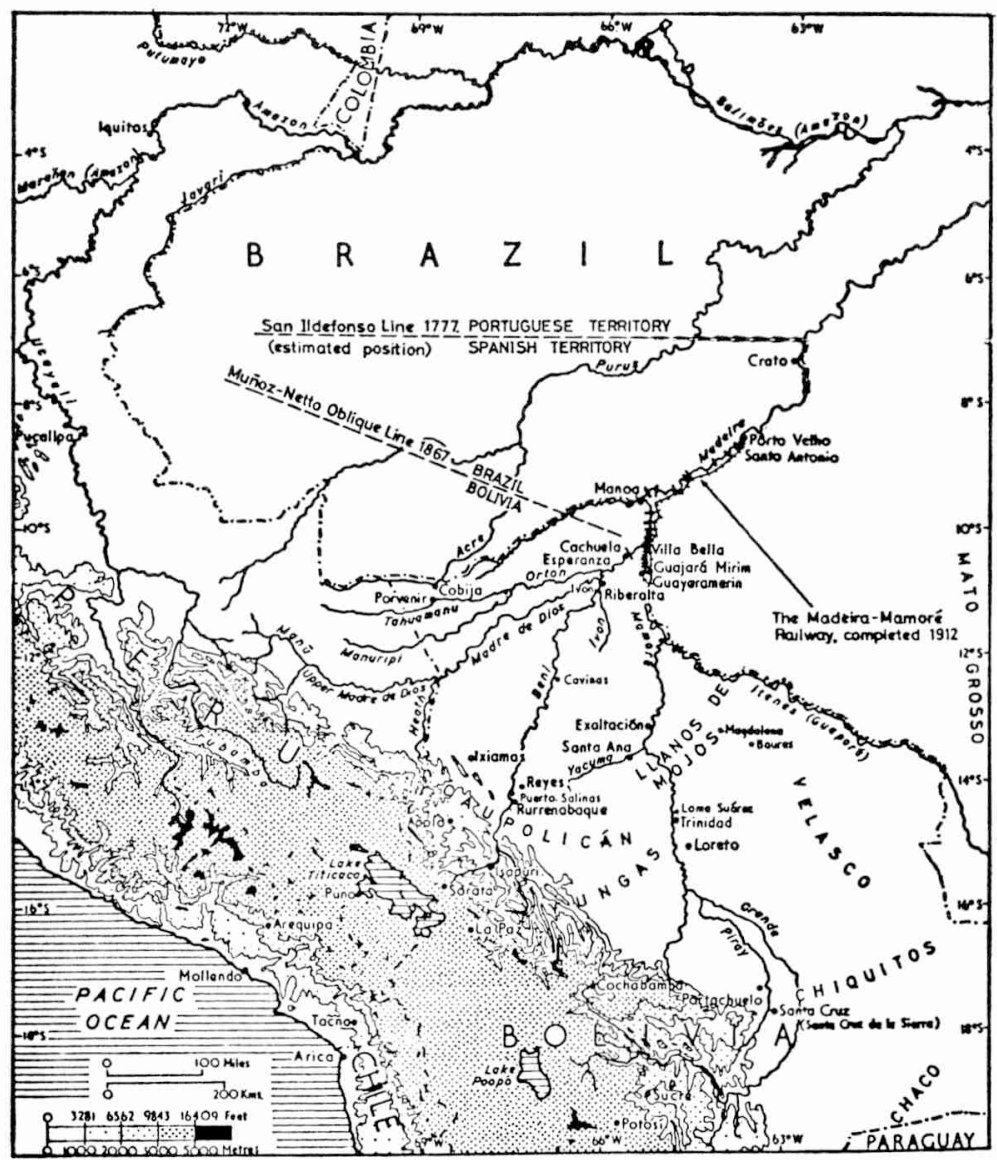


De los miles de brasileros que empezaron a migrar de este estado a zonas donde se podía explotar el caucho, una cantidad considerable penetró hasta el Acre boliviano. Tambs estima que a fines del siglo pasado entre 15.000 y 60.000 brasileros se habían establecido en este territorio llegando a constituir el grueso absoluto de su población. ${ }^{50}$

Debido a la falta de un control nacional efectivo sobre prácticamente toda la régión septentrional del país - dificultada no solamente por el vacío demográfico sino también por la falta de vías de acceso fáciles a la régión desde la zona andina en la cual residía la mayoría absoluta de la población ya desde las primeras décadas posteriores a la independencia, gobiernos bolivianos intentaron promover su colonización masiva. En 1844 el presidente José Ballivián negoció con una compañía de colonizacón formada por el rey Leopoldo I de Bélgica el establecimiento de colonos europeos en la región. Este proyecto fue abandonado después del derrocamiento de Ballivián en 1847. La precaria situación de Bolivia en territorio amazónico se manifestó agudamente cuando en 1867, bajo el gobierno de Melgarejo, se firmó en La Paz, entre el enviado brasilero F. López Netto y el canciller boliviano Duarte Muñoz, el Tratado de Amistad, Límites, Navegaciớn y Extradicción con el Brasil. Por este tratado Bolivia se vió obligada a reconocer la teoría del "uti possidetis de facto" sostenida por el Brasil y tuvo que renunciar en favor de este país a un territorio de $300.000 \mathrm{~km} .{ }^{2}$ Establecida la nueva línea fronteriza, el gobierno de Melgarejo se empeñó en obtener créditos para explorar, colonizar e implementar obras de infraestructura en la parte superior del Acre. Los proyectos que se lograron emprender con la National Bolivian Navigation Company y con la Colonization and Commercial Company of Bolivia fueron abandonados al poco tiempo. En 1880 Bolivia buscó arrendar a una compañía de desarrollo y colonización con sede en Londres un territorio de $751.530 \mathrm{~km}$. ${ }^{2}$ comprendido entre el Acre y el río Bermejo. La compañía, que se comprometió a asentar a 100.000 colonizadores en el lapso de una década, construir dos ferrovías a través del Chaco, establecer arsenales en el Beni y mantener una fuerza naval en el Mamoré, fracasó al no obtener en Londres el capital necesario. ${ }^{51}$

Con la penetración brasilera se acrecentó la producción de goma en el Acre, cuya parte superior, de acuerdo con el Tratado Muñoz-Netto de 1867, era territorio boliviano. Para afirmar su soberanía en este territorio, el gobierno de Bolivia fundó Puerto Alonso en enero de 1899 - vale decir en un momento en el cual la producción de caucho se había convertido en el principal producto de exportación del país - sobre la margen izquierda del río Acre, con la finalidad de recaudar impuestos por la extracción de la goma. Caucheros de la zona respondieron a este acto con una sublevación sepa- 
ratista liderada por José Carvalho (original de Ceará) que eclosonió en la fundación de la República Independiente del Acre en julio de 1899. Bolivia tuvo que enviar tres costosas expediciones hasta que a comienzos de 1901 logró reestablecer su soberanía en la región. Una nueva sublevación en agosto de 1902, apoyada por las autoridades brasileras, terminó con la toma de Puerto Alonso por los insurrectos en abril de 1903 y obligó a Bolivia a firmar meses más tarde el Tratado de Petrópolis. Por este tratado Bolivia entregó al Brasil $190.000 \mathrm{~km}^{2}$ en el Acre a cambio de 2.5 millones de libras esterlinas y la promesa de la construcción de un ferrocarril de puerto San Antonio, sobre el río Madera, hasta Guajaramerím, sobre el Mamoré, incluyendo un ramal hasta Villa Bella. ${ }^{52}$

Con la crisis del Acre, Bolivia reavivó su empeño por encontrar apoyo foráneo para promover la colonización de aquella región.

En junio de 1900 la embajada alemana en Petrópolis informaba a Berlín que el señor Salinas Vega, entonces embajador boliviano en el Brasil, "ha hecho ya varios intentos de arrendar el territorio del Acre a un sindicato." ${ }^{53}$ Indica el informe que Salinas Vega realizó sin éxito una oferta de esta naturaleza al señor E.B. Harden, y que el 12 de mayo de 1900 "celebró un tratado de arrendamiento del territorio del Acre con un conocido comerciante de Rio de Janeiro, el señor Joaquín Arsenio Cintra da Silva; (desde entonces, L.B.) este contrato ha caducado porque el mencionado empresario no pudo encontrar los capitales necesarios." ${ }^{54}$ Escasamente un mes más tarde, el 7 de junio de 1900, Salinas Vega dirigió una carta estrictamente reservada y confidencial al conde d'Arco Valley, Ministro de Alemania en el Brasil. En ella el diplomático boliviano explicaba que su gobierno, debido a la falta de medios de transporte, tenía serias dificultades para administrar el Acre y que por ello "estaría dispuesto a entregarlo en administración sea a la Alemania, sea a un sindicato o compañía alemana, sin más condiciones que las siguientes: $1^{\circ}$ Reconocer la soberanía de Bolivia y admitir sus autoridades políticas y judiciales, siendo las fiscales y municipales nombradas por el Sindicato o por quien tenga la administración. $2^{\circ}$ Colonizar la región, para lo que se daría gratuitamente tierras; y comunicar con el interior por un ferrocarril, al cual se garantizaría el $6 \% .3^{\circ}$ Hacer la navegación de los tributarios del Amazonas que corren en suelo boliviano para lo que se otorgaría concesiones especiales." "La carta indica a su vez que el gobierno boliviano deseaba entregar en administración tanto la región del Acre como también "toda la Delegación del Purus que abarca de 50 a 60.000 leguas." ${ }^{56}$ Con respecto a la distribución de las rentas aduaneras de la región, el gobierno boliviano estaba dispuesto a conceder un $30 \%$ de las mismas al sindicato, otro 
$30 \%$ debía depositarse como garantía para la construcción de un ferrocarril o de otras obras, quedando el resto en manos del estado boliviano. De acuerdo con la importancia de los trabajos que emprendería el sindicato, el porcentaje nombrado en primer término era susceptible de ser elevado hasta un $40 \%$. Salinas Vega concluía pidiendo al embajador alemán informar sobre el particular al gobierno de su país o a corporaciones que pudiesen interesarse en la oferta. ${ }^{57}$

Al mes siguiente de realizar esta proposición, el 6 de julio de 1900, Salinas Vega ofrecía al conde d'Arco Valley erigir un protectorado alemán en Bolivia.

El11 de junio de 1901 el Enviado Extraordinario y Plenipotenciario de Bolivia en Londres, Félix Avelino Aramayo, firmó con el representante de The Bolivian Syndicate, Federico Willingford Whitridge, el contrato de mayor transcendencia con respecto al territorio del Acre. Este contrato, aprobado por el congreso boliviano en diciembre del mismo año, preveía la entrega de un área de casi $13.000 \mathrm{~km}^{2}$ al nombrado sindicato por espacio de 30 años. El Sindicato debía organizarse con un capital mínimo de 500.000 libras esterlinas, teniendo el gobierno boliviano derecho prioritario a adquirir acciones por valor de 100.000 libras. A los tres años de constituirse en el Acre, el Sindicato iba a percibir el 40 y el gobierno de Bolivia el $60 \%$ de las utilidades netas de la región. Las utilidades percibidas por el Sindicato estarían exentas de cualquier contribución o impuesto; a su vez, él quedaba exento de todo empréstito forzoso o de cualquier requisición. A partir del quinto año de la ratificación del contrato, el sindicato obtenía el derecho exclusivo de comprar tierras en la région que administraba. Estas tierras podían ser entregadas en arriendo. Al Sindicato se otorgaba el derecho exclusivo de extender concesiones de navegación en el territorio del Acre, debiendo respetar las claúsulas sobre navegación previstas en el tratado pertinente que Bolivia había firmado con el Brasil. En un memorándum anexo a los artículos del contrato se estableció que el Sindicato iba a mantener una fuerza policial para la protección de los habitantes de la zona y para velar por la observancia de las leyes de la República de Bolivia. El Sindicato se comprometía a realizar estudios para vincular por ferrovía o por canales los ríos Abuna, Ortón y Madre de Dios con el río Acre. Estas labores debían iniciarse un año después de entrar en vigencia la administración. Al término del contrato, el territorio con todas las pertenencias, excepto las tierras adquiridas por el Sindicato, revertía a manos del estado boliviano. ${ }^{58}$ Como lo expresó a cabalidad Sir Martin Conway, quien en 1900 recibió la oferta de arrendamiento de parte del gobierno boliviano y la transmitió aF. 
Whitridge, la concesión "grants to the Syndicate rights of a Chartered Company, similar to Rhodesia." 59

El Bolivian Syndicate recibió adhesión financiera de la Central Trust Co., la Vermilye Co., la Metropolitan Life Insurance Co., la Morton Bliss \& Co., la Brown Brothers \& Co., así como de Mr. K. Twombly, Mr. S.W. Cross, Mr. Adrian Iselin jr., Mr. Emlen Roosevelt, prima del entonces presidente de los Estados Unidos, de la familia Vanderbilt y de los señores Cary y Whitridge. A esta participación norteamericana se añadía la de Lord Avebury, director del Banco Lubbock y presidente de las Cámaras Unidas de Comercio de Gran Bretaña y la de Mr. August Belmont, representante del grupo Rothschild en Londres. ${ }^{60}$ El Secretario de Estado de los Estados Unidos, Mr. Hay, quien junto al presidente de este país avalaron la empresa, describió al Sindicato como "as strong a body as could be brought together in New York." ${ }^{61}$ Desde un comienzo el Bolivian Syndicate, ofrecido inicialmente a un súbdito inglés (el mencionado Sir M. Conway), quedó controlado por capitales estadounidenses. Para los Estados Unidos la concesión del Acre tenía una eminente importancia: de hecho significabacomo acertadamente lo formuló el embajador del Imperio Alemán en el Perú - el primer paso de ocupación territorial por parte de este país en Suramérica. ${ }^{62}$

A pesar de ello los accionistas norteamericanos desde un comienzo buscaron internacionalizar el Sindicato. La razón ha sido manifestada por Sir Conway. El observó que si bien la presencia de hombres de empresa norteamericanos tan poderosos hacía viable obtener todo el capital necesario en los Estados Unidos, "they have decided that as the territory in question is entirely surrounded by Peruvian and Brazilian lands, and as access to the territory is through Brazil, and as diplomatic questions may therefore arise with those countries, it is advisable to make the company not merely a US but an international company. For this reason, while prepared to obtain half the required capital in the US, they think it advisable to enlist the interest of Germany, Belgium and Great Britain in the remaining half." ${ }^{\circ 3}$ Partiendo de este razonamiento, el Bolivian Syndicate buscó levantar suscripciones por valor de 5 millones de dólares en Bélgica y Alemania.

Entre junio y octubre de 1902, Sir Conway y Mr. Whitridge negociaron con la Cancillería del Imperio Alemán, con la Deutsche Bank y con la Hamburg American Line la participación de capitales alemanes en el Sindicato. La oferta despertó un relativo interés, tanto por parte del banco como por parte de la compañía naviera alemana, pero terminó fracasando ${ }^{64}$ En el lapso de dos años, entre mediados de 1900 y mediados de 1902, Alemania 
había recibido tres ofertas de participar en una empresa colonizadora en Bolivia que le proporcionaba un valioso acceso a la explotación de la goma natural: las dos presentadas a consideración por el diplomático Salinas Vega y aquella ofrecida por los representantes del Bolivian Syndicate en Berlín. Alemania rechazó todas estas ofertas. Diversas razones determinaron esta actitud.

Respecto a la primera oferta, la de Salinas Vega de junio de 1900, el conde Arco d'Valley advirtió a su gobierno en Berlín que ella era demasiado vaga en lo que se refiere a la extensión territorial de la concesión. ${ }^{65}$ Señaló a su vez que la situación demográfica, tanto en el Acre como en la Delegación del Purus, era totalmente desfavorable para Bolivia, ya que la población asentada en esas regiones "tendía al Brasil y de cualquier modo no está subordinada a la influencia boliviana." ${ }^{66}$ Por esta razón la toma de posesión y la pacificación de aquellos territorios "sólo sería posible, ..., si se llega a un acuerdo con el gobierno del Brasil." ${ }^{67}$ Finalmente, el diplomático alemán manifestó su temor de que un consentimiento de parte de su país a la propuesta boliviana podría tener repercusiones negativas, tanto para la situación de los alemanes radicados en el Brasil como para los amplios intereses comerciales del Imperio Alemán en este país. ${ }^{68}$ Exactamente dos semanas después de recibir la segunda oferta de Salinas Vega, aquella que proponía la erección de un protectorado alemán en Bolivia, el conde Arco d'Valley subrayó otra dificultad a la que se vería enfrentado el Imperio Alemán en caso de aceptar las propuestas bolivianas: el factor climático como obstáculo para implementar una colonización efectiva. ${ }^{69}$

No existen indicios de que el primer ofrecimiento hecho por Salinas Vega llegó a ser considerado seriamente por el gobierno alemán. El segundo fue rechazado categóricamente. El 15 de agosto de 1900 la Cancillería del Imperio Alemán envío a su representante en Petrópolis la siguiente instrucción: si Salinas Vega vuelve a tocar la cuestión del protectorado "le ruego responderle que, aparte de otras consideraciones, es convicción personal suya que Alemania está tan absorbida por las convulsiones del Asia Oriental que la sugerencia de un plan de tal transcendencia parece imposible de ser realizado por el momento." ${ }^{70}$ A comienzos de septiembre del mismo año el conde Arco d'Valley informó al canciller alemán que Salinas Vega no ha vuelto a insistir en el proyecto del protectorado y ha pedido la devolución de la correspondencia relacionada al asunto. ${ }^{71}$

Tres razones persuadieron al Imperio Alemán a no participar en el Bolivian Syndicate: el litigio entre Bolivia, Brasil y Perú con respecto al territorio del Acre, la presión brasilera y, sobre todo, la percepción de que Alemania iría a desempeñar una función subordinada en el proyecto. En cuanto a la pre- 
sión brasilera, el barón Rio Branco hizo notar al gobierno de Alemania después de la segunda visita de Sir Conway y Mr. Whitridge a Berlín en octubre de 1902 "que los alemanes poseen en el Brasil ... fecundos campos de actividad y dejó traslucir que una participación de Alemania en este Sindicato probablemente va a tener una repercusión muy poco deseada sobre el estado de ánimo en Brasil contra los alemanes." ${ }^{72}$

En los primeros días de noviembre de 1902, tanto el Deutsche Bank como el gobierno de Berlín tomaron la decisión de no adherirse al Bolivian Syndicate. El Deutsche Bank temía complicaciones con el Brasil así como con otros países suramericanos y no deseaba dar su apoyo a una empresa que con respaldo de capitales alemanes facilitaría la expansión de los Estados Unidos en Suramérica. Para la institución bancaria era evidente que este país iba a jugar el rol principal en el proyecto y que la venta de productos industriales, como ser ferrocarriles, maquinaria, etc., iba a ser realizada exclusivamente por la nación norteamericana. El Deutsche Bank argüía también con la falta de suficiente apoyo gubernamental. ${ }^{73}$ Evidentemente, el gobierno de Berlín ya había comunicado a Sir Conway y a Mr. Whitridge que no estaba dispuesto a promocionar instituciones financieras interesadas en la cuestión del Acre.

El 2 de noviembre de 1902 la Cancillería del Imperio Alemán envió una notificación a sus embajadas en Petrópolis, Buenos Aires y Lima en la cual daba a conocer su rechazo de participar en el Bolivian Syndicate. En ella se puntualizaba que no responde a los intereses alemanes "si en el corazón de Suramérica llega a organizarse una empresa americana tan vasta como la concebida, tampoco en el caso de que ésta inicialmente recibiese un bárniz internacional a consecuencia de la captación de capitales alemanes, belgas e ingleses. Ello, porque es de esperar que a corto o largo plazo los americanos van a desplazar a los interesados no americanos o van a adquirir sus provisiones. Por otra parte existe el peligro de que una participación de bancos alemanes en el Sindicato del Acre vaya a tener una repercusión no deseada sobre nuestras relaciones políticas generales con diversos estados suramericanos como Brasil, Argentina y Perú." ${ }^{\text {74 }}$

No es posible establecer en forma definitiva la influencia que capitales del Imperio Alemán tuvieron en la explotación de la goma boliviana. En todo caso no es conocida ninguna inversión de peso realizada por él en este campo. Las grandes compañías bolivianas establecidas a partir de 1880 en la región septentrional del país para explotar y comercializar caucho estaban vinculadas a las finanzas británicas y francesas. Este ha sido el caso de la empresa levantada por Antonio Vaca Diez, quien en 1876 estableció sus 
primeras barracas sobre el río Beni y expandió más tarde sus negocios a la parte inferior del Madre de Dios y a la desembocadura del río Ortón. Por falta de capitales Vaca Diez se vió obligado a buscar apoyo financiero en Europa a comienzos de la última década del siglo XIX. Negoció con banqueros y con otras fuentes potenciales de crédito en Alemania, Francia y Gran Bretaña. En estos dos últimos países tuvo éxito y logró fundar en Londres a comienzos de 1897 The Orton (Bolivia) Rubber Co. Ltd. con un capital de 340.500 libras esterlinas. ${ }^{75}$ Pocos años más tarde esta compañía pasó a manos de la Casa Suárez que fue la empresa más grande en el norte de Bolivia. Desde su central en Cachuela Esperanza ella controlaba vastos territorios comprendidos entre los ríos Beni, Madre de Dios y Mamoré, y había logrado establecer una serie de barracas sobre el río Acre. Sus tierras con bosques de goma llegaron a sumar 6.466.970 hectáreas. La Casa Suárez, una empresa nacional controlada por la familia Súarez, estuvo vinculada íntimamente al mercado y a las finanzas británicas. En 1909 las tres sucursales de la empresa, la Suárez Hermanos, la R. Suárez \& Co. y la Suárez Hermanos \& Co. que estaban establecidas en Bolivia y en Gran Bretaña, se registraron en Londres como Suárez Hermanos \& Co. Ltd. con un capital de 750.000 libras esterlinas. ${ }^{76}$

Aparte de las empresas levantadas por Vaca Diez y los hermanos Suárez, existieron otras de menor importancia. Algunas de ellas estaban controladas por capitales franceses, como la Société Picollet, británicos, como la Anglo-Bolivian Rubber Estates, o por capitales norteamericanos como The Chicago-Bolivian Rubber Co. y The Bolivian Rubber Co. of Baltimore. $^{77}$

De manera muy limitada, Francia, en escala más apreciable Gran Bretaña y, sobre todo, los Estados Unidos realizaron inversiones en la explotación del caucho boliviano. Estos dos últimos países también movilizaron capitales para promover la colonización de la región del Acre. El Imperio Alemán rehusó hacer lo propio y no existe ningún indicio de que haya realizado inversiones similares a las británicas o norteamericanas.

Sin embargo, hay un hecho que dificulta establecer la influencia de Alemania en el boom gomero que vivió Bolivia. Desde las últimas décadas del siglo pasado, inmigrantes alemanes abrieron un número importante de casas comerciales en el oriente boliviano que estaban vinculadas íntegra o, al menos, parcialmente con el negocio de la goma. En Trinidad se instalaron Barber y Julow; en Reyes von Ancken \& Co. y Brieger; en Riberalta Alfredo W. Barber \& Co., von Becks Co., Hengartner \& Giebler, Benno Haase, Velasco y Henicke y la Firma Gmo. Demmer; en Puerto Suárez Stösen, Schnack, Voß y Müller y en Santa Cruz Zeller, Rößer, Villinger, 
Mozer, Gasser y Schweitzer. ${ }^{78}$ Se trata de casas que en regiones tropicales, junto a los ríos Piray, Grande, Itenes, Yacuma, Mamoré, Madera, Madre de Dios, Ortón y Beni, llegaron a tener una participación sobresaliente en el comercio que giraba básicamente en torno al caucho o al trabajo de los gomales. Como aquellos alemanes que incursionaron en la minería de la región andina, también los alemanes que se establecieron en la zona oriental levantaron sus negocios con capitales propios. Probablemente muchas de las casas comerciales alemanas radicadas en los departamentos del Beni y de Santa Cruz participaron en la extracción de la goma, sea de manera directa, sea a través de créditos otorgados a propietarios de gomales. De haber sido este el caso y en la medida que estas casas comerciales hayan trabajado con capitales provenientes de Alemania - hecho que, por ejemplo, parece evidente en el caso de la Firma Gmo. Demmer que estuvo relacionada con la Firma Ed. Weber \& Co. de Hamburgo ${ }^{79}$ - evidentemente se puede establecer una participación de capital del Imperio Alemán en la extracción de la goma boliviana.

En todo caso parece razonable afirmar que la participación financiera de Alemania en la explotación del caucho de Bolivia fue limitada y quedó muy a la zaga de la de empresas nacionales vinculadas al capital británico o de empresas como la inglesa o las norteamericanas mencionadas anteriormente.

La importancia que el auge de la goma tuvo para el Imperio Alemán fue fundamentalmente la misma que el de la minería de la plata y del estaño. Por un lado permitió a la nación europea abastecerse con un producto natural de vital importancia para su desarrollo industrial, por el otro tuvo efectos seguramente apreciables en el fomento de las exportaciones efectuadas por ella a Bolivia. Sobre todo a este segundo momento contribuyeron significativamente los súbditos alemanes que inmigraron a este país y establecieron casas comerciales entre Trinidad y Santa Cruz de la Sierra.

3. Evaluación de la influencia del Imperio Alemán en el sector extractivo de Bolivia

Hasta el presente no es posible discernir con claridad el grado de influencia que tuvo el capital alemán en la explotación de materias primas bolivianas durante el período 1880-1920. A la luz de datos e indicadores disponibles se puede, sin embargo, establecer que él ha sido de escasa importancia y que no significó una competencia para el capital británico y menos aún para el estadounidense. A diferencia de lo ocurrido con Gran Bretaña y posterior- 
mente con los Estados Unidos, el Imperio Alemán no llegó a controlar ninuna empresa de gran magnitud en el sector extractivo de Bolivia. Tampoco es conocida una participación importante de capitales suyos en compañías mineras o caucheras erigidas por empresarios nacionales. El aporte quizás más notorio del capital alemán al desarollo minero bolivano durante la época señalada, cual es el empréstito otorgado por bancos y empresas industriales a Simón Patiño a comienzos de la segunda década del siglo XX, no devino en una participación directa del Imperio Alemán en la industria minera de Bolivia. En cuanto al caso de la goma, es interesante advertir que el argumento central con el cual Alemania finalmente rehusó participar en un proyecto de colonización que potencialmente le ofrecía la posibilidad de un acceso directo a la extracción del caucho, fue el temor al poderío de los Estados Unidos.

El ascenso de los Estados Unidos a potencia imperialista y su consiguiente expansión económica en América Latina fue para Alemania un obstáculo insuperable para materializar sus propios designios expansionistas en esta región. En el caso de la industria extractiva boliviana, tanto la minera como la del caucho, Alemania tuvo que ceder posiciones al coloso norteamericano. Como se verá en el capítulo siguiente, este no fue el único campo en el cual las pretensiones del capital alemán se vieron coartadas debido a la competencia de los Estados Unidos.

En el correr de la segunda mitad del siglo XIX miembros de la colonia alemana en Bolivia incursionaron en la minería y establecieron una serie de casas comerciales tanto en la región andina como en el oriente del país. Si bien estas empresas fueron levantadas con capitales de los propios inmigrantes y en la mayor parte de los casos no conocieron ningún tipo de financiamiento externo, es muy probable que algunas de ellas hayan tenido vínculos con capitales del Imperio Alemán. La dificultad de establecer estas vinculaciones constituye un escollo fundamental para apreciar la participación que tuvo Alemania en la industria extractiva boliviana. A pesar de ello, sí se puede afirmar que el monto de inversiones realizado por súbditos alemanes residentes en Bolivia, tanto en la extracción minera como en la de la goma, fue de poca importancia en comparación con los capitales que empresarios bolivianos, Gran Bretaña y los Estados Unidos invirtieron en estos campos. La absorción de la Böttiger, Trepp \& Co., la compañía minera más importante que controlaron inmigrantes alemanes en Bolivia con anterioridad a 1920, por la empresa de Simón Patiño, en la cual a partir de 1924 el capital estadounidense jugó un rol fundamental, es prueba palmaria de este hecho. 
En todo caso es errado el planteamiento de aquellos autores que consideran la participación de alemanes afincados en Bolivia en la exploración, explotación y comercialización de materias primas como parte de la influencia económica y financiera del Imperio Alemán en aquel país.

Para el Imperio Alemán el desarrollo de la industria extractiva boliviana fue de gran importancia a nivel del comercio exterior. El auge de la minería y de la goma permitió a Alemania obtener materias primas imprescindibles para su desarrollo industrial y disponer, a su vez, de un mercado en expansión capaz de absorber cantidades cada vez mayores de productos manufacturados. 


\section{III - ALEMANIA Y EL DESARROLLO DEL SISTEMA DE TRANSPORTES Y COMUNICACIONES EN BOLIVIA}

La integración de Bolivia al mercado mundial en calidad de proveedor de materias primas tuvo por consecuencia una importante modernización de su sistema de transportes y comunicaciones. La creciente demanda mundial de materias primas no sólo fue estímulo para el desarrollo de la producción minera y gomera en Bolivia sino que también hizo necesario el establecimiento de medios de comunicación rápidos y eficientes para vincular al país con los centros internacionales del comercio y de las finanzas.

Al comenzar la penúltima década del siglo pasado, el transporte de personas y mercaderías así como la transmisión de mensajes y noticias, tanto en el interior de Bolivia como entre el país y el mundo exterior, seguía realizándose con los medios rudimentarios de la época colonial. Si bien existía un servicio de carretas que unía a varias ciudades importantes del país y facilitaba, en cierta medida, la comunicación con algunos países limítrofes, el transporte de mercaderías era efectuado básicamente con acémilas y auquénidos. Muy común era el empleo del indio como estafeta, pero también como transportador de cargas de entre 50 y 100 libras.

A lomo de acémilas y de indios fueron transportadas por territorio peruano las piezas para construir el primer vapor que surcó las aguas del lago Titicaca. Este vapor entró en servicio en la ciudad peruana de Puno en 1860. A pesar de esta importante innovación y su desarrollo en los años subsiguientes, la navegación lacustre boliviana continuó efectuándose fundamentalmente en minúsculas embarcaciones de rústica fabricación. En los ríos del oriente, con una extensión navegable de aproximadamente 20.000 kilómetros, el transporte se realizaba en primitivas balsas de diverso tipo.

Entre 1880 y 1925 el sistema de transportes y comunicaciones de Bolivia se modernizó substancialmente. Bajo el gobierno de Aniceto Arce (1888-1892) se construyeron o se mejoró el estado de importantes carreteras provinciales e interdepartamentales y, en 1889, se inauguró el primer tramo ferroviario, el cual desde territorio chileno llegó a la ciudad de Uyuni en el departamento de Potosí. En 1905 se inauguró en Cochabamba el primer servicio de automóviles; un año más tarde empezó a funcionar este tipo de servicio entre las ciudades de La Paz y Oruro. El auge de la producción del caucho repercutió en una modernización de la navegación fluvial, 
tanto en los afluentes del río Amazonas como en el río Paraguay. En 1880 se inauguró el sistema telegráfico y hacia 1920 el país contaba con una amplia red de telegrafía, de teléfonos así como con varias estaciones radiotelegráficas.

En este trabajo no se analizará el desarrollo del sistema de transporte carretero y fluvial, como tampoco el de la telefonía. Sólo de manera tangencial se mencionará la expansión de la red telegráfica. La aviación civil en Bolivia data de 1925; es decir que su desarrollo corresponde a una fase posterior a la que abarca este trabajo. Por ello también se prescindirá de exponer detalles sobre el surgimiento y la expansión de este medio de transporte. Cabe, sin embargo, mencionar que la colonia alemana de Bolivia fue la promotora del transporte aéreo en este país y que la Républica de Weimar fue la principal fuente de suministro de material para la aviación civil boliviana en los primeros años posteriores a su inauguración.

En la primera parte de este capítulo se expone el desarrollo del sistema ferroviario de Bolivia hasta 1925, prestando especial atención a los empeños de Alemania por vincularse a él. El acápite siguiente se centra en los esfuerzos desplegados por el Imperio Alemán para obtener la concesión de instalar estaciones radiotelegráficas en Bolivia. En la tercera parte se resume y valora el rol que le cupo jugar a Alemania en la expansión de los medios de comunicación señalados.

\section{El desarrollo ferroviario}

Las primeras construcciones de ferrovías en Bolivia se realizaron en la región costera del Atacama durante la década del 70 del siglo pasado. Ellas tenían la finalidad de facilitar la explotación y el transporte del salitre y dela plata descubierta en Caracoles. Hasta el inicio de la Guerra del Pacífico en 1879 sólo se concluyó el tendido de la vía de Antofagasta al Salar del Carmen que entró en funcionamiento a fines de $1873 .{ }^{1}$ Con la Guerra del Pacífico, Bolivia perdió toda su costa marítima y hasta 1889, cuando se entregó al tráfico el tramo de Ascotán en Chile a Uyuni, no contó con un solo kilómetro de vía férrea en todo su territorio que en aquel entonces abarcaba aproximadamente $1.800 .000 \mathrm{~km} .{ }^{2}$ De aquel año en adelante se registró un importante avance en materia de construcción ferroviaria. En 1920 la red ferroviaria en operación sumaba 1.786 kilómetros y otros 371 kilómetros estaban en construcción. ${ }^{2}$ Lo que permitió este desarrollo fue una amplia disponibilidad de capitales. Estos capitales procedieron de tres fuentes: del 
auge de las exportaciones, de las indemnizaciones que pagaron el Brasil y Chile en cumplimiento de los tratados de paz firmados en 1903 y 1904 respectivamente y de una serie de empréstitos foráneos.

$\mathrm{Al}$ igual de lo que ha sucedido en casi todos los países latinoamericanos, también en Bolivia la política ferroviaria estuvo orientada prácticamente de manera unilateral a facilitar el transporte de materias primas a los puertos de embarque. Debido a su situación mediterránea a partir de 1884, Bolivia se vio forzada a construir ferrovías hacia países limítrofes con acceso directo al mar. Hasta 1925, cuando empezó el servicio de trenes con la Argentina, el grueso absoluto del tendido de rieles sirvió para vincular al país con Chile, Perú y la Argentina. En comparación con estas construcciones, las destinadas únicamente a conectar diversas regiones del interior fueron de carácter absolutamente secundario.

A continuación se expondrán sumariamente algunos detalles sobre la red ferroviaria boliviana construida hasta 1925, dirigiendo la atención sobre todo a las vías tendidas hacia países limítrofes. Seguidamente se hará una breve reseña de construcciones que no fueron concluidas y de los proyectos más importantes que no llegaron a implementarse. En base a esta exposición se detallarán las fuentes de financiamiento para luego analizar el interés y la ingerencia que tuvo Alemania en el sistema ferroviario boliviano.

En el correr de los años 80 del siglo pasado, el ferrocarril de Antofagasta al Salar del Carmen fue extendido en dirección noreste hacia la frontera boliviano-chilena de postguerra. Como se ha señalado, este ferrocarril llegó a Uyuni en 1889. Inmediatamente se construyó un ramal a los centros mineros de Pulacayo y de Huanchaca y después de solucionar algunas dificultades financieras se inició el tendido de rieles de Uyuni en dirección norte hacia Oruro. En mayo de 1892 fue inaugurado el servicio de trenes hasta esta ciudad. De los 924 kilómetros de extensión del tramo ferroviario Antofagasta-Oruro, 486 fueron construidos en territorio boliviano. Si se deja de lado el ferrocarril Antofagasta-Salar del Carmen, que hasta 1879 estaba situado en territorio boliviano, aquellos 486 kilómetros y los 39 kilómetros (de acuerdo con otras referencias 48 kilómetros) del ramal Uyuni-Pulacayo-Huanchaca pueden ser considerados los primeros tendidos de vía férrea con que contó Bolivia.

En 1900 el gobierno autorizó la construcción de un ferrocarril para vincular la ciudad de La Paz con el lago Titicaca. Esta obra de 97 kilómetros de extensión que se inició en Guaqui sobre el mencionado lago, fue concluida hasta El Alto de La Paz en 1903 y llegó hasta la ciudad de la Paz en 1905. Con el ferrocarril La Paz-Guaqui Bolivia llegó a tener una segunda vía de comuni- 


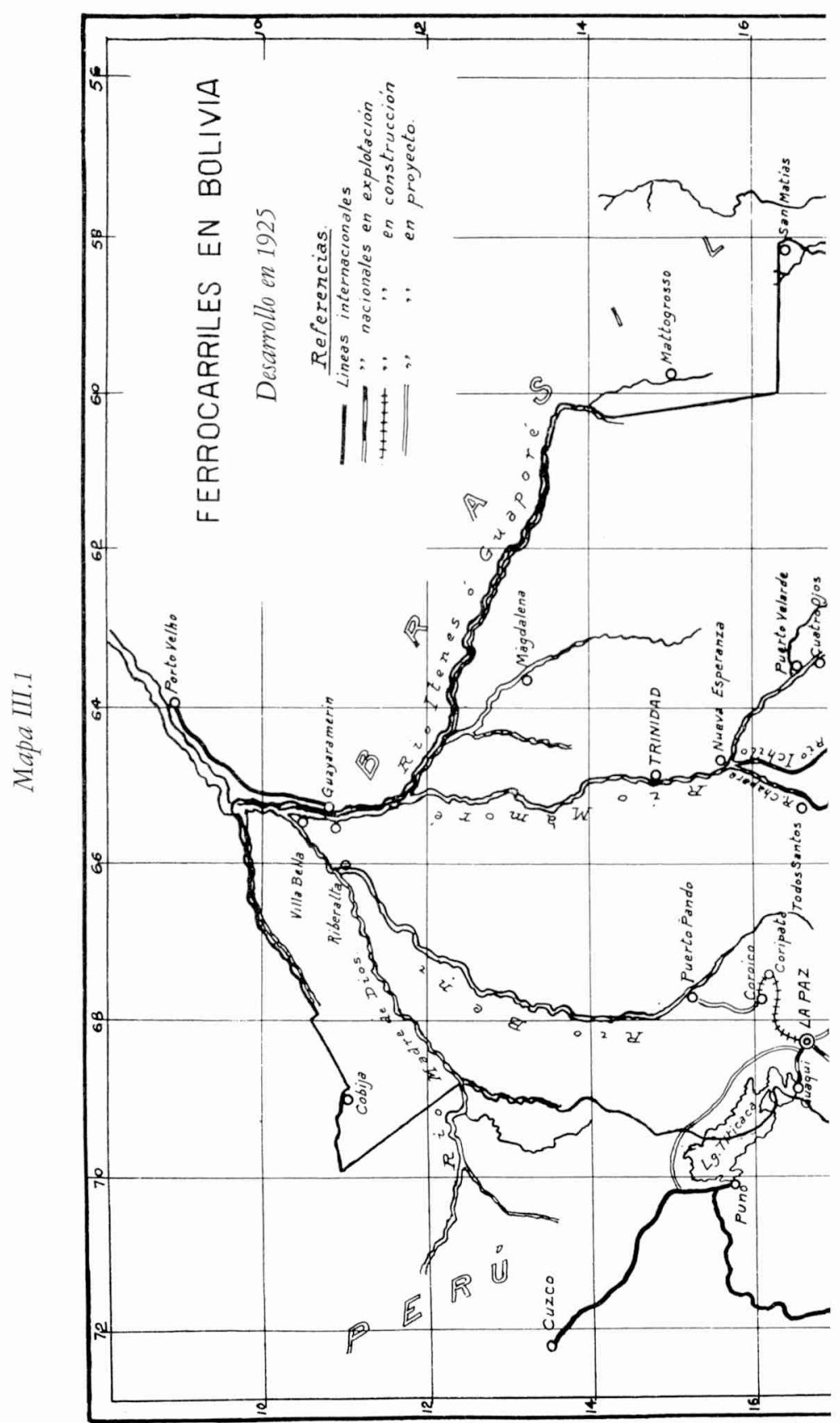




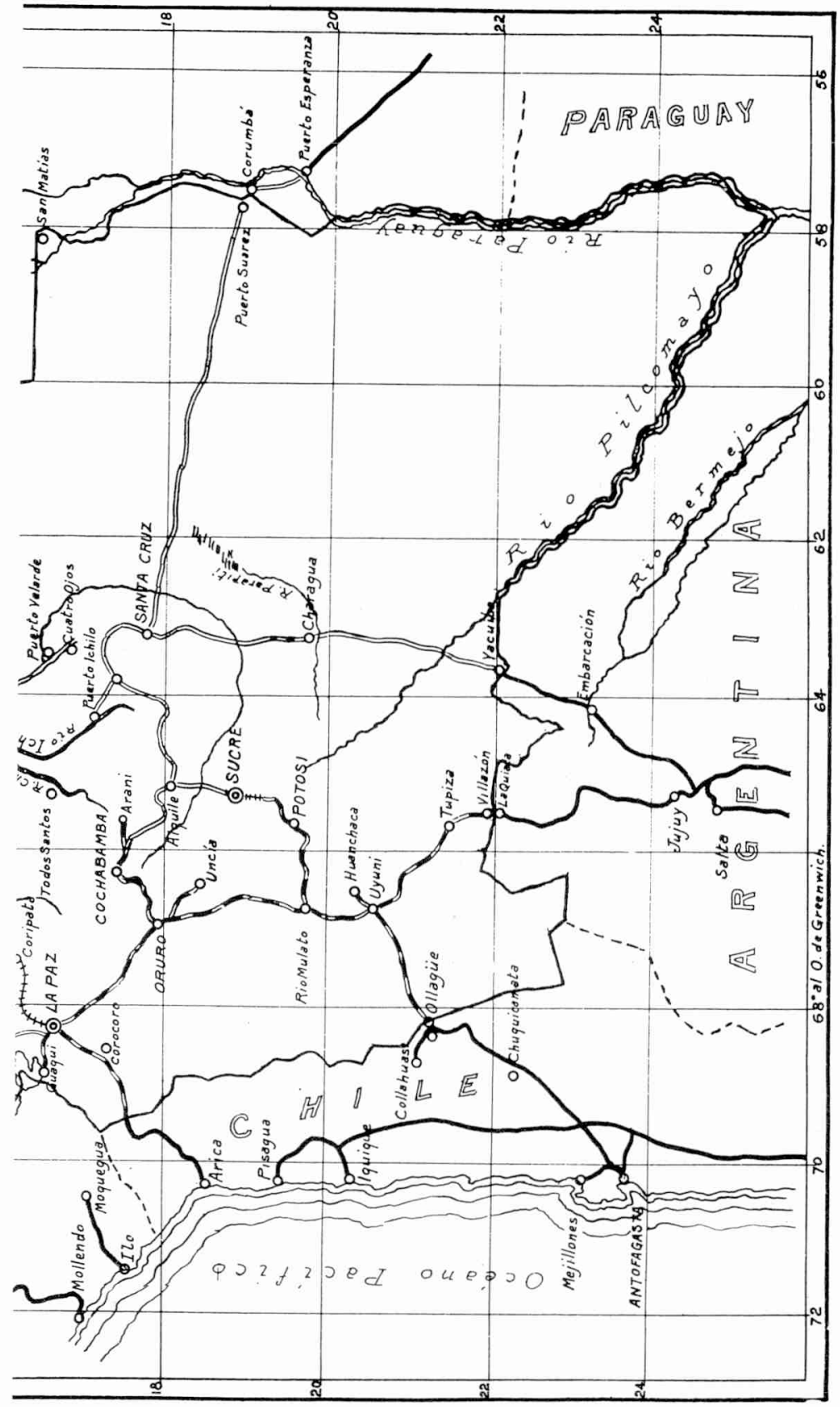


cación moderna con la costa del Pacífico. DeGuaqui el trayecto continuaba por vapor hasta Puno y de ahí proseguía en ferrocarril hasta el puerto peruano de Mollendo.

La tercera ruta ferroviaria al mar la obtuvo Bolivia a consecuencia del Tratado dePaz y Amistad firmado con Chile en octubre de 1904. Por este tratado Chile se comprometió a construir un trayecto ferroviario desde el puerto de Arica hasta El Alto de La Paz. La obra se inició en 1906 y fue concluida en 1913. De acuerdo con lo estipulado en el mencionado tratado y en un protocolo firmado en ocasión de la inauguración del ferrocarril, Chile traspasó en 1928 a Bolivia en propiedad el tramo que corría por su territorio, vale decir los 234 kilómetros comprendidos entre Charaña y El Alto de La Paz. A finales de 1913 también entró en funcionamiento un pequeño ramal de 8.5 kilómetros que unía al centro cuprífero de Corocoro con la mencionada ferrovía. ${ }^{3}$

La abertura de tres ferrovías hacia la costa del Pacífico en el lapso de 24 años tuvo un tremendo impacto para el comercio exterior de Bolivia. Estas ferrovías permitieron acortar considerablemente la duración de los viajes y elevar cuantiosamente los volúmenes de exportación. Mitre constata una interrelación directa entre la llegada del ferrocarril de Antofagasta a Bolivia y el aumento de la producción argentífera de la Compañía Huanchaca. Esta se habría elevado de 3.9 millones de marcos entre 1882-1888 a 7.2 millones de marcos entre 1889-1895. ${ }^{4}$ De 1888 a 1904 las exportaciones bolivianas por el puerto de Antofagasta aumentaron en un $70 \%$, y de 1900 a 1904 aquellas embarcadas por la vía de Guaqui al puerto de Mollendo se elevaron en un $30 \%{ }^{5}$ La carga transportada por ferrocarril a Arica llegó más que duplicarse en el lapso de 4 años al pasar de 47.000 toneladas en 1914 a 105.000 toneladas en $1917 .{ }^{6}$ Con la inauguración de las mencionadas ferrovías, el comercio exterior de Bolivia se volcó casi íntegramente hacia la costa del Pacífico. Por los puertos de Antofagasta, Mollendo y Arica no se embarcaban solamente los productos minerales de los departamentos de La Paz y Oruro así como de la región norte del departamento de Potosí. También una gran parte de la producción de los importantes centros mineros del sur de este departamento que con anteroridad eran transportados con carretas y a lomo de acémilas hacia el puerto de Rosario en la Argentina, empezaron a tomar la vía de Antofagasta. A su vez, casi todas las exportaciones agrícolas de la región occidental del país, incluyendo la goma extraída en las provincias de Yungas y Caupolicán (veáse al respecto capítulo II, nota 77), empezaron a ser trasladadas en ferrocarriles con dirección a Chile o al Perú. En 1910 del 70 al $75 \%$ del comercio exterior boliviano se realizó por el puerto de Antofagasta. ${ }^{7}$ 
Los trabajos para establecer un servicio ferroviario entre Bolivia y la Argentina se iniciaron en 1906 y fueron concluidos sólo en 1925. El primer tramo ejecutado fue el de Uyuni a Atocha que entró en funcionamiento en 1913. Entre 1912 y 1914 se construyó una parte del trayecto de Villazón a Tupiza. Con los trabajos realizadas de 1921 a 1925 finalmente se logró vincular este trecho con la estación de Atocha. La construcción de los 290 kilómetros de ferrovía entre Uyuni y Villazón, aldea ubicada sobre la frontera argentina, fue de enorme importancia para la economía boliviana. El nuevo ferrocarril facilitó el transporte de los importantes recursos minerales explotados en la región suroriental del departamento de Potosí, los cuales desde la inauguración del ferrocarril a Antofagasta habían sido trasladados con animales de carga a la estación de Uyuni para su transporte ferroviario a la costa del Pacífico. La conclusión de la ferrovía Uyuni-Villazón permitió una vinculación directa con el ferrocarril argentino que desde 1908 recorría el trayecto desde La Quiaca hasta los puertos de Rosario y Buenos Aires. Deeste modo una parte considerable de la producción minera del sur de Bolivia que con anterioridad era embarcada por el puerto de Antofagasta empezó a ser exportada hacia puertos de la República Argentina. La nueva ruta acortó el tiempo en el transporte de los productos de la región meridional boliviana y, en comparación con las rutas del Pacífico, abrevió a la mitad de tiempo la duración del tráfico comercial con Europa. ${ }^{8}$

Hasta mediados del presente siglo, cuando se inauguró el ferrocarril de Corumbá a Santa Cruz, no existió una vinculación ferroviaria directa entre Bolivia y Brasil. Sin embargo, ya durante la segunda mitad del siglo XIX se proyectó la construcción de un ferrocarril en la frontera nororiental de aquel país con el Brasil. En esta frontera, los saltos de agua de los ríos Mamoré y Madera hacen prácticamente imposible una navegación fluvial sin trasbordos por tierra. Dada esta dificultad, a partir de 1867 diversos gobiernos bolivianos incentivaron la construcción de una ferrovía que permitiese evadir el trayecto fluvial. A pesar de que se logró obtener un empréstito británico y posteriormente uno norteamericano para realizar la construcción, dificultades técnicas, factores climáticos así como la falta de suficientes capitales y de mano de obra hicieron fracasar hasta 1879 cuatro diversos intentos de implementar el proyecto. ${ }^{9}$ Este no llegó a materializarse hasta después de la firma del Tratado de Petrópolis en 1903. Como ya se ha señalado en el capítulo anterior, por este tratado Brasil se comprometió a construir un ferrocarril desde el puerto de San Antonio sobre el río Madera hasta Guajaramerím sobre el río Mamoré incluyendo un ramal que debía llegar a Villa Bella en territorio boliviano. Sobrellevando enormes dificultades y con un elevado costo en vidas humanas, en 1912 se terminó de cons- 
truir la vía de algo más de 300 kilómetros desde San Antonio a Guajaramerím, por un precio evaluado en casi 6 millones de libras esterlinas. ${ }^{10} \mathrm{La}$ obra para vincular este ferrocarril a través de un puente sobre el Mamoré con Villa Bella no llegó a ejecutarse. Tampoco se materializó el proyecto de extender la vía desde Guajaramerím hasta la ciudad boliviana de Riberalta. A pesar de ello, el ferrocarril Madera-Mamoré fue de gran significado para la exportación del caucho boliviano que salía por la ruta del Amazonas al Atlántico. Antes de inaugurarse el ferrocarril, las mercaderías transportadas por el Mamoré y el Madera debían ser transbordadas a tierra entre 40 y 60 veces por lo cual el precio de los productos se elevaba hasta 12 veces. A pesar de sus elevadas tarifas, el nuevo medio de comunicación permitió rebajar los costos de transporte. Gracias a éste, el tiempo de viaje de Guajaramerím a San Antonio, que antes demoraba entre 4 y 8 semanas, se redujo a escasamente 12 horas. ${ }^{11}$

La construcción de las dos primeras ferrovías, la de Antofagasta a Oruro y la de Guaqui a La Paz, no llegó a vincular al interior del país ni siquiera a un centro urbano de importancia con otro y, además, dejó dividida la red ferroviaria en una sección sur y una sección norte. Esta situación sólo cambió en 1909, cuando se inauguró el trayecto de Oruro a Viacha. Con él se empalmó ambas secciones ferroviarias y se facilitó la vinculación interurbana entre las ciudades de Oruro y La Paz. Hacia 1925 fue concluida la construcción de otros cuatro tramos ferroviarios, destinados a unificar importantes centros del territorio nacional. En 1912 se inauguró el trayecto de Río Mulato (sobre la línea Uyuni-Oruro) a Potosí, con lo cual esta ciudad se conectó por ferrovía a las ciudades de Oruro y La Paz. En 1916 se terminó de construir la línea de Viacha a La Paz y un año más tarde la de la ciudad de Oruro a la ciudad de Cochabamba. En 1921 entró en circulación el ferrocarril de Machacamarca (sobre la vía Uyuni-Oruro) a los centros mineros de Huanuni y Uncía. El servicio de trenes de la ciudad de Potosí a la de Sucre no pudo ser habilitado en toda su extensión hasta los comienzos de la década del 40.

Hasta mediados del presente siglo, cuando desde la frontera argentina y la brasilera comenzaron a circular los primeros trenes en dirección a Santa Cruz de la Sierra, toda la red ferroviaria boliviana estaba situada en la región occidental del país. En el oriente no se llegaron a construir las ferrovías a Villa Bella y a Riberalta. Los trabajos ferroviarios que se iniciaron durantela segunda década del siglo de La Paz al Beni por la ruta de los Yungas y de Cochabamba al rîo Ichilo, que tenían el propósito de conectar la zona occidental con rios navegables que se dirigen a los llanos septentrionales del 
país, no llegaron a concluirse y, finalmente, fueron abandonados. Con anterioridad a la construcción del ferrocarril Yacuiba-Santa Cruz en la década del 40, existió un solo plan ferroviario para toda la zona meridional del oriente. El plan preveía un tendido de rieles del río Paraguay a esta ciudad. En 1905, y nuevamente en 1912, el gobierno boliviano otorgó vastas concesiones a diversas empresas para implementar el proyecto, sin que se llegase a obtener resultado positivo alguno.

\section{Cuadro III.1}

Red ferroviaria de Bolivia en 1925

Extensión y costo

\begin{tabular}{l|rl|lr|r}
\hline Ferrocarril & Longitud & $\begin{array}{c}\text { Capital } \\
\text { invertido }\end{array}$ & $\begin{array}{c}\text { Costo } \\
\text { klmto. }\end{array}$ \\
\hline Oruro-Ollague & $486 \mathrm{~km}$ & $£$ & $1.900 .000 .-$ & $£ 3.909$ \\
Viacha-La Paz & 41 & $\mathrm{~km}$ & $£$ & $728.725 .-$ & $£ 17.771$ \\
Oruro-Viacha & $202 \mathrm{~km}$ & $£$ & $1.095 .779 .-$ & $£ 5.421$ \\
Oruro-Cochabamba & $205 \mathrm{~km}$ & $£$ & $3.874 .859 .-$ & $£ 18.903$ \\
Río Mulato-Potosí & $174 \mathrm{~km}$ & $£$ & $1.549 .665 .-$ & $£ 8.902$ \\
Uyuni-Atocha & $90 \mathrm{~km}$ & $£$ & $555.447 .-$ & $£ 6.176$ \\
Guaqui-La Paz & $97 \mathrm{~km}$ & $£$ & $400.000 .-$ & $£ 4.124$ \\
Machacamarca-Uncía & $96 \mathrm{~km}$ & $£$ & $991.667 .-$ & $£ 10.330$ \\
Uyuni-Huanchaca & $39 \mathrm{~km}$ & $£$ & $195.000 .-$ & $£ 5.000$ \\
Charaña-Alto La Paz & $234 \mathrm{~km}$ & $£$ & $1.264 .345 .-$ & $£ 5.403$ \\
Villazón-Atocha & $198 \mathrm{~km}$ & $£$ & $2.803 .568 .-$ & $£ 14.159$ \\
Cochabamba-Aiquile & & & & & \\
(Hasta Vila-Vila & & & & & \\
y Ramal Cliza-Arani) & $141 \mathrm{~km}$ & $£$ & $1.520 .341 .-$ & $£ 10.728$ \\
Ramal Corocoro & $8,5 \mathrm{~km}$ & $£$ & $42.434 .-$ & $£ 4.992$ \\
La Paz-Beni & $54 \mathrm{~km}$ & $£$ & $773.796 .-$ & $£ 14.329$ \\
\hline Total & $2.065,5 \mathrm{~km}$ & $£ 17.695 .626 .-$ & $£ 8.569$ \\
\hline
\end{tabular}

Fuente: Cesáreo Aramayo Avila, Ferrocarriles Bolivianos. Pasado Presente Futuro, La Paz 1959, p. 80. (Del cuadro se ha excluido el trayecto Potosí-Sucre.)

Con la conclusión del trayecto hasta la frontera argentina, la red ferroviaria de Bolivia (sin incluir el tramo construido hasta entonces entre Potosí y Sucre) llegó a tener una extensión de algo más de 2.000 kilómetros. Hasta 
el presente no existen datos absolutamente viables sobre el costo de esta red. De acuerdo con las cifras que reproduce Aramayo Avila en base a cálculos realizados en 1930 por Juan Rivero Torres, en ella se habrían invertido cerca de 17.7 millones de libras esterlinas, vale decir casi 8.600 libras esterlinas por kilómetro.

La falta de estudios pormenorizados hace prácticamente imposible determinar con exactitud la forma en que fueron levantados los empréstitos que permitieron llevar adelante las obras ferroviarias. En consecuencia, no es posible diferenciar a cabalidad los grupos de accionistas de los diversos empréstitos. Sin embargo, las informaciones disponibles permiten discernir el origen del grueso de los capitales con los cuales fueron financiadas aquellas obras.

El aporte más importante provino de Gran Bretaña. En 1883 la Compañía Huanchaca de Bolivia recibió del gobierno la concesión para construir el ferrocarril de Ascotán a Uyuni. Cinco años más tarde esta empresa transfirió la concesión a una compañía británica, constituida en 1887 en Londres con el nombre The Antofagasta and Bolivia Railway Company. Ella aportó el capital necesario para finalizar los trabajos hasta Uyuni y para prolongar el trayecto a Oruro. En 1906 el gobierno de Bolivia otorgó a la Speyer and Company y The National City Bank de los Estados Unidos el derecho de construir un conjunto de ferrovías en la región occidental del país. En 1908 estas instituciones traspasaron su derecho a The Antofagasta and Bolivia Railway Company que aportó la mayor parte del capital (según Aramayo Avila el $73 \%{ }^{12}$ ) para la construcción de los ferrocarriles OruroViacha, Oruro-Cochabamba, Rio Mulato-Potosí y Uyuni-A tocha. En 1911 la mencionada empresa obtuvo la concesión para tender la línea de Viacha a la ciudad de La Paz. Capitales británicos también jugaron un papel importante en la construcción del ferrocarril Arica-Alto de La Paz y en la fase posterior de la construcción del ferrocarril Guaqui-La Paz.

El Estado de Bolivia fue la segunda fuente más importante de capitales. El ferrocarril mencionado en último término fue financiado en su primera etapa con los ingresos que obtuvo el Estado de los impuestos al Estanco de Alcoholes y Aguardientes y a la goma extraída en el departamento de la Paz. Debido a la falta de capital el Estado negoció un empréstito con la Peruvian Corporation Limited a la cual transfirió el ferrocarril en 1910 por un valor de 350.000 libras esterlinas. La mencionada corporación se constituyó en 1890 en el Perú con la finalidad de viabilizar un contrato firmado con la compañía Grace de los Estados Unidos. Mediante este contrato, el gobierno peruano entregó a los accionistas de los empréstitos tomados en 1869, 1870 y 1872 varias líneas ferroviarias (entre ellas la de Mollendo-Are- 
quipa-Puno) por el lapso de 66 años. De este modo el Estado peruano se deshizo de las obligaciones contraídas al contratar aquellos empréstitos. ${ }^{13}$ Con la suma entregada por la Peruvian Corporation Limited y con fondos del Tesoro Nacional el Estado boliviano inició en años posteriores la construcción del ferrocarril de Potosí a Sucre. El Estado de Bolivia aportó una parte importante de las indemnizaciones recibidas de Chile y del Brasil para la construcción de las ferrovía Oruro-Viacha, Oruro-Cochabamba, Río Mulato-Potosí y Uyuni-Atocha; tomó a su cargo el tendido de rieles del ramal a Corocoro y financió la primera fase del trayecto de La Paz a los Yungas.

El ferrocarril Uyuni-Pulacayo-Huanchaca fue construido por la Compañía Huanchaca, en la cual coparticipaban capitales bolivianos y chilenos. Es probable que capitales británicos hayan tenido participación en la obra. La empresa de Simón Patiño tendió la ferrovía Machacamarca-HuanuniUncía, la cual fue integrada en 1924 a la Patiño Mines Enterprises Consolidated, Inc. La Sociedad Anónima Luz y Fuerza Eléctrica de Cochabamba, que fue organizada con capitales privados bolivianos, construyó a partir de 1910 trayectos de tranvías eléctricos en el valle de Cochabamba, los cuales sentaron las bases para el plan ferroviario que debía unir a la capital de este departamento con el río Ichilo y, posteriormente, con Santa Cruz de la Sierra.

La participación de capitales franceses y estadounidenses en la construcción de la red reseñada fue de mucho menor importancia que la británica. Francia otorgó dos créditos que permitieron adelantar los trabajos del trayecto de La Paz a los Yungas y sobre todo del trayecto de Tupiza a Villazón. Como ya se ha señalado, los Estados Unidos recibieron la concesión para la construcción de una red ferroviaria destinada a vincular importantes centros al interior de Bolivia. Esta concesión fue transferida en 1908 a la empresa británica The Antofagasta and Bolivia Railway Company. Es difícil determinar qué participación tuvo desde entonces el capital norteamericano en las obras realizadas por esta empresa. A través de la Peruvian Corporation Limited los Estados Unidos participaron junto a los viejos acreedores de bonos en el Perú en el ferrocarril Guaqui-La Paz. A partir de 1917 las empresas norteamericanas Equitable Trust Company, Stifel Nicolaus y Ulen Contracting Company otorgaron créditos para finalizar el trayecto de Uyuni a Villazón. En 1922 los Estados Unidos facilitaron un empréstito para continuar la obra ferroviaria de Potosía Sucre y un empréstito para ejecutar trabajos sobre el trayecto de Cochabamba al río Ichilo. La concesión para la construcción del ferrocarril Madera-Mamoréfue otorgada en 1907 al sindicato estadounidense formado por Parcifall Faquhar. ${ }^{14}$ 
Cuadro III. 2

Financiamiento del sistema ferroviario de Bolivia 1887-1925

\begin{tabular}{|c|c|c|}
\hline Trayecto & $\begin{array}{l}\text { Período de } \\
\text { construcción }\end{array}$ & Fuente \\
\hline Ascotán - Oruro & $1887-1892$ & $\begin{array}{l}\text { Gran Bretaña. Participación de capital } \\
\text { boliviano (Compañía Huanchaca) y } \\
\text { probablemente de capital chileno. }\end{array}$ \\
\hline Uyuni-Huanchaca & 1889 & $\begin{array}{l}\text { Bolivia (Compañía Huanchaca). } \\
\text { Participación chilena y probablemente } \\
\text { de Gran Bretaña. }\end{array}$ \\
\hline Guaqui - La Paz & $1900-1905$ & $\begin{array}{l}\text { Estado de Bolivia. A partir de } 1902 \\
\text { crédito de la Peruvian Corporation } \\
\text { controlada por los Estados Unidos con } \\
\text { participación de accionistas británicos. }\end{array}$ \\
\hline Arica-El Alto & $1906-1913$ & $\begin{array}{l}\text { Gran Bretaña. Probablemente } \\
\text { participación chilena. }\end{array}$ \\
\hline Ramal Corocoro & 1913 & Estado de Bolivia. \\
\hline Uyuni - Atocha & $1906-1913$ & $\begin{array}{l}\text { Gran Bretaña (participación mayoritaria } \\
\text { a partir de 1908). Estado de Bolivia. }\end{array}$ \\
\hline Atocha-Villazón & $1912-1925$ & Francia y los Estados Unidos. \\
\hline Madera - Mamoré & $1906-1912$ & Estados Unidos. \\
\hline $\begin{array}{l}\text { Oruro - Viacha } \\
\text { Río Mulato-Potosí } \\
\text { Viacha - La Paz } \\
\text { Oruro-Cochabamba }\end{array}$ & $1906-1917$ & $\begin{array}{l}\text { Gran Bretaña (participación mayoritaria } \\
\text { a partir de 1908). Estado de Bolivia. }\end{array}$ \\
\hline Machacamarca-Uncía & $1913-1921$ & $\begin{array}{l}\text { Bolivia (Empresa Patiño). Probable- } \\
\text { mente con empréstitos foráneos. }\end{array}$ \\
\hline Potosí - Sucre & $1916-1943$ & $\begin{array}{l}\text { 1era. fase Estado de Bolivia. } 2 \text { da. fase } \\
\text { Estados Unidos. 3era. fase Gran Bretañal } \\
\text { Estado de Bolivia. 4ta. fase Estados Unidos }\end{array}$ \\
\hline La Paz - Yungas & $1914-$ & $\begin{array}{l}\text { 1era. fase Estado de Bolivia. Francia. } \\
\text { Estados Unidos. }\end{array}$ \\
\hline Cochabamba-Ichilo & $1910-$ & $\begin{array}{l}\text { 1era. fase Bolivia (empresa privada) } \\
\text { Estados Unidos. }\end{array}$ \\
\hline
\end{tabular}

Fuente: Cuadro elaborado por el autor a base de los datos expuestos anteriormente. 
La exposición sobre las fuentes de fianciamiento de la red ferroviaria boliviana y el cuadro que se ha elaborado en base a ella (véase Cuadro III. 2) muestran que Alemania no participó con un solo empréstito en la construcción de esta red. Este hecho no significa que el Imperio Alemán y, posteriormente, la República de Weimar no hayan mostrado interés por el desarrollo ferroviario de Bolivia. Al contrario. El interés alemán por este desarrollo ya se puso en evidencia durante la penúltima década del siglo XIX, vale decir cuando se planificaron y empezaron a construir las primeras ferrovías de importancia en territorio boliviano, y se avivó a medida que los planes ferroviarios y el tendido de rieles en el país andino cobraban envergadura. Prueba palmaria de ello dan la correspondencia diplomática y artículos de la prensa alemana. Aquélla y éstos no solamente buscaron informar a círculos oficiales e interesados sobre el particular, sino que de manera explícita o implícita perseguían la finalidad de exteriorizar las posibilidades potenciales que la modernización de las vías de comunicación de Bolivia ofrecía a los intereses económicos de Alemania.

Esta tendencia ya se manifiesta en pasajes de un informe que el embajador del Imperio Alemán en Santiago de Chile transmitió en mayo de 1888 al canciller von Bismarck. El informe señala que a consecuencia de la elección de Aniceto Arce como presidente de Bolivia se iban a otorgar una serie de concesiones ferroviarias hasta entonces vetadas y que, de éstas, una de las de mayor importancia iba a ser la prolongación del trayecto de Antofagasta a la frontera boliviana hasta las minas de plata de Huanchaca. ${ }^{15}$ El diplomático alemán relievó a su vez el significado de este proyecto para la modernización del país y para capitales europeos. En los años venideros Bolivia "se verá enfrentada a un florecimiento económico que elevará a este país, tan rico en todo tipo de productos naturales, al rango de un Estado civilizado y digno de la atención de los mercados europeos de capitales." ${ }^{16}$ Es interesante notar que el mencionado embajador no ocultó su clara simpatía por Aniceto Arce quien, como principal accionista de la empresa Huanchaca, luchó denodadamente contra poderosos grupos de su país para llevar adelante la construcción de una ferrovía que vinculase sus propiedades mineras con la costa del Pacífico. Finalizada la construcción del ferrocarril Antofagasta-Oruro, el periódico Export resumió la importancia y los beneficios de esta obra y llamó a su vez, la atención respecto a nuevos planes ferroviarios para vincular a Bolivia con el exterior: "Cuán enorme fue ya el auge de la exportación desde que los ingleses construyeron el ferrocarril Antofagasta-Oruro, que no paga mal pese a que sólo cruza el poco acogedor altiplano andino! Pues bien, el Congreso Argentino ha determinado la prolongación del ferrocarril centralnorte desde Jujuy a territorio boliviano y, 
sin lugar a dudas, se abrirán este año aún las propuestas públicas para la construcción." ${ }^{17}$

En 1913 Heidinger, el técnico alemán que dirigió los trabajos de ingeniería de la sección chilena del ferrocarril Arica-El Alto de La Paz, notifició a la Embajada del Imperio Alemán en Bolivia que el gobierno de este país ya no estaba opuesto a prolongar la línea del mencionado ferrocarril hasta la ciudad de La Paz y "expresó su pesar por el hecho de que el Deutsche Bank haya desperdiciado la oportunidad de asegurarse esta excelente empresa ferroviaria que, sobre todo en combinación con el ferrocarril longitudinal chileno, ofrece extraordinarias perspectivas de desarrollo." ${ }^{18}$ El informe añade que las casas alemanas de importaciones radicadas en La Paz "en general se muestran muy contentas de que sea un alemán el que tenga a su cargo la dirección técnica y, al parecer, también parte de la dirección administrativa del ferrocarril." ${ }^{19}$ Estas casas jugaban un papel importante en el comercio germano-boliviano. Ellas preferían realizar sus operaciones comerciales a través del puerto de Arica, dado a que por esta vía el transporte era más rápido y barato que por la vía de Antofagasta.

En 1904 el Staatsanzeiger publicó la noticia de que el gobierno de Bolivia tenía la intención de construir un ferrocarril de La Paz a los Yungas. ${ }^{20}$ Casi dos décadas más tarde el embajador alemán en Bolivia informó a Berlín que hasta 1922 sólo se habían llegado a tender 49 kilómetros de este trayecto y que "por el momento los trabajos para la continuación del ferrocarril están totalmente paralizados por falta de medios financieros. Tanto es así, que el material adquirido para la traza entre los kilómetros 49 y 63 se vendió, y el resto ha sido dejado al abandono." ${ }^{21}$

Los párrafos citados, tanto de la correspondencia diplomática como de órganos de prensa, vislumbran, a veces claramente, otras de manera subrepticia, que Alemania avizoró en la construcción ferroviaria de Bolivia oportunidades de inversión lucrativa y, a su vez, un medio idóneo para fortalecer las relaciones comerciales entre ambos países.

A pesar de su marcado interés, el capital alemán no tuvo grandes oportunidades para participar con empréstitos en la implementación de obras ferroviarias en Bolivia. Ello se debe a un hecho fundamental: Alemania no llegó a tener ni siquiera la oportunidad de intervenir como solicitante en las concesiones más importantes que Bolivia otorgó hasta comienzos de la década del 20. En cuanto a los casos en los cuales el capital alemán tuvo la posibilidad de obtener una concesión, su intervención terminó fracasando ya sea por la propia indecisión, porque la concesión fue otorgada a otro solicitante o porque el proyecto fue abandonado. 
En 1888 la Compañía Huanchaca transfirió sin previa propuesta pública a la Antofagasta and Bolivia Railway Company la concesión que le había otorgado el gobierno boliviano para construir la ferrovía de Ascotán hasta Uyuni. Sin tener que enfrentarse a otro interesado, esta empresa pudo prolongar posteriormente el tramo hasta la ciudad de Oruro. Sin entrar en negociaciones con ninguna otra empresa, el Estado de Bolivia vendió en 1910 a la Peruvian Corporation el ferrocarril Guaqui-La Paz. En mayo de 1906 otorgó a la Speyer and Company y al National City Bank una concesión a base de la cual se construyeron los ferrocarriles Oruro-Viacha, Río Mulato-Potosí, Viacha-La Paz y Oruro-Cochabamba. También esta concesión se realizó sin previa convocatoria a propuestas. ${ }^{22}$

De esta manera, de los 2.065 kilómetros de vía férrea con los que contó Bolivia en 1925 (excluidos los kilómetros construidos entre Potosí y Sucre), 1.157 kilómetros, vale decir más del $50 \%$ del total, fueron tendidos con el apoyo decisivo de capitales británicos y con aportes relativamente reducidos de los Estados Unidos y, probablemente, de Chile, sin que se hubiese ofrecido una posibilidad de participación a otras fuentes potenciales de financiamiento. Alemania prácticamente tampoco tuvo ninguna posibilidad de intervenir con empréstitos en la construcción del ferrocarril de Viacha a La Paz y en las obras ferroviarias Uyuni-Huanchaca y Machacamarca-Uncía, que fueron financiadas por empresas mineras nacionales íntimamente vinculadas a Gran Bretaña y a los Estados Unidos respectivamente.

Considerando estos antecedentes, el margen de posibilidades del capital alemán para obtener concesiones fue muy limitado. En realidad se circunscribió a los siguientes proyectos: Arica-El Alto de la Paz, Uyuni-Villazón, La Paz-Yungas, Cochabamba-Río Ichilo-Santa Cruz y Potosí-Sucre.

En 1905, en 1907 y nuevamente en 1909 el gobierno de Chile convocó a propuestas para la construcción del ferrocarril de Arica al Alto de la Paz. En la primera oportunidad la concesión fue solicitada por dos empresas nacionales, una británica, y por el Banco Alemán Trasatlántico que representaba los intereses del Deutsche Bank y de la Philipp Holzmann \& Compañía Limitada de Francoforte. El privilegio fue otorgado a una de las empresas nacionales la cual tropezó con serias dificultades para llevar adelante la obra. Anulado el contrado fue lanzada una nueva convocatoria en 1907. En diciembre de ese año el gobierno chileno aceptó la propuesta hecha por el Deutsche Bank. Exigencias de este banco determinaron el derogamiento del contrato y llevaron a una nueva licitación que se abrió en 1909. A ésta se presentó la Sociedad Sir John Jackson Limited de Gran Bretaña y nueva- 
mente el Banco Alemán Trasatlántico en representación de las instituciones ya mencionadas. En mayo del mismo año Chile aprobó la oferta presentada por la compañía británica, la cual finalmente construyó el ferrocarril. $^{23}$

En 1908 se terminó de construir el trayecto de Jujuy a La Quiaca, con lo cual la red ferroviaria argentina llegó hasta la frontera boliviana. Cuatro años más tarde se finalizó en Bolivia el tramo de Uyuni a Atocha. Para proseguir con los trabajos que finalmente permitieron conectar este tramo con la red argentina, el gobierno boliviano llamó a mediados de 1913 a propuestas públicas para construir la línea Tupiza-Villazón. Inmediatamente la representación diplomática alemana acreditada en La Paz informó sobre el particular a la Cancillería en Berlín, ${ }^{24}$ la cual remitió el aviso a 4 grandes instituciones bancarias y a 15 empresas industriales. Entre estas figuraba la ya mencionada Philipp Holzmann \& Co. Ltd., la Firma Lenz \& Co., que en la década del 20 se interesó por arrendar la sección boliviana del ferrocarril AricaEl Alto de La Paz, y la Firma Orenstein \& Koppel A.G. de Berlín. ${ }^{25}$ Como se desprende de su respuesta a la Cancillería, la empresa nombrada en último término estaba sumamente interesada en el proyecto. Ya con anterioridad, ella había establecido por intermedio de sus agentes contactos con instituciones bolivianas directamente responsables del asunto. ${ }^{26}$ En realidad, las probabilidades de que la Firma Orenstein \& Koppel A.G. o cualquier otra empresa alemana obtuviese la concesión fueron, si acaso, mínimas, ya que con anterioridad al llamado a propuestas el gobierno de Bolivia había contratado un empréstito de un millón de libras esterlinas con el Crédit Mobilier Français para la construcción de la ferrovía. En el texto del contrato de este empréstito, Bolivia accedió a compromisos que descartaban prácticamente toda competencia para ejecutar la obra. Cuando en diciembre de 1913 la Embajada de Alemania en Bolivia se informó del crédito otorgado por Francia, aconsejó que "en estas circunstancias la Firma Orenstein \& Koppel-Arthur Koppel A.G. debería renunciar a una solicitud para construir el ferrocarril. “27 Como se ha señalado ya, la ferrovía de Atocha a Villazón se terminó de construir en 1925 con el aporte del empréstito francés y de un crédito otorgado posteriormente por los Estados Unidos. Entre 1910 y 1913 se construyeron en el valle de Cochabamba dos cortos trayectos de tranvías eléctricos que permitieron vincular la ciudad de Cochabamba con Vinto en el occidente y con Arani en el oriente. Como se ha indicado, estas obras las realizó la empresa privada Luz y Fuerza Eléctrica de Cochabamba. Un informe de la Embajada Alemana en Bolivia de abril de 1926 menciona la participación de capitales alemanes en esta empresa. ${ }^{28}$ Si bien es difícil establecer de qué capitales se trata, es poco factible que ellos 
hayan procedido de Alemania. El carácter relativamente insignificante de estas obras y, sobre todo, la falta de referencias relativas a la mencionada participación en la correspondencia diplomática alemana son indicios que permiten afirmar que los capitales en cuestión fueron aportados por súbditos alemanes residentes en Bolivia que estaban vinculados a la empresa de tranvías.

Finalizado el tramo Cochabamba-Arani, se discutió en Bolivia durante varios años la posibilidad de prolongar la vía al río Ichilo y a Santa Cruz de la Sierra. En 1920 el gobierno creó una Comisión Técnica para estudiar el plan. La comisión estuvo presidida por el ingeniero alemán Dr. Hans Grether quien tres años más tarde presentó en 20 volúmenes "el estudio más completo que se haya hecho de ferrocarril boliviano alguno." ${ }^{29} \mathrm{El} \mathrm{estu-}$ dio del ingeniero alemán fue aprobado por la Cámara de Diputados de Bolivia en febrero de 1922. Al mes siguiente Grether advertía al embajador de Alemania en La Paz que en calidad de Director de la Comisión de Estudios „tengo la oportunidad de observar cuan grande es la posibilidad que los norteamericanos hagan el negocio porque probablemente en Europa nadie se interesa en él." ${ }^{30}$ A renglón seguido agregó: "Sin embargo, pienso que precisamente Alemania debería hacer un esfuerzo por obtener la orden de construcción. Si la empresa no pudiera concebirse como exclusivamente alemana, tal vez sea posible realizarla con algún estado neutral, en el sentido de que Alemania asuma principalmente el suministro de materiales, mientras que la otra parte se encarga de proporcionar el capital.... Desde luego que sería una gran ventaja contar con posibilidades de ventas seguras, libres de las triquiñuelas aduaneras de los países importadores. Como interesados, por parte de Alemania, habrían de considerarse esencialmente consorcios de la gran industria, los que, por un lado tienen interés en ventas directas, mientras que, por el otro, se ven obligados a buscar fuentes para su suministro petrolífero. Y no cabe duda que con la construcción del ferrocarril devendrán concesiones de petróleo." 31

En agosto de 1922 el gobierno de Bolivia llamó a propuestas públicas para construir el ferrocarril Cochabamba-Santa Cruz. En el mismo mes laEmbajada Alemana informó sobre el particular al Ministerio de Relaciones Exteriores en Berlín, señalando las condiciones más importantes de la oferta e indicando que las casas comerciales Gildemeister \& Co. de Oruro y Gustavo Hinke de Oruro y La Paz serían las adecuadas para fungir como represantes de las empresas alemanas interesadas. ${ }^{32}$ El Ministerio de Relaciones Exteriores de Alemania notificó a la Confederación de Industrias Alemanas, al Deutsche Bank y a la Diskonto-Gesellschaft sobre el proyecto. ${ }^{33} \mathrm{Ni}$ éstas, como tampoco ninguna otra empresa foránea llegó a interesarse en 
él. Hasta el 30 de junio de 1923, última fecha fijada por el gobierno de Bolivia para presentar solicitudes, éste no había recibido una sola oferta. La misión especial encomendada a H. Grether en 1925 para negociar un crédito en los Estados Unidos tampoco tuvo un resultado positivo. ${ }^{34}$

En cuanto a la ferrovía de La Paz a los Yungas, obra que no se llegó a terminar por falta de medios económicos, y a la ferrovía de Potosía a Sucre, la cual por la misma razón demoró décadas en concluirse, no existen evidencias de que el capital alemán se haya interesado seriamente por participar en su implementación.

El capital alemán mostró interés en el plan ferroviario destinado a vincular el río Paraguay con la ciudad de Santa Cruz. Para implementar este proyecto, el gobierno de Bolivia otorgó a finales de 1901 una concesión a la compañía belga L'Africaine para que construyera un puerto en Bahía Negra sobre el mencionado río y un ferrocarril desde este puerto hasta Santa Cruz de la Sierra. ${ }^{35}$ En noviembre de 1905 la concesión fue transferida al Sindicato Fomento del Oriente Boliviano. Los términos del contrato preveían que éste, a cambio de recibir $50.000 \mathrm{~km}$. ${ }^{2}$ de tierra, derechos de navegación y de explotación de fuentes de energía hidroeléctrica, así como una garantía del $5 \%$ sobre el capital invertido, se comprometía a construir un amplio puerto sobre el río Paraguay y a tender una línea ferroviaria y telegráfica de unos 650 a 700 kilómetros para unir el puerto con la ciudad de Santa Cruz. Posteriormente el Sindicato obtuvo el derecho de construir ramales ferroviarios a Chimoré, Lagunillas, Villa Montes y Yacuiba. ${ }^{36}$

La construcción de esta red ferroviaria respondía por un lado al interés que tenía Bolivia tanto por obtener una salida rápida al Atlántico a través del río Paraguay como por modernizar las vías de comunicación para el transporte de la goma extraída en el departamento de Santa Cruz. Ella respondía, por otro lado, al interés de la Argentina en la explotación de los árboles de quebracho, ubicados en la región fronteriza suroriental boliviana.

El Sindicato Fomento del Oriente de Bolivia se organizó en la ciudad de Buenos Aires con la participación de los poderosos empresarios argentinos Devoto, Musini, Vicente Casares, Francisco Moreno y de los alemanes Weber y Stricker que participaron en la construcción del puerto de la capital argentina. Para iniciar la obra el Sindicato se propuso obtener un capital de 16 millones de marcos alemanes. Una mitad del mismo la quería concertar en la Argentina, la otra en Europa. ${ }^{37}$ La dirección técnica de la obra fue delegada al ingeniero británico Goudge y al Consejero de Fomento alemán C. Offermann. Este aceptó el cargo a título honorífico con el beneplácito de la Embajada del Imperio Alemán en la Argentina "debido a que también 
intereses alemanes estaban vinculados a la empresa a través del Deutsche Bank y del Banco Alemán Trasatlántico. ${ }^{38}$ De acuerdo con Offermann, la captación de capitales hizo progresos. Sin embargo, el Deutsche Bank "probablemente debido a sus fuertes preocupaciones en el Oriente se mostró completamente renuente, cuando el asunto cobró seriedad, lo cual, como he podido comprobar, amainó el interés de Inglaterra." ${ }^{39}$ A consecuencia de la actitud adoptada por la banca alemana, todos los interesados abandonaron el proyecto, en el cual se habían llegado a invertir por concepto de expediciones y de otros trabajos preparatorios 1.5 millones de marcos oro alemanes. ${ }^{40}$ Disuelto el Sindicato Fomento del Oriente Boliviano, el gobierno de Bolivia otorgó en 1912 la concesión a la Bolivian Development and Colonization Company, empresa controlada por el Sindicato de Parcifall Farquhar, el cual había obtenido con anterioridad la concesión para construir el ferrocarril Madera-Mamoré. A pesar de haberse registrado en los Estados Unidos con un capital de aproximadamente 25 millones de dólares, la Compañía abandonó el proyecto un año más tarde. ${ }^{41} \mathrm{~A}$ juicio de la Embajada del Imperio Alemán en Bolivia, este paso ofrecía "al capital y a la industria alemana una nueva oportunidad de asegurarse una tarea vasta y lucrativa." ${ }^{42}$ A pesar de que la Cancillería de Berlín informó sobre esta nueva oportunidad a instituciones bancarias y empresas industriales alemanas y algunas de éstas, como Orenstein \& Koppel-Arthur Koppel A.G. y Staudt \& Co., reaccionaron favorablemente, ${ }^{43}$ ninguna de ellas así como tampoco ninguna otra compañía extranjera volvió a solicitar una concesión. Una explicación plausible para este desinterés la articuló Kade, el presidente de la Casa Ernesto Tornquist \& Co. la cual en su momento tuvo un vivo interés por el proyecto ferroviario en el oriente de Bolivia. Según Kade era imposible reunir los medios financieros necesarios para una empresa que "recién después de muchos años estaría en condiciones de arrojar beneficios." ${ }^{44}$

La exposición anterior muestra que las posibilidades de Alemania para intervenir en el financiamiento de la red ferroviaria boliviana construida hasta 1925 fueron limitadas y que aquellos casos en los cuales el capital alemán se interesó o pugnó por otorgar empréstitos terminaron perennemente en fracasos. Sin embargo, el desarrollo de aquella red sí tuvo un impacto positivo para la industria alemana al ofrecer a ésta oportunidades de venta de material ferroviario y de accesorios necesarios para el tendido de ferrovías. Si se consideran las concesiones de construcción otorgadas a Gran Bretaña y, en menor medida, a los Estados Unidos, es lícito suponer que el aporte de Alemania al total de las adquisiciones de material rodante realizado por 
Bolivia quedó muy a la zaga del británico y del estadounidense. ${ }^{45}$ Sin embargo sorprende constatar que, a pesar de su nula participación en materia de inversiones, Alemania logró realizar importantes suministros de material ferroviario. Las estadísticas relativas al comercio germano-boliviano muestran que en diversos años este material constituyó un rubro importante de las exportaciones alemanas. En 1904 el Imperio Alemán vendió a Bolivia mercadería por valor de algo más de 2.1 millones de marcos. De ellos, 324.000 marcos, vale decir casi el 16\% del total, fueron obtenidos por concepto de venta de locomotoras y locomóviles. Estas máquinas constituyeron el tercer rubro en importancia dentro de la gama de productos exportados de Alemania al país andino. ${ }^{46}$ En 1913 Bolivia importó de Alemania para el servicio ferroviario de Arica al Alto de la Paz locomotoras por valor de 459.501 bolivianos y vagones de tren por valor de 806.660 bolivianos. Además importó artículos de ferretería por casi 5 millones de bolivianos, explosivos por algo menos de 1 millón de bolivianos y maquinaria eléctrica por cerca de 744.000 bolivianos. Es muy probable que una parte importante de estas importaciones fueron destinadas a las diversas obras ferroviarias que en aquel entonces se hallaban en construcción. ${ }^{47}$ En 1921, cuando las relaciones comerciales entre ambos países estaban en situación de franco deterioro debido a la ruptura de relaciones diplomáticas en 1917, Alemania vendió a Bolivia material rodante ferroviario por valor de 38.078 bolivianos. ${ }^{48}$ Este material fue adquirido de la empresa Orenstein \& Koppel-Arthur Koppel A.G. para el ferrocarril Machacamarca-Uncía que entró en servicio en aquel año. Con el restablecimiento de las relaciones diplomáticas en 1922, el comercio germano-boliviano se volvió a incrementar considerablemente. En 1924 y en 1925 Bolivia importó de Alemania material para construcción ferroviaria, calderas, accesorios de máquinas, cuchillería y otros productos de ferretería por valor de 1 millón y de 2 millones de marcos respectivamente. Estos productos constituyeron en $1924-$ junto a la lana-el segundo rubro y en 1925 con amplio margen de distancia, el rubro más importante de las exportaciones que Alemania realizó a Bolivia. $^{49}$

\section{El establecimiento de estaciones radiotelegráficas}

Mientras que la temática sobre la implementación de la red ferroviaria en Bolivia ha sido objeto de diversos estudios, es prácticamente imposible encontrar trabajos relativos al desarrollo de la radiotelegrafía en este país. Debido a ello y a la imposibilidad de incluir en el análisis fuentes bolivianas 
que podrían facilitar el esclarecimiento de diversos problemas, la exposición que se desarrolla a continuación se basa casi íntegramente en material documental encontrado en archivos de la República Federal de Alemania. Este material permite ilustrar el interés que tuvo el Imperio Alemán por obtener la primera concesión de importancia que otorgó el Estado de Bolivia en el campo de la radiotelegrafía y permite, a su vez, exponer - desde la perspectiva alemana - la pugna entre Gran Bretaña y el Imperio Alemán por arrogarse aquella concesión. Lamentablemente, los documentos revisados no bastan para delinear, como se ha hecho en la exposición relativa a la red ferroviaria, una serie de datos y fechas importantes relativos al establecimiento de las diversas estaciones de telegrafía sin hilos en territorio boliviano hasta aproximadamente 1925. Partiendo de estas limitaciones y teniendo presente el carácter parcial de la literatura consultada, se expondrá seguidamente la rivalidad germano-británica en el campo de la radiotelegrafía durante las dos primeras décadas del siglo XX para delinear a continuación la competencia entre la empresa británica Marconi y la compañía Telefunken de Alemania por obtener la mencionada concesión boliviana.

En 1901 Gran Bretaña empezó con los experimentos para establecer estaciones radiotelegráficas de larga distancia. Desde entonces aquel país se preocupó por obtener concesiones en países industrializados para instalar este tipo de estaciones. A su vez concibió un plan para vincularse por radiotelegrafía con sus posesiones en ultramar y para unificar a sus colonias a través de este medio de comunicación. Paralelamente desplegó esfuerzos para que otros países subdesarollados se vinculasen a la red radiotelegráfica planificada. Inmediatamente después de que la Marconi logró implantar con éxito el sistema de telégrafos sin hilos a larga distancia, Gran Bretaña estableció un monopolio radiotelegráfico marítimo de cuyo servicio empezaron a depender las companías navieras de otras naciones. Para el Imperio Alemán los hechos señalados constituyeron un síntoma evidente de que Gran Bretaña estaba deseosa por extender su supremacía mundial en el campo de la telegrafía alámbrica al campo de la radiotelegrafía. ${ }^{50}$

Alemania llegó a impulsar enérgicamente la telegrafía con hilos en un momento en el cual una gran parte de la red telegráfica mundial ya estaba controlada por poderosas empresas de otras naciones y fundamentalmente por Gran Bretaña. Para evadir su fuerte dependencia del sistema telegráfico internacional británico, el Imperio Alemán se preocupó por establecer a la brevedad posible und red radiotelegráfica mundial propia. Con esta finalidad, la Allgemeine Elektrizitätsgesellschaft (AEG) y la Sie- 
Distancias de los enlaces radiotelegráficos de Alemania y de Gran Bretaña en 1914

(en kilómetros)

\begin{tabular}{lr|lc}
\hline \multicolumn{1}{c|}{ Alemania } & & \multicolumn{2}{c}{ Gran Bretaña } \\
Enlace & Distancia & Enlace & Distancia \\
\hline Nauen-Sayville & 6.500 & Irlanda-Canadá & 3.200 \\
Sayville-Cartagena & 3.500 & Inglaterra-EEUU & 5.300 \\
Eilvese-Tuckerton & 6.500 & Inglaterra-Gibraltar & 1.800 \\
Nauen-Togo & 5.400 & Inglaterra-Malta & 2.200 \\
Togo-Africa Suroccid. & 3.600 & Gibraltar-Malta & 1.800 \\
Tsingtau-Yap & 3.200 & Inglaterra-España & 1.450 \\
Yap-Nauru & 3.400 & & \\
Nauru-Apia & 2.700 & & \\
Totales & 34.800 & Totales & 15.750 \\
\hline
\end{tabular}

Fuente: Hans Bredow, Denkschrift über funkentelegraphische Weltprojekte, Berlín 1916, en:Die drabtlose (Funken-) Telegraphie, 1914-1917, R 85/Vorl. 753, Bundesarchiv Koblenz.

mens \& Halske crearon en 1903 la compañía Telefunken que se empeñó en desarollar la tecnología necesaria para quebrar tanto la posición como las aspiraciones monopólicas de la Marconi Wireless Telegraph Company Ltd. en el campo de la telecomunicación. La Telefunken logró desarrollar hasta 1909 los medios técnicos para enviar mensajes radiotelegráficos a larga distancia. Entre 1911 y 1912 fue habilitada en Nauen la primera estación radiotelegráfica alemana de alta potencia. Un año más tarde ella empezó a transmitir mensajes a la estación instalada por la Telefunken en Sayville en los Estados Unidos. De ahí en adelante el Imperio Alemán empezó a desplegar actividades para convertir a esta estación en una central radiotelegráfica para Centro y Suramérica. En 1912 la Telefunken obtuvo una concesión de Colombia para instalar y supervisar una emisora y receptora radiotelegráfica en Cartagena y entabló, a su vez, negociaciones con varios países latinoamericanos para implementar centrales radiotelegráficas en ellos. El éxito de las tratativas permitió al Imperio Alemán establecer hasta poco antes de la Primera Guerra Mundial una amplia red radiotelegráfica en América Latina que incluía estaciones en Argentina, Brasil, Colombia, Cuba, Chile, Perú y Uruguay. En 1914 Alemania y los Estados Unidos lograron desarrollar los tubos de rayos catódicos. Esta innovación permi- 
tió reducir substancialmente los costos para amplificar las emisoras y obtener una mejor receptividad. De esta manera el Imperio Alemán se aseguró la posibilidad de establecer conexiones radiotelegráficas a nivel mundial. En el año mencionado fue inaugurada la línea Nauen-Togo-Windhuk. ${ }^{51}$ Al comenzar la Primera Guerra Mundial, el radio de acción de la red radiotelegráfica alemana era mucho más amplio que el de la red británica.

De acuerdo con afirmaciones vertidas en 1915 durante la XVIII Reunión General de la Marconi Wireless Telegraph Co. Ltd., la impetuosa expansión alemana en el campo de la radiotelegrafía fue producto de las actividades desarrolladas por la Telefunken. "It had for its direction the most, or some of the most, eminent and able commercial men in Germany - men who were then the Directors of some of the biggest commercial industries of that country. It had, further, the great advantage of the financial aid (from, L.B.) some of the principal German banks, and it had finally, a very

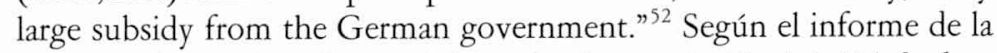
mencionada reunión, el potencial y poder de negociación de la Telefunken le permitió llegar a tener en todas partes del mundo y con las solas excepciones de Italia, Francia y Gran Bretaña "the preponderating position in this industry (la radiotelegrafía, L.B.).... Wherever one went, whatever negotiations one had with a foreign Government, one was always in competition with the powerful German agency; ... It is easy to understand, that to a Company like this German Company, which had the support of the German Government and conducted the greater part of its business under the direction of the German Government - always with the aim of obtaining the contracts or concessions for the construction of the Wireless Telegraph stations in foreign countries, having in view the importance which they one day would play, and with the prospect where a German station was built that German hands would work that station - it mattered little or nothing to the German Company, with the German Government behind it, at what price, or in what condition it entered into contracts for the construction of those stations. ${ }^{53}$ En esas circunstancias, observa el informe, la Marconi tuvo grandes dificultades de salvaguardar sus propios contratos. $^{54}$

Durante la segunda década del siglo XX, la Marconi y la Telefunken se convirtieron en las empresas hegemónicas de la radiotelegrafía mundial.

Después de su inauguración en 1880 la red telegráfica de Bolivia se expandió rápidamente. En 1900 tenía una extensión de 5.013 kilómetros. ${ }^{55} \mathrm{~A}$ partir de aquel año la expansión tuvo un ritmo mucho más pausado; en 1912 la red sumó 6.683 kilómetros. ${ }^{56} \mathrm{El}$ informe de la Dirección General de Telé- 
grafos de Bolivia del año 1912 muestra que la red telegráfica - al igual que el sistema ferroviario - se concentraba en casi su totalidad en la región occidental del país. ${ }^{57}$ Con la intención de superar esta situación y de ampliar la telecomunicación al oriente, el gobierno de Bolivia, a partir de 1909, se empezó a interesar por la instalación de estaciones radiotelegráficas. Debido al elevado costo de instalación y mantenimiento así como a problemas de rentabilidad, el Estado boliviano sólo podía realizar este proyecto con el apoyo financiero y técnico de empresas foráneas. ${ }^{58}$

\section{Cuadro III. 4}

Presupuestos para la instalación de 7 estaciones radiotelegráficas en Bolivia 1911

\begin{tabular}{l|c|c|c}
\hline & Marconi & Telefunken & Lorenz \\
\hline La Paz & $£ 22.000$ & $£ 5.100$ & $£ 4.045$ \\
Villa-Bella & $£ 4.500$ & $£ 4.650$ & $£ 3.375$ \\
Cobija & $£ 4.500$ & $£ 4.650$ & $£ 3.375$ \\
Santa Cruz & $£ 6.750$ & $£ 4.650$ & $£ 3.375$ \\
Puerto Suárez & $£ 6.750$ & $£ 6.820$ & $£ 4.340$ \\
Trinidad & $£ 4.500$ & $£ 4.650$ & $£ 3.375$ \\
Yacuiba (Villa Montes) & $£ 4.500$ & $£ 4.650$ & $£ 3.375$ \\
Sumas & $£ 53.500$ & $£ 35.170$ & $£ 25.260$ \\
\hline Por el montaje No. 1 de la propuesta C. Lorenz, aparte & $£ 6.286$ \\
Suma total de esta última propuesta
\end{tabular}

Fuente: Rosendo Villalobos, Informe, Dirección General de Telégrafos 1911-1912, Anexos, p. 10, en: Die Telegraphen Verbältnisse in Südamerika, 1908-1913, R 85/Vorl. 838, Nr. 55, Bundesarchiv Koblenz.

Con anterioridad al llamado a propuestas públicas, el representante de la Telefunken en Bolivia, Gustavo Hinke, y la Compagnie de télégraphie sans fils de Francia se interesaron por el proyecto. ${ }^{59}$

En enero de 1911 el gobierno boliviano promulgó una ley que fijó un presupuesto de 600.000 bolivianos para instalar estaciones radiotelegráficas en los siguientes 7 lugares del país: La Paz, Villa Bella o Riberalta, Cobija, Trinidad, Santa Cruz, Puerto Suárez y Yacuiba. Hasta marzo de aquel año la Marconi Wireless Telegraph Co. Ltd., la empresa Lorenz de Berlín y la Gesellschaft für Drahtlose Telegraphie en representación del sistema Telefunken presentaron solicitudes para obtener la concesión. ${ }^{60}$ El presupuesto presentado por la Marconi ascendía a 53.500 libras esterlinas (equivalen- 


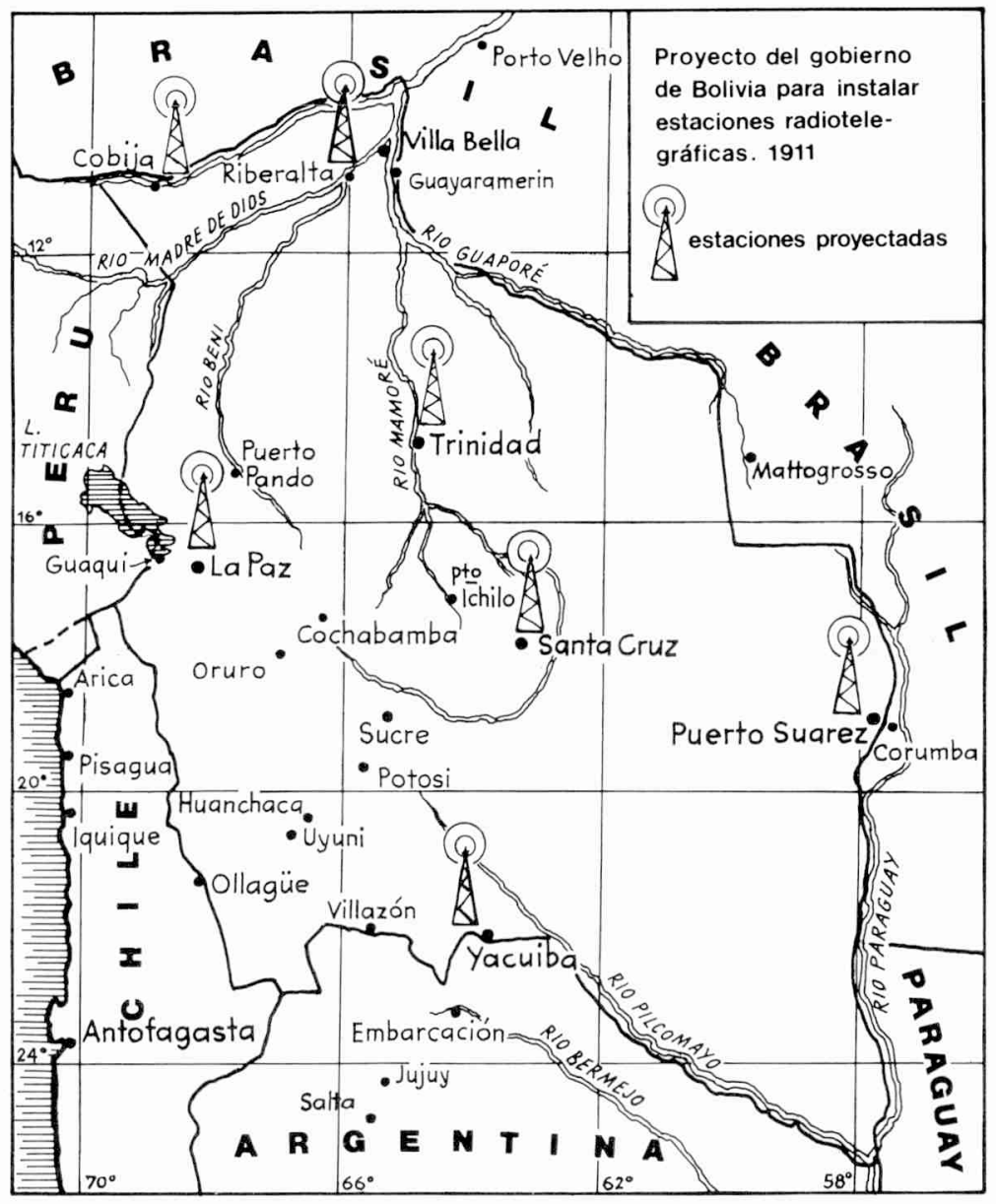

tes a 682.125 bolivianos), el de la Gesellschaft für Drahtlose Telegraphie a 35.170 libras esterlinas (equivalentes a $448.417 .^{50}$ bolivianos) y el de la Compañía Lorenz a 31.546 libras esterlinas (equivalentes a 401.574 bolivianos). ${ }^{61}$

Debido probablemente a un fallo que la Oficina Imperial de Patentes de Alemania emitió contra la Compañía Lorenz por haberse apropiado ilícitamente del sistema de transmisión patentado por la Telefunken, su propuesta, que era la menos onerosa, fue descartada por el gobierno de Boli- 
via. ${ }^{62}$ Como se desprende del Cuadro III. 4, la llamativa diferencia de precios entre la oferta de la Marconi y la de la Telefunken se debió a que el costo para la estación de La Paz presupuestado por aquélla era cuatro veces más elevado que el tasado por la empresa alemana. El elevado precio requerido por la Marconi se debió a su intención de instalar en La Paz una emisora de alta potencia, capaz de transmitir noticias directamente a la estación que esta misma empresa había instalado a unos 1.000 kilómetros de distancia en la cuenca amazónica del Brasil. A diferencia de la compañía británica, la Gesellschaft für Drahtlose Telegraphie proponía instalar una estación normal en La Paz que debía vincularse con el Brasil a través de receptoras intermedias en Villa Bella o en Riberalta. Debido a la diferencia de costos fijados para la estación de la Paz, la propuesta de la Marconi excedía por más de 80.000 bolivianos al presupuesto total fijado por el gobierno de Bolivia, mientras que la propuesta alemana quedaba por buen margen por debajo de él.

Durante más de un año el gobierno de Bolivia realizó consultas con peritos y reunió una serie de dictámenes para decidir sobre el otorgamiento de la concesión. La mayor parte de la información acumulada intercedía claramente en favor del sistema Telefunken. Los argumentos en favor de este sistema eran básicamente dos: la calidad de las instalaciones de ambas empresas no ofrecía diferencias, en cambio la oferta alemana tenía claras ventajas económicas. Según Beart du Dézert - técnico profesional francés, a quien el embajador de Bolivia en París, Ismael Montes, pidió elevar un dictamen-, las dos compañías solicitantes ofrecían la misma calidad técnica, tanto en materia de transmisión como de mantenimiento de las comunicaciones. B. du Dézert sostenía que para la ciudad de La Paz no era necesaria una estación tan potente y onerosa como la que ofrecía la Marconi. ${ }^{63}$ Un informe posterior, presentado por la Dirección de Obras Públicas de Bolivia, ratificaba que la calidad técnica de ambos sistemas era la misma. Este juicio fue reconocido expresamente por el propio gobierno boliviano en junio de 1912. ${ }^{64}$ Dos gerentes de la Dirección General de Telégrafos, el general Ampuero y Rosendo Villalobos, también se manifestaron en favor del sistema Telefunken. En su informe, presentado en 1912 al Ministerio de Gobierno y Fomento, R. Villalobos dió a conocer que la Dirección General de Telégrafos manifiesta "su concepto favorable a las instalaciones Telefunken, tanto por los motivos de orden económico, cuanto por los de orden técnico, ..., no sin hacer antes la indicación de que quizá fuera conveniente, ..., conceder la instalación de las estaciones que desembarquen en Mollendo y en Rosario a la Compañía Telefunken, ..., y la de las que 
tuviere que recibirse por la vía de Manaos a la Compañía Marconi, no obstante el inconveniente de la falta de unidad que resultaría de esto; ..." El informe de Villalobos revela que la mayoría de los peritos consultados por diplomáticos bolivianos en los países vecinos (así, por ejemplo, el Inspector de Telégrafos de Chile, el Jefe del Servicio Radiotelegráfico de la Armada Argentina, el Director General de Telégrafos de Brasil) aconsejaron optar en favor de la oferta de la Gesellschaft für Drahtlose Telegraphie. $^{6}$

En favor de la Marconi se expresó el Encargado de Negocios de Bolivia en Santiago de Chile, Claudio Pinilla, quien de acuerdo a informaciones proporcionadas por la armada chilena pudo constatar que los aparatos Telefunken "son incialmente más caros que los aparatos Marconi de 3 k.w., requiriendo más repuestos porque son menos sólidos ... en este ramo (la radiotelegrafía, L.B.) como en otros parece que la industria inglesa consulta ante todo la solidez, mientras que la alemana consulta la economía. ${ }^{67} \mathrm{De}$ acuerdo con el informe de C. Pinilla, la Marconi iba a instalar en un futuro próximo una serie de estaciones radiotelegráficas en Chile. ${ }^{68}$ Esta observación tenía la finalidad de advertir al gobierno de Bolivia que la red británica ofrecía al país la posibilidad potencial de comunicaciones radiotelegráficas, tanto por el Atlántico a través del Brasil, como por el Pacífico a través de las instalaciones proyectadas en Chile. Probablemente la acotación tendía a contrarrestar una ventaja que el sistema alemán ofrecía a Bolivia: la de vincular el sistema radiotelegráfico que debía instalarse en el país con el Atlántico a través de las estaciones de San Antonio, Manaos, Santarem y Para, y con el Pacífico a través de las estaciones Telefunken de Iquitos y Lima. Sin la instalación de estaciones en Chile, esta última posibilidad quedaba descartada para la Marconi. ${ }^{69}$

El 9 de julio de 1912 el gobierno de Bolivia otorgó a la empresa Marconi la concesión para instalar las 7 estaciones radiotelegráficas. Para Alemania, cuatro razones motivaron esta decisión: el trabajo de propaganda y agitación desarrollado por la Marconi, la influencia decisiva de Ismael Montes en el asunto, el poder de las finanzas británicas y francesas en Bolivia y, sobre todo, la rebaja de costo que la empresa británica ofreció en último momento.

Para obtener la concesión, la empresa Marconi "puso a disposición de su agente en La Paz, el francés René Demont, recursos pecuniarios que le permitieron desarrollar una vasta propaganda que minó a toda la ciudad; además, Demont tenía a su disposición algunos aparatos con los cuales pudo hacer cierto alarde." ${ }^{70}$ A diferencia de la Telefunken, la Marconi se 
percató prematuramente de la poderosa influencia que el embajador boliviano en París, Ismael Montes (él había ocupado con anterioridad la presidencia del país y era el jefe del Partido Liberal que desde 1901 controlaba el poder político en Bolivia), tenía sobre las decisiones del gobierno de su país. Cuando la companía alemana "tomó contacto con esta influyente personalidad, la Marconi ya la había persuadido eficientemente." ${ }^{71}$ De acuerdo con una referencia del embajador del Imperio Alemán en Bolivia, von Sanden, la opción por la oferta Marconi "estaba prácticamente decidida cuando en agosto del año pasado (1911, L.B.) el embajador boliviano en París comunicó telegráficamente a su gobierno que la Sociedad Marconi le había asegurado que ella sería la única capaz de ofrecer buenos resultados en la instalación así como en la comunicación directa con todos los países." 72 El diplomático alemán observó, a su vez, que Montes "desde un comienzo sujetó las riendas en el asunto de la instalación de la radiotelegrafía." ${ }^{73}$ y que él fue la figura clave a través de la cual círculos financieros de Londres y París lograron persuadir al gobierno de Bolivia de votar en favor del sistema Marconi. Además, agregó von Sanden, el agente de aquellos grupos financieros en Bolivia, André Risler, desarrolló, junto a R. Demont, una agitación muy efectiva en favor de este sistema. ${ }^{74}$ "Bajo estas circunstancias y dada la actitud del capital de París y Londres el gobierno (de Bolivia, L.B.) tuvo que tomar un giro favorable a la Marconi." 75

Que todos los factores señalados no fueron suficientes para inclinar la opinión del gobierno boliviano en contra de la oferta alemana lo demuestra el hecho de que la Marconi, en último momento, se vio forzada a reducir su presupuesto a un monto inferior al tasado por la Gesellschaft für Drahtlose Telegraphie. $^{76}$

El contrato firmado en julio de 1912 con la Marconi preveía la entrega del material de construcción en el lapso de 8 meses a partir de la firma del convenio y la conclusión de las obras 4 meses más tarde. La compañía británica no cumplió con este compromiso. Una vez firmado el contrato ella se empeñó en modificar las claúsulas establecidas, con la finalidad de poder instalar un número mayor de estaciones así como de amplificar la potencia de algunas de las instalaciones previstas. Estas sugerencias, "tendientes a elevar el precio total de la obra" ${ }^{\text {"7 }}$, fueron rechazadas por el gobierno de Bolivia. Sin embargo, en septiembre de 1913, vale decir un mes después de que I. Montes asumió por tercera vez la presidencia de Bolivia, R. Demont logró firmar un nuevo contrato con el gobierno que preveía mayores suministros de material y otras condiciones más ventajosas para la Marconi. Probablemente no es equívoco suponer "que las estipulaciones de este nuevo 
contrato fueron acordadas en París, respectivamente en Londres, con el señor Montes, ..., y que ellas constituyen una compensación parcial por el empréstito de 1 millón de libras esterlinas levantado (por Bolivia, L.B.) en París en condiciones relativamente ventajosas para contruir el ferrocarril La Quiaca-Tupiza." ${ }^{78}$ Después de acalorados debates en los cuales "se criticó severamente el comportamiento del gobierno y de la Sociedad (Marconi, L.B.) y se realzó las ventajas del sistema Telefunken" ${ }^{79}$, el Congreso de Bolivia ratificó, a finales de 1913, el nuevo contrato. Esta ratificación incluía un aditamento que fue rechazado por la Marconi. El nuevo impasse llevó al gobierno boliviano a anular el 5 de diciembre de 1914 los contratos firmados en julio de 1912 y en septiembre de 1913 con la empresa radiotelegráfica británica. Bolivia se comprometió a adquirir de la Marconi las 4 estaciones entregadas hasta entonces al precio establecido en el último contrato y a desembolsar en favor de esta empresa una indemnización de 3.000 libras esterlinas. $^{80}$

A partir de 1910 la Gesellschaft für Drahtlose Telegraphie no escatimó esfuerzos para obtener el derecho de construir estaciones radiotelegráficas en Bolivia y puso todo su empeño por eliminar la competencia de la Marconi. A comienzos del año señalado, el agente de la compañía alemana, Gustavo Hinke, proporcionó al gobierno boliviano "estimaciones de costo detalladas" para la instalación de una red radiotelegráfica en el país. ${ }^{81}$ Al mismo tiempo, y con la expresa finalidad de contrarrestar el interés mostrado inicialmente por la mencionada Compagnie de télégraphie sans fils, G. Hinke invitó al Ministro de Finanzas de Bolivia, Carlos Torrico, quien con anterioridad ocupara el cargo de Director General de Telégrafos y había manifestado explícitamente su preferencia por la compañía francesa, a conocer en Antofagasta, a bordo del vapor Kosmos, la estación radiotelegráfica Heluan instalada por la Telefunken. "Para dirigir los experimentos vino especialmente de Buenos Aires un especialista de la Sociedad Telefunken. Los experimentos fueron un éxito completo, pero tuvieron el no deseado efecto colateral de que la estación Marconi en Valparaiso interceptó los telegramas, con lo cual la companía británica obtuvo conocimiento de la intención del gobierno de Bolivia de instalar estaciones radiotelegráficas en el país." ${ }^{82}$ Para afrontar la influencia que a partir de entonces llegó a tener la Marconi, desde fines de 1911, Alemania hizo gestiones para vincularse con Ismael Montes e influenciarlo en su sentido. ${ }^{83}$ El embajador von Sanden no omitió esfuerzos para influenciar al entonces Director General de Telegráfos de Bolivia Rosendo Villalobos. ${ }^{84}$ A poco de firmarse el primer contrato con la Marconi, "Telefunken entró a la palestra ofreciendo un 
precio más bajo" que el presupuestado por la compañía británica ${ }^{85}$ Esta oferta fue rechazada por el ministro competente con el argumento de que el gobierno de Bolivia no había llegado a tener conocimiento oportuno de ella; hecho que posteriormente fue confirmado por el agente de la Telefunken, el señor Chambres. ${ }^{86}$

Inmediatamente después de que la concesión fuera entregada a la Marconi, von Sanden indagó al Ministro de Gobierno de Bolivia sobre las posibilidades que todavía le restaban a la Gesellschaft für Drahtlose Telegraphie. El ministro señaló que ello dependía del cumplimiento del convenio por parte de la empresa británica ${ }^{87}$ De ahí en adelante, tanto la Embajada del Imperio Alemán como los agentes de la Telefunken en Bolivia, presionaron por intermedio de sus contactos en el Congreso y en la prensa para obligar a la Marconi a cumplir con las estipulaciones del contrato. Esta presión se vio favorecida por los empeños de la empresa británica de negociar revisiones del convenio. La intención de los grupos que intercedían en favor del sistema Telefunken era demostrar al gobierno y a la opinión pública que la Marconi no estaba en condiciones de instalar al costo fijado las estaciones previstas y que, por ende, el contrato debía ser anulado. De ahí que la propaganda y la agitación contra el convenio se centró en demandar la ejecución de toda la obra por el precio convenido. Con énfasis especial se prestó atención a que la Marconi cumpliese con su oferta de instalar en La Paz una estación de escasamente 10 kilowatios, la cual, de acuerdo con lo estipulado, debía servir para establecer una communicación directa con la estación de Porto Velho en el Brasil. La importancia que se dio a este particular provenía del hecho de que la rebaja ofrecida en último momento por la Marconi estaba basada en el cálculo de que con una estación mucho menos potente que la ofrecida inicialmente se podía establecer el contacto directo desde La Paz hasta la región amazónica brasilera. Posteriormente, la propia Marconi se vio forzada a admitir la imposibilidad de realizar esta comunicación con una estación equipada con una potencia de 10 kilowatios. $^{88}$

Si bien es difícil ponderar el efecto que tuvo la presión ejercida por la diplomacia alemana y por los representantes de la Telefunken, ella seguramente influenció la rescisión de los contratos firmados en 1912 y en 1913 por el gobierno de Bolivia con esta empresa. La ley del 5 de diciembre de 1914, que anuló aquellos contratos, fue acogida con satisfacción por von Sanden. En febrero de 1915 él informó al Canciller del Imperio Alemán que "por lo menos ahora la vía está libre para la Telefunken; ojalá pronto llegue el momento en que ella pueda dotar a Bolivia con la red radiotelegráfica reconocida, a la sazón, como urgentemente necesaria." ${ }^{89}$ 
Entre 1915 y 1925 se instalaron 12 estaciones radiotelegráficas en Bolivia. De ellas 8 fueron construidas por la Marconi y 4 por la Telefunken. Mientras que el radio de acción de aquéllas alcanzó los 4.549 kilómetros, el de estas últimas sólo llegó a los 1.080 kilómetros.

\section{Cuadro III. 5}

Estaciones radiotelegráficas de Bolivia 1925

\begin{tabular}{|c|c|c|c|}
\hline \multicolumn{2}{|c|}{ Sistema Marconi } & \multicolumn{2}{|c|}{ Sistema Telefunken } \\
\hline Estación & Radio de acción & Estación & Radio de acción \\
\hline Ballivián & $380 \mathrm{~km}$ & Trinidad & $550 \mathrm{~km}$ \\
\hline Esteros & $380 \mathrm{~km}$ & Santa Ana & $150 \mathrm{~km}$ \\
\hline D'Orbigni & $380 \mathrm{~km}$ & Todos Santos & $300 \mathrm{~km}$ \\
\hline Riberalta & $800 \mathrm{~km}$ & Villa Bella & $80 \mathrm{~km}$ \\
\hline Viacha & $800 \mathrm{~km}$ & & \\
\hline Yacuiba & $800 \mathrm{~km}$ & & \\
\hline Cobija & $209 \mathrm{~km}$ & & \\
\hline Santa Cruz & $800 \mathrm{~km}$ & & \\
\hline $\begin{array}{l}\text { Total Radio } \\
\text { de acción }\end{array}$ & $4.549 \mathrm{~km}$ & & $1.080 \mathrm{~km}$ \\
\hline
\end{tabular}

Fuente: Bolivia en el Primer Centenario de su Independencia, La Paz 1925, p. 443.

Tanto las instalaciones radiotelegráficas como también la expansión de la telegrafía alámbrica en Bolivia ofrecieron a Alemania posibilidades para ampliar su comercio con ese país. Para la red radiotelegráfica la Telefunken vendió estaciones. Para la instalación de varias líneas de telegrafía alambrada Bolivia compró postes de acero y aisladores acorazados de la empresa Mannesmann y de la firma Siemens respectivamente. ${ }^{90}$ En 1913 el ejército de Bolivia adquirió de la Telefunken 4 estaciones portátiles de transmisión para la región del Chaco. ${ }^{91} \mathrm{La}$ falta de datos estadísticos hace imposible cuantificar el valor de estas ventas y realzar su importancia en el marco de las exportaciones alemanas hechas a Bolivia. Lo que se puede establecer es que la Marconi frustró en gran medida las ambiciones alemanas en el campo de la telecomunicación boliviana. En 1911 aquella empresa asistió, con un equipo propio, la conducción de maniobras del ejército de Bolivia sin pedir ninguna gratificación. Al respecto el embajador del Imperio Alemán en La Paz observó que "es difícil comprender por qué la Sociedad Tele- 
funken no intenta engendrar con el mismo procedimiento un estado de ánimo (en Bolivia, L.B.) que le favorezca. A mí, y a muchos de mis compatriotas aquí, nos parece un craso error que ella no haya tenido ninguna participación en las maniobras, ... Menciono, confidencialmente, que, en general, la representación de la Sociedad Telefunken en este país me parece ser algo negligente." ${ }^{92}$ Como lo demuestra el tardío intento de establecer contactos con Ismael Montes, la negligencia de los agentes de la Telefunken también se manifestó en la pugna por obtener la concesión para instalar 7 estaciones radiotelegráficas. Sin embargo, sería desatinado reducir a este factor el mediocre desempeño alemán en el desarrollo radiotelegráfico de Bolivia.

\section{Resumen y evaluación}

Una comparación de la influencia económica que Alemania logró obtener en Bolivia por un lado en el sector extractivo, por el otro en el desarrollo ferroviario y radiotelegráfico, permite establecer dos diferencias importantes. Mientras que no es posible estimar aquella influencia a cabalidad en el sector extractivo, ella se deja ponderar con facilidad en lo que respecta al desarrollo de los medios de infraestructura señalados. En el campo de la extracción minera y cauchera en Bolivia, Alemania no fue rival para los capitales británicos y estadounidenses. En cambio en el campo del sistema de transportes y comunicaciones sí fue un importante contendiente de otros países altamente industrializados. En algunos casos, como en el de la radiotelegrafía y, después de 1925, en el de la aviación civil, Alemania incluso llegó a ser un rival de verdadero peso.

Desde un comienzo Alemania mostró interés por el desarrollo ferroviario y por la instalación de estaciones radiotelegráficas en Bolivia. La economía alemana concibió la modernización de la infraestructura boliviana como fuente potencial de inversiones lucrativas y como medio para ampliar su comercio exterior. Por diversas razones Alemania no logró arrogarse una sola concesión ferroviaria en Bolivia. Si bien la limitación de opciones para solicitar el derecho de construcción fue un factor determinante para explicar este resultado, en varios casos (ferrocarril Arica-El Alto de La Paz, Atocha-Villazón, Potosí-Sucre, La Paz-Yungas, Cochabamba-Río Ichilo-Santa Cruz y el proyectado desde el río Paraguay a Santa Cruz), fue más bien producto de la falta de decisión, la debilidad y del desinterés que mostró el capital alemán. En todo caso, y de manera paralela a lo que sucedió en la 
esfera extractiva, el capital británico, en menor medida el francés y, en una fase posterior, el capital de los Estados Unidos no dejaron prácticamente ninguna posibilidad al Imperio Alemán, y más tarde a la República de Weimar, para invertir capitales en la red ferroviaria de Bolivia.

En Bolivia el Imperio Alemán mostró un poder competitivo y de negociación mucho mayor en el campo de la radiotelegrafía que en el de los ferrocarriles. Varias razones permiten explicar este hecho. A diferencia de lo sucedido con su industria pesada, cuyo desarollo fue relativamente tardío en comparación sobre todo con la británica, el Imperio Alemán fue uno de los pioneros en el campo de la telecomunicación sin hilos. Importantes descubrimientos e innovaciones tecnológicas permitieron a Alemania convertirse, en vísperas de la Primera Guerra Mundial, en una potencia hegemónica en el desarrollo de la radiotelegrafía. Además, esta rama industrial se caracterizó desde sus inicios por su elevado grado de concentración y centralización. Ella contó con el apoyo de la banca y disponía de un amplio respaldo por parte del gobierno imperial.

En contraste con las indecisiones, la debilidad y el desinterés que mostró Alemania frente a la construcción de ferrocarriles en Bolivia, aquel país puso todo su empeño por obtener la concesión de instalar las 7 estaciones radiotelegráficas que el gobierno boliviano requirió en 1911. Sin embargo, los esfuerzos desplegados por la Telefunken no pudieron contrarrestar plenamente la poderosa influencia de la empresa británica Marconi, la única adversaria seria a la que se tuvo que enfrentar la compañía alemana. En comparación con la Marconi, el poder de negociación de la Telefunken mostró claras deficiencias. Sin subestimar este factor, parece atinado suponer que en última instancia la vigorosa presencia de intereses financieros británicos en Bolivia fue la razón fundamental que limitó las posibilidades alemanas. Si bien la Telefunken no tuvo la fuerza suficiente para hacer valer irrestrictamente sus aspiraciones, su poderío logró perturbar las aspiraciones británicas de obtener el monopolio exclusivo en el aprovisionamiento de material para las 7 estaciones de radiotelegrafía.

Al igual que lo sucedido en la esfera extractiva, Alemania no llegó a realizar ninguna inversión de capital en el sistema ferroviario y radiotelegráfico de Bolivia. Sin embargo, la explotación de materias primas y la modernización de la infraestructura en este país fueron factores claves para la expansión que registró el comercio germano-boliviano a partir de fines del siglo XIX. 


\section{IV $\cdot$ LAS RELACIONES COMERCIALES GERMANO-BOLIVIANAS}

Entre 1880 y 1920 el comercio exterior de Bolivia se expandió masivamente. En el marco de esta expansión el Imperio Alemán desempeñó un rol de suma importancia. En efecto, en el ámbito de las relaciones económicas germano-bolivianas en el período mencionado, se puede constatar una notoria discrepancia entre la función que tuvo Alemania en el campo de las inversiones de capital por un lado y en la esfera del intercambio comercial por el otro. Mientras que en materia de inversiones de capital no llegó a tener peso notorio, su importancia en el comercio internacional del país andino fue altamente significativa hasta 1917.

Partiendo de una descripción de la expansión del comercio exterior boliviano, en el presente capítulo se expondrán tres aspectos: la importancia del Imperio Alemán en esta expansión, los factores determinantes de este hecho y la decadencia de la influencia alemana en el comercio internacional de Bolivia a consecuencia de la Primera Guerra Mundial.

\section{La expansión del comercio exterior de Bolivia}

A comienzos del siglo XX el comercio exterior de Bolivia, en términos comparativos internacionales, era insignificante. En $1906 \mathrm{el} \mathrm{valor} \mathrm{total} \mathrm{de}$ las transacciones comerciales internacionales de Gran Bretaña ascendía a casi 20 mil millones de marcos alemanes y el del Imperio Alemán a casi 14.5 mil millones de marcos alemanes. El monto total de las exportaciones e importaciones realizadas por Bolivia en el mismo año sumaba escasamente 137 millones de marcos. En otros términos, el valor del comercio exterior de Gran Bretaña era 146 y el del Imperio Alemán 106 veces más elevado que el de Bolivia. ${ }^{1}$ Pero también a nivel suramericano el comercio internacional de este país era poco significativo. En 1907 el valor total de las exportaciones e importaciones suramericanas ascendió a algo más de 6.1 millones de marcos alemanes. ${ }^{2}$ Bolivia aportó a este total escasamente con el $2.2 \%$. Su influencia en el comercio exterior de la région estaba muy por debajo de la de Argentina, Brasil o Chile y era de una gravitación módicamente mayor a la que tenían Venezuela y Colombia. 
Cuadro IV. I

Participación de paises suramericanos en el total del comercio exterior de la región 1907

\begin{tabular}{lc|lc}
\hline País & $\begin{array}{c}\text { Participación } \\
\text { en el 100\% }\end{array}$ & País & $\begin{array}{c}\text { Participación } \\
\text { en el 100\% }\end{array}$ \\
\hline Argentina & 38.3 & Bolivia & 2.2 \\
Brasil & 30.6 & Venezuela & 1.75 \\
Chile & 15.7 & Colombia & 1.7 \\
Uruguay & 4.9 & Paraguay & 0.8 \\
Perú & 3.6 & & \\
\hline
\end{tabular}

Fuente: Julius Uzarski, Bolivia. Natur und wirtschaftliche Verbältnisse, Bonn (Inaugural-Dissertation) 1911, p. 74.

Es difícil establecer el año exacto a partir del cual se han publicado estadísticas oficiales sobre el desarrollo del comercio exterior de Bolivia. Mientras que, por ejemplo, V. Mendoza López las remite al año 1895, fuentes alemanas señalan que ellas sólo existen a partir de $1900 .{ }^{3}$ A su vez, tanto en la literatura boliviana como en el material de archivos alemanes existe un sinnúmero de discrepancias con respecto a las cifras. En algunos casos estas discrepancias no son significativas, en otros, en cambio, son de proporciones substanciales. ${ }^{4}$

A pesar de las diferencias que se pueden establecer al comparar las diferentes estadísticas, todas ellas confirman una serie de rasgos peculiares del comercio exterior boliviano. En primer lugar ellas atestiguan su persistente incremento.

De 1900 a 1920 el valor de las exportaciones se elevó de 35.6 a 156 millones de bolivianos, en tanto que el valor de las importaciones pasó de 13.3 a 65.3 millones de bolivianos. El valor total del comercio exterior llegó casi a quintuplicarse en el correr de las dos décadas señaladas. En todo este lapso de tiempo el país contó con una balanza comercial altamente favorable. Durante los años 1915-1920 la extraordinaria demanda de materias primas y las limitaciones de la capacidad exportadora de los países altamente industrializados a causa de la Primera Guerra Mundial permitieron a Bolivia incrementar de manera descomunal sus exportaciones, al mismo tiempo que sus posibilidades de importación quedaron restringidas. Esta situación permitió obtener elevados superávits en la balanza comercial. Todas las estadísticas pertinentes confirman un rasgo estructural del comercio exte- 


\section{Cuadro IV. 2}

Desarrollo del comercio exterior de Bolivia 1895-1920

(valor en bolivianos)

\begin{tabular}{lrrr}
\hline Año & Exportaciones & Importaciones & Valor total \\
\hline 1895 & 20.914 .140 & 3.897 .404 & 24.811 .544 \\
1900 & 35.657 .689 & 13.344 .114 & 49.001 .803 \\
1901 & 38.955 .084 & 16.953 .223 & 55.908 .307 \\
1902 & 28.041 .578 & 14.143 .342 & 42.184 .920 \\
1903 & 25.169 .148 & 16.252 .885 & 41.422 .033 \\
1904 & 31.465 .026 & 16.909 .586 & 48.374 .612 \\
1905 & 41.795 .937 & 20.298 .771 & 62.094 .708 \\
1906 & 55.654 .516 & 35.087 .325 & 90.741 .841 \\
1907 & 50.331 .549 & 37.897 .610 & 88.229 .159 \\
1908 & 47.138 .319 & 40.732 .543 & 87.870 .862 \\
1909 & 63.764 .466 & 34.224 .765 & 97.989 .231 \\
1910 & 75.622 .146 & 58.302 .395 & 133.924 .541 \\
1911 & 82.631 .171 & 58.371 .409 & 141.002 .580 \\
1912 & 90.122 .987 & 49.508 .990 & 139.631 .977 \\
1913 & 93.721 .513 & 54.162 .834 & 147.884 .347 \\
$1914 *$ & 27.756 .715 & 13.692 .351 & 117.784 .966 \\
1915 & 95.210 .351 & 22.574 .567 & 132.583 .016 \\
1916 & 101.484 .800 & 31.098 .216 & 191.228 .885 \\
1917 & 157.748 .054 & 33.480 .831 & 217.612 .738 \\
1918 & 182.612 .851 & 34.999 .887 & 22.358 .25 \\
1919 & 144.251 .528 & 34.655 .796 & \\
1920 & 156.018 .745 & 65.339 .505 & \\
\hline
\end{tabular}

* sólo el segundo semestre

Fuente: Para 1895 y 1914 a 1920 Vicente Mendoza López, Las finanzas públicas de la República de Bolivia, en: Bolivia en el Primer Centenario de su Independencia, La Paz 1925, p. 471, 473. Para 1900 Export, Año XXIV, Nr. 26, Berlin 1902, en: Admiralstab der Marine, RM 5/V, Nr. 5396, Bundesarchiv/Militärarchiv, Freiburg i. Br. Para 1901 Staatsanzeiger del 23. 12. 1902, en: op. cit. Para 1902 a 1913 E. Pfannenschmidt, Boliviens Land- und Volkswirtschaft, Berlin 1916, p. 48.

rior boliviano. Al igual que el resto de los países latinoamericanos, en el correr de la segunda mitad del siglo XIX Bolivia afianzó su carácter como exportador de materias primas e importador de productos manufacturados. El capítulo referente a la explotación de materias primas contiene 
diversas estadísticas y una serie de datos los cuales demuestran que a partir de fines del siglo pasado productos minerales y, con una incidencia menor, la goma conformaban el grueso absoluto de las exportaciones bolivianas. Año tras año estos productos sumaban en su conjunto más del $90 \%$ del valor total de las ventas realizadas al exterior. Entre 1900 y 1920 Bolivia importó primordialmente tejidos de lana y algodón, diverso tipo de indumentaria y productos alimenticios. De menor importancia fueron las importaciones de herramientas y de maquinaria. A fines de la primera década del siglo XX Bolivia importaba de Alemania sobre todo tejidos de lana, algodón y seda, azúcar, herramientas, máquinas para las minas y artículos luminosos; de Gran Bretaña tejidos de lana y algodón, en especial la bayeta, y de los Estados Unidos alimentos, conservas, máquinas, herramientas para la minería y material ferroviario. ${ }^{5}$ En 1920 los principales productos de importación, en orden de importancia, fueron: tejidos de lana y algodón, harina, carbón, azúcar, ganado en pie, máquinas, hierro, productos de acero así como armas y municiones. ${ }^{6}$

Cuadro IV. 3

Bolivia. Importaciones

(en dólares)

\begin{tabular}{lrc}
\hline Producto & 1902 & 1903 \\
\hline Tejidos & 3.852 .408 & 2.973 .134 \\
Alimentos & 1.778 .347 & 1.842 .269 \\
Vinos y licores & 614.947 & 736.567 \\
Ropa & 861.658 & 566.926 \\
Drogas y medicamentos & 265.088 & 349.874 \\
Artículos de papelería & 298.713 & 308.976 \\
Hilados y redes & 196.338 & 273.560 \\
Aceites & 228.707 & 273.233 \\
Máquinas & 257.530 & 270.644 \\
Maderas & 157.045 & 227.471 \\
Monedas de oro y plata & 2.380 .107 & 214.450 \\
Velas & 225.395 & 186.718 \\
Cerámica y vidrios & 184.505 & 177.130 \\
Calzados & 160.043 & 143.948 \\
Armas y municiones & 126.445 & 106.048 \\
\hline
\end{tabular}

Fuente: Cuadro elaborado en base a las cifras del Staatsanzeiger del 12 de diciembre de 1904, en: Admiralstab der Marine, op. cit. 
Debido a la expansión de su comercio exterior hasta fines de la década del 20 Bolivia firmó tratados comerciales con Francia (1887), Gran Bretaña (1911), Bélgica (1912), Japón (1914), así como con todos los países suramericanos a excepción del Paraguay. Los elementos básicos de estos tratados eran el principio de la reciprocidad absoluta, del resguardo de la propiedad y el de la claúsula de la nación más favorecida. ${ }^{7}$ El Imperio Alemán firmó con Bolivia un tratado de esta naturaleza en julio de 1908.

\section{La importancia de Alemania en el comercio exterior de Bolivia hasta 1917}

De 1890 a 1900 el valor total del intercambio comercial de Gran Bretaña, del Imperio Alemán, de los Estados Unidos y de Francia con Suramérica se elevó de algo menos de 2.3 a casi 2.7 mil millones de marcos alemanes. Entre ambos años se registraron notorios cambios con respecto a la importancia que aquellos países tuvieron en el comercio exterior del subcontinente.

En 1890 la mayor parte de las importaciones suramericanas provinieron de Gran Bretaña. En orden de importancia seguían Francia, los Estados Unidos y el Imperio Alemán. En 1900 Gran Bretaña y los Estados Unidos continuaban ocupando el primer y tercer lugar respectivamente, mientras que el Imperio Alemán había logrado desplazar a Francia al cuarto lugar. En 1890 los Estados Unidos eran el principal importador de Suramérica, seguidos por Francia, el Imperio Alemán y Gran Bretaña. Una década más tarde este orden había quedado totalmente alterado. Gran Bretaña pasó al primer lugar delegando a los Estados Unidos al último y el Imperio Alemán desplazó a Francia de la segunda a la tercera posición. En cuanto a la importancia de cada uno de estos países respecto al valor total del intercambio comercial, tenemos la siguiente situación: tanto en 1890 como en 1900 Gran Bretaña ocupó el primer y los Estados Unidos el tercer lugar, mientras que Francia tuvo que ceder al Imperio Alemán el segundo puesto.

Si se desagregan las relaciones comerciales de Alemania con Suramérica por países, se pueden establecer marcados contrastes. Así, por ejemplo, en 1900 el valor total del comercio germano-argentino ascendió a 296.3, el del germano-brasileño a 158.2 y el del germano-chileno a 128.4 millones de marcos. Con otros países los valores eran mucho más reducidos. Con Uruguay 27.3, con Perú 16.8, con Ecuador 16.2, con Venezuela 14.3 y con Bolivia 11.9 millones de marcos. 


\section{Cuadro IV. 4}

Intercambio comercial de países desarrollados con Suramérica (en millones de marcos)

\begin{tabular}{l|l|l}
\hline & 1890 & 1900 \\
\hline Gran Bretaña & & \\
Exportaciones & 517.3 & 433.9 \\
Importaciones & 268.3 & 534.7 \\
$\quad$ Total & 785.6 & 968.6 \\
Imperio Alemán & & \\
Exportaciones & 139.1 & 188.3 \\
Importaciones & 300.1 & 489.6 \\
Total & 439.2 & 677.9 \\
Estados Unidos & & \\
Exportaciones & 147.8 & 152.4 \\
Importaciones & 355.3 & 371.7 \\
Total & 503.1 & 524.1 \\
Francia & & \\
Exportaciones & 236.6 & 104.3 \\
Importaciones & 334.0 & 396.9 \\
Total & 570.6 & 501.2 \\
\hline
\end{tabular}

Fuente: Cuadro elaborado en base a cifras de Wihelm Sievers, Südamerika und die deutschen Interessen. Eine geographisch-politische Betrachtung, Stuttgart 1903, pp. 51-52.

En términos comparativos suramericanos el intercambio comercial germano-boliviano era obviamente reducido. Su valor tan sólo sobrepasaba al del comercio germano-colombiano (8.5 millones de marcos) y era casi tres veces inferior al del comercio germano-argentino. ${ }^{8}$

Para el conjunto de las relaciones comerciales del Imperio Alemán el intercambio de productos con Bolivia era de muy poca importancia. En cambio, para este país el comercio con Alemania era altamente significativo. Entre fines del siglo XIX y el inicio de la Primera Guerra Mundial, Alemania fue casi cada año después de Gran Bretaña el consumidor más importante de productos bolivianos. Fue, además, casi ininterrumpidamente el proveedor más importante de mercaderías del país andino. Es decir, si se establece una comparación entre el grado de importancia del comercio alemán a nivel suramericano en 1900 con la situación del comercio germano-bolivia- 


\section{Cuadro IV. 5}

Desarrollo del comercio germano-boliviano 1895-1913

(en bolivianos*)

\begin{tabular}{lc|c|c}
\hline Año & $\begin{array}{c}\text { Export Bolivia } \\
\text { a Alemania }\end{array}$ & $\begin{array}{c}\text { Export Alemania } \\
\text { a Bolivia }\end{array}$ & Valor total \\
\hline 1895 & 867.000 & 1.400 .000 & 2.267 .000 \\
1896 & 733.000 & 1.400 .000 & 2.133 .000 \\
1897 & 1.933 .300 & 1.133 .300 & 3.066 .600 \\
1898 & 2.600 .000 & 1.333 .300 & 3.933 .300 \\
1900 & & 3.109 .518 & \\
1901 & & 3.243 .090 & \\
1902 & & 2.516 .315 & \\
1903 & 2.553 .997 & 2.982 .099 & 5.536 .096 \\
1904 & 5.666 .600 & 2.666 .600 & 13.400 .000 \\
1905 & 10.200 .000 & 3.200 .000 & 19.199 .900 \\
1906 & 15.533 .300 & 3.666 .600 & 20.199 .900 \\
1907 & 14.333 .300 & 5.866 .600 & 14.733 .200 \\
1908 & 10.466 .600 & 4.266 .600 & 22.695 .705 \\
1910 & 18.166 .871 & 4.528 .834 & 28.277 .300 \\
1911 & 22.443 .558 & 5.833 .742 & 31.072 .392 \\
1912 & 23.525 .153 & 7.547 .239 & 32.334 .968 \\
1913 & 24.985 .889 & 7.349 .079 & \\
\hline
\end{tabular}

* Algunas de las fuentes consultadas registran el valor en marcos alemanes. La conversión a bolivianos se ha hecho en base a las cotizaciones siguientes: para los años de 1895 a 19081 boliviano $=1.50$ marcos; para los años 1910 a 19171 boliviano $=$ 1.63 marcos.

Fuente: Años 1895 a 1898 Bericht No. 168/J No. 855, Petropolis 26. 6.1900, en: Die inneren Zustände und Verbältnisse Boliviens, 1.1.1899-31. 7.1900, Abth. A., Bolivien Nr. 1, Vol. 3, Politisches Archiv des Auswärtigen Amts, Bonn. Año 1900 Bericht No. 94, Lima 1. 11. 1901, en: op. cit., Vol. 4. Años 1901 y 1902 Staatsanzeiger del 23. 12. 1903, en: Admiralstab der Marine, op. cit. Año 1903, Export del 22. 6.1905, en: op. cit. Año 1904 y 1905 Export del 16. 8. 1906, en: op. cit. Años 1906 a 1908 Denkschrift zum Deutsch-Bolivianischen Handelsvertrag, p. 9, en: Verträge des Deutschen Reichs mit Bolivien, 1909-1927, Akten des Königl. Staatsministeriums, R VI. 69, Hauptstaatsarchiv Stuttgart. Años 1910 a 1913 Denkschrift zum Entwurf eines Gesetzes über die Wiederinkraftsetzung des Freundschafts- und Handelsvertrages zwischen Deutschland und Bolivien vom 22. 7. 1908, en: op. cit. 
no entre aproximadamente 1895 y 1913, obtenemos las siguientes relaciones: Alemania como importadora de productos bolivianos ocupó un lugar correspondiente a su promedio suramericano; en cambio, como exportadora a Bolivia ocupó un sitio por encima del de su promedio regional. Esta situación no se alteró radicalmente hasta 1917 cuando se rompieron las relaciones diplomáticas entre ambos países y cuando, a su vez, la penetración de los Estados Unidos en la esfera mercantil boliviana empezó a arreciar substancialmente.

Entre 1895 y 1913 las exportaciones del Imperio Alemán a Bolivia llegaron a quintuplicarse pasando de 1.4 a 7.3 millones de bolivianos. Un crecimiento mucho más imponente registraron las exportaciones de este a aquel país. Ellas se elevaron de 867.000 bolivianos en 1895 a casi 25 millones de bolivianos en 1913. Al multiplicarse por algo más de 28 veces, las exportaciones a Alemania quedaron muy por encima de la tasa de incremento del total de las ventas que Bolivia realizó al exterior entre 1900 y 1920 . El intercambio comercial germano-boliviano arrojó superávits para Alemania en 1895, 1896 y 1903. Para Bolivia fue altamente favorable durante toda la década transcurrida entre 1904 y 1913. La estructura del intercambio comercial correspondió plenamente a la estructura general que caracterizó al comercio de Bolivia con otros países industrializados. Como se ha señalado en el correr de este trabajo, Bolivia abasteció al Imperio Alemán con materias primas e importó de ella productos manufacturados. Los Cuadros IV. 6 y IV. 6a, en los cuales se detallan para diversos años los productos comprendidos en el intercambio entre ambos países, corroboran esta afirmación. Estadísticas correspondientes a los años 1904 y 1908 muestran que al igual que en 1900 (véase Cuadro IV. 6a) las principales exportaciones del Imperio Alemán a Bolivia fueron productos textiles. ${ }^{9}$ En 1912 el $93.9 \%$ de las ventas realizadas por este país a la nación europea se componían de materias primas, mientras que el $77.3 \%$ de las exportaciones de Alemania a Bolivia fueron productos manufacturados. ${ }^{10}$

El enorme peso que tenían las importaciones bolivianas de artículos de algodón y de lana fueron consecuencia de la bajísima producción nacional de textiles debido a la falta de métodos adecuados para un aprovechamiento mejor de la lana ovina y de los auquénidos en la zona del altiplano así como al escaso cultivo del algodón. ${ }^{11}$ Si bien el Imperio Alemán proveyó a Bolivia con maquinaria para modernizar la explotación minera y con material destinado a fomentar obras de infraestructura, las estadísticas comerciales ponen de manifiesto que la incidencia de estos productos en el valor total de las exportaciones era de mucho menor importancia que la de artículos de la rama textil. 
CuadroIV. 6

Exportaciones de Bolivia a Alemania

(en bolivianos*)

\begin{tabular}{l|rr}
\hline Producto & 1904 & \multicolumn{1}{c}{1908} \\
\hline Minerales de estaño & 3.172 .666 & 7.933 .333 \\
Caucho y gutapercha & 1.552 .666 & 1.133 .333 \\
Minerales de plata & 471.333 & 266.666 \\
Bismuto y otros metales preciosos & 306.000 & \\
Bismuto & & 600.000 \\
Minerales de plomo & & 266.666 \\
Minerales de cobre & & 133.333 \\
Totales & 5.502 .665 & 10.333 .331 \\
\hline
\end{tabular}

* Las fuentes consultadas registran el valor en marcos alemanes. La conversión en bolivianos se ha hecho en base a la cotización de 1 boliviano $=1.50$ marcos .

Fuente: Año 1904 Export del 16. 8. 1906, en: Admiralstab der Marine, op. cit. Año 1908 Denkschrift zum Deutsch-Bolivianischen Handelsvertrag, p. 9, en: Verträge des Deutschen Reichs mit Bolivien, 1909-1927, op. cit.

Cuadro IV. $6 a$

Exportaciones de Alemania a Bolivia en 1900

(en bolivianos)

Diversos

Artículos de algodón

$767.224^{24}$

Artículos de lana

$477.695^{12}$

Alimentos

$430.187^{44}$

Artículos de ferretería quincalla

$399.367^{17}$

Vestidos

$344.215^{88}$

Artículos de seda

$313.318^{17}$

Bebidas y alcohol

$139.815^{10}$

Drogas

$134.254^{19}$

Muebles

$59.021^{59}$

Artículos de lino

$31.844^{88}$

No definidos

$11.795^{73}$

$778^{62}$

Total

$3.109 .518^{13}$

Fuente: Bericht No. 94, Lima 1. 11. 1901, en: Die inneren Zustände und Verbältnisse Boliviens, 1. 8.1900-21. 6.1902, Abth. A., Bolivien Nr. 1, Vol. 4, Politisches Archiv des Auswärtigen Amts, Bonn. 
A base de las cifras de los Cuadros IV. 2 y IV. 5 se ha calculado para diversos años la participación porcentual de Alemania en el comercio exterior de Bolivia.

\section{Cuadro IV. 7}

Participación del Imperio Alemán en el comercio exterior de Bolivia

(en por cientos del total)

\begin{tabular}{l|c|c|c}
\hline Año & $\begin{array}{c}\text { En el total de las } \\
\text { exportaciones }\end{array}$ & $\begin{array}{c}\text { En el total de las } \\
\text { importaciones }\end{array}$ & En el valor total \\
\hline 1895 & 4.1 & 35.9 & 9.1 \\
1904 & 18 & 15.7 & 17.2 \\
1905 & 24.4 & 15.7 & 21.5 \\
1908 & 22.2 & 10.4 & 16.7 \\
1910 & 24 & 7.7 & 16.9 \\
1913 & 26.6 & 13.5 & 21.8 \\
\hline
\end{tabular}

Fuente: Elaborado por L.B. a base de las cifras de los cuadros IV. 2 y IV. 5.

Esta participación pasó del $9.1 \%$ en 1895 al 21.8\% en 1913, vale decir que entre ambos años llegó más que a duplicarse. La participación en el total de las exportaciones también muestra un crecimiento significativo a partir de 1895. Su promedio para los años computados entre 1904 y 1913 fue del $23 \%$. En cambio, el aporte de Alemania a las importaciones realizadas por Bolivia sufrió un brusco descenso entre 1895 y 1904 al contraerse de casi 36\% a algo más del $16 \%$. El promedio respectivo para los años registrados entre 1904 y 1913 fue del 12.6\%. Estas cifras muestran que el Imperio Alemán tuvo una incidencia mucho mayor en el campo de las exportaciones que en el campo de las importaciones bolivianas. A pesar de esta relación Alemania sólo llegó a ser, después de Gran Bretaña, el segundo país importador más importante de productos bolivianos. En cambio, hasta la Primera Guerra Mundial figuró durante muchos años, a veces por un margen muy estrecho frente a Gran Bretaña, como primer exportador de mercaderías a Bolivia. 


\section{Cuadro IV. 8}

Participación del Imperio Alemán y de

Gran Bretaña en el comercio exterior de Bolivia

(en bolivianos)

\begin{tabular}{|c|c|c|c|c|}
\hline \multicolumn{5}{|c|}{ Participación en las exportaciones } \\
\hline & 1898 & 1902 & 1903 & $1905^{*}$ \\
\hline \multicolumn{5}{|l|}{$\begin{array}{l}\text { Total de } \\
\text { exportaciones }\end{array}$} \\
\hline bolivianas & 27.456 .677 & 28.041 .578 & 25.169 .148 & 41.795 .937 \\
\hline Gran Bretaña & 12.250 .000 & 13.100 .000 & 6.314 .783 & 2.859 .733 \\
\hline \multirow[t]{3}{*}{ Alemán } & 9.500 .000 & 8.800 .000 & 2.553 .997 & 1.166 .200 \\
\hline & \multicolumn{3}{|c|}{ Participación en las importaciones } & \\
\hline & 1900 & 1902 & 1903 & $1908 *$ \\
\hline \multicolumn{5}{|l|}{$\begin{array}{l}\text { Total de } \\
\text { importaciones }\end{array}$} \\
\hline bolivianas & 13.344 .114 & 14.143 .342 & 16.252 .885 & 40.732 .543 \\
\hline \multicolumn{5}{|l|}{ Imperio } \\
\hline Alemán & 3.109 .521 & 2.516 .315 & 2.982 .099 & 9.866 .766 \\
\hline Gran Bretaña & 2.265 .306 & 2.409 .228 & 2.749 .871 & 6.368 .400 \\
\hline
\end{tabular}

* La fuente consultada registra los valores en marcos alemanes. La conversión a bolivianos se ha hecho en base a la cotización de 1 boliviano $=1.50$ marcos.

Fuente: Año 1898 Bericht No. 94, Lima 1.11. 1901, en: Die inneren Zustände und Verbältnisse Boliviens, 1.8.1900-21.6.1902, op, cit. Año 1900, op. cit. Año 1902 Staatsanzeiger del 23. 12. 1903, en: Admiralstab der Marine, op. cit. Año 1903 Der Handel Boliviens, en: Die Weltwirtschaft, 1.Jg., H. 3/4, Wien/Leipzig 1905, pp. 12-13. Año 1905 y 1908 Julius Uzarski, Bolivien. Natur und wirtschaftliche Verhältnisse, p. 75, 77.

La situación básica reflejada en el Cuadro IV. 8 no llegó a alterarse hasta los años inmediatamente anteriores a la primera gran conflagración mundial. En 1912 la participación de Gran Bretaña en el total de las exportaciones bolivianas alcanzó el $74.29 \%$ y en 1913 el $80.8 \%$. Los respectivos porcentajes para el Imperio Alemán fueron del $12.42 \%$ y del $8.5 \%$. En 1912 Bolivia importó de Alemania por un valor de 16.513 .630 bolivianos y en 1913 por un valor de 20.091.363 bolivianos. Los montos correspondientes a Gran Bretaña para esos años llegaron tan sólo a 9.069.516 y a 11.101.269 bolivianos. ${ }^{12}$ 
El establecimiento de relaciones diplomáticas entre Berlín y La Paz en 1902 fue una consecuencia directa de la importancia que tuvo el Imperio Alemán desde fines del siglo XIX en el comercio exterior de Bolivia; particularmente en el campo de las importaciones que realizaba este país.

En 1901 los únicos países de importancia internacional que tenían una representación diplomática en Bolivia eran Francia, Bélgica y los Estados Unidos. En aquel entonces la embajada norteamericana era la encargada de salvaguardar los intereses británicos en Bolivia. ${ }^{13}$

En 1870 el Imperio Alemán designó su primer cónsul para Bolivia, quien desempeñó su cargo hasta 1881. En las dos décadas siguientes el embajador alemán en el Perú fue el encargado de resguardar los intereses de su país en Bolivia. ${ }^{14}$

Entre 1899 y 1901 tanto Alemania como Bolivia insistieron reiteradas veces en la necesidad de establecer relaciones diplomáticas a nivel de embajadas. Para ambas partes este paso constituía un corolario inminente al grado de importancia que había alcanzado el intercambio comercial entre ambos países. Al respecto cabe destacar que en el caso del Imperio Alemán no fue el gobierno quien inicialmente tomó la iniciativa en este sentido, sino grupos interesados en fomentar la expansión comercial en ultramar. El siguiente pasaje de un artículo publicado en 1899 en el periódico Export destaca palmariamente este hecho: "Con su inmensa extensión territorial Bolivia pertenece indudablemente a los países que ofrecen tierras de reserva para numerosas inmigraciones futuras. Como los intereses comerciales de Bolivia están por lo general en manos alemanas, este país es ya por esta razón de gran importancia para nosotros. Desafortunadamente nuestros representantes en la costa occidental o no se han dado cuenta de las ventajas que ofrecería una representación diplomática propia en Bolivia, cuyo establecimiento hemos propuesto reiteradas veces; $i$ o acaso ven estos señores diplomáticos una merma de su esfera de influencia en el establecimiento de tal puesto? ... Creemos ... que precisamente la confusa situación política de este gran país debería incitarnos a dar un puesto, como lo hicieron América del Norte y Francia ya hace tiempo, a un diplomático eficaz y con buenos conocimientos político-comerciales en aquel lugar donde probablemente en un futuro no lejano se encenderá nuevamente el conflicto entre las contradicciones suramericanas, vale decir en Bolivia." 15

A diferencia de la actitud reservada que mantuvo el gobierno alemán hasta finales de 1901, el gobierno de Bolivia ya en 1900 expresó su claro deseo de establecer relaciones diplomáticas. En aquel año el embajador boliviano en el Brasil, Salinas Vega, hizo una oferta al respecto al conde de Arco Valley, representante diplomático del Imperio Alemán en este país. Salinas Vega 
envió a de Arco Valley una nómina de casas comerciales establecidas en Bolivia por súbditos alemanes y recalcó "que Alemania tiene en Bolivia considerables y crecientes intereses comerciales. ${ }^{16}$ La reacción alemana fue cautelosa. El embajador alemán en Petrópolis se limitó a averiguar el estado de las relaciones diplomáticas bolivianas y a informar sobre el particular a la Cancillería en Berlín. ${ }^{17}$

La reticente actitud del gobierno alemán sólo cambió entre fines de 1901 e inicios del año 1902. En ello influyó de manera decisiva el informe que envió el $1^{\circ}$ de noviembre de 1901 el embajador del Imperio Alemán en el Perú, Doctor Gustav Michahelles, al canciller de su país. En él Michahelles comienza por señalar "que tanto viajeros provenientes de Bolivia como colegas míos acreditados frente al gobierno de La Paz me han llamado reiteradas veces la atención sobre la eminente posición que tiene el comercio alemán en Bolivia." ${ }^{18}$ Seguidamente expone los datos que a pedido suyo le facilitó el embajador boliviano en Lima, Braun, sobre el desarrollo del comercio exterior de Bolivia en los años 1898 y 1900 y, en particular, sobre el intercambio comercial germano-boliviano en esos dos años. El informe realza que a diferencia de la situación en el Perú, donde el comercio mayorista está controlado por firmas británicas y norteamericanas y el comercio al menudeo por inmigrantes italianos, las casas comerciales más grandes en todos los centros importantes de Bolivia están controladas por alemanes. Partiendo de estas y algunas otras consideraciones, así como de una apreciación positiva respecto a las perspectivas comerciales que ofrecía el país, Michahelles sugirió al canciller von Bülow "establecer relaciones diplomáticas regulares con Bolivia." ${ }^{\prime 19}$ De acuerdo con el diplomático alemán, era necesaria una decisión de esta naturaleza, tanto para dar un mayor respaldo a los súbditos alemanes en aquel país como para contrabalancear con mayor efectividad los enérgicos esfuerzos de los Estados Unidos por conquistar con sus productos industriales los mercados suramericanos. El informe cierra con la observación de que el presidente de Bolivia, el general Pando, conforme a una información del embajador Braun, vería con agrado "si ante él se acreditara un representante diplomático del Imperio." ${ }^{20}$ A fines de febrero de 1902 la cancilleria del Imperio Alemán respondió a Michahelles que en vista "de la eminente posición que ha logrado adquirir el comercio alemán en Bolivia" y en "condescendiente consideración del deseo expresado en círculos comerciales alemanes", el emperador alemán ha decidido establecer relaciones diplomáticas con Bolivia. ${ }^{21}$ Haciéndose eco de la sugerencia de Michahelles, el gobierno alemán optó por encargar a su embajada en Lima la representación diplomática en Bolivia. Michahelles presentó sus credenciales al presidente Pando el 15 de mayo de 1902 con lo 
cual quedaron establecidas las relaciones diplomáticas entre ambos países. El 25 de julio de 1902 la Münchner Allgemeine Zeitung comentó el acontecimiento en los siguientes términos: "Considerando las aspiraciones de los norteamericanos de monopolizar toda América casi exclusivamente para sí, es conveniente para las potencias europeas demostrar oportunamente que existen todavía en este mundo. Por esta razón celebramos que el Imperio Alemán haya enviado por primera vez un representante diplomático a Bolivia." ${ }^{22}$

La reservada actitud del gobierno alemán frente a las demandas de establecer lazos diplomáticos con Bolivia y el hecho de que sólo en 1904 Berlín designó un Ministro Residente con sede en La Paz son claros indicios de que para la política del Imperio Alemán tardíamente Bolivia llegó a tener la importancia que desde fines del siglo XIX le otorgaron círculos alemanes interesados en la expansión comercial. Debido probablemente a razones de índole financiera, Bolivia no designó hasta en 1910 un embajador con sede en Berlín.

A pesar de su importancia, las relaciones comerciales entre Alemania y Bolivia hasta 1908 no estaban reguladas por ningún convenio. La iniciativa que tomó Bolivia en 1888 a través de su embajador en Santiago de Chile para firmar un tratado comercial fue ignorada por el gobierno de Berlín. ${ }^{23}$ Años más tarde el periódico Export criticó severamente esta actitud: "Un tratado de esta naturaleza nos hubiese favorecido especialmente a nosotros, porque qué son los intereses bolivianos en Alemania en comparación con nuestros intereses comerciales e industriales en Bolivia." ${ }^{24}$

El 22 de julio de 1908 el Imperio Alemán y Bolivia firmaron en La Paz un Tratado de Amistad y Comercio. La claúsula fundamental de este tratado era la de la nación más favorecida, a la cual hacia referencia el tercer artícu$10 .{ }^{25}$ En realidad, este tratado sancionó una situación que de hecho existía desde hacía por lo menos una década. El convenio fue ratificado por ambas partes en 1909. De acuerdo con lo estipulado en el último artículo, debía quedar en vigencia durante 10 años a partir de su ratificación. La ruptura de relaciones diplomáticas por parte de Bolivia en 1917 conllevó su abrogación dos años antes de lo convenido.

\section{Factores determinantes de la influencia del Imperio Alemán}

La importancia que con anterioridad a la Primera Guerra Mundial llegó a tener el Imperio Alemán en el comercio suramericano fue producto de su 
impetuoso ascenso económico. Sin embargo, este factor por sí sólo no basta para explicar a cabalidad el ascendiente que logró obtener este país en el comercio internacional de Bolivia. Este fue condicionado decisivamente por la posición prácticamente hegemónica que llegaron a ocupar inmigrantes alemanes en el comercio boliviano.

Diversas referencias de fines del siglo XIX y comienzos del siglo XX atestiguan la poderosa presencia de súbditos alemanes en la esfera mercantil de Bolivia. En 1899 el periódico Export afirmó que "la mayor parte de los intereses comerciales de Bolivia se encuentran en manos de alemanes. ${ }^{26}$ En 1902 un periódico de La Paz expresó su beneplácito por la decisión del gobierno alemán de establecer relaciones diplomáticas con Bolivia, aduciendo que los intereses del Imperio Alemán en este país "son muy significativos y no existe casi ningún lugar de importancia en el cual no seencuentre establecida una casa comercial alemana." ${ }^{27}$ En 1905 un artículo de la prensa alemana constató que "de las casas comerciales establecidas en Bolivia las alemanas son las más numerosas; luego vienen las inglesas, francesas e italianas, las peruanas, españolas y norteamericanas." ${ }^{28}$

Los inmigrantes alemanes que llegaron a ocupar un lugar tan descollante en el comercio de Bolivia empezaron a afluir al país en el correr del último cuarto del siglo XIX. Desde la costa sur del Perú ellos tomaron el camino hacia el altiplano boliviano por la vía de Guaqui y en el correr de las tres décadas siguientes se esparcieron hacia aquellos centros en los cuales el desarrollo de la minería y de la goma promovió una intensa actividad económica. En esos centros establecieron casas de exportación eimportación, muchas de las cuales estaban íntimamente vinculadas con Hamburgo o eran, de hecho, filiales de empresas comercializadoras establecidas en esta ciudad. La fundación y el dinámico desarrollo de estas casas de compra y venta dió un impulso decisivo al intercambio comercial germano-boliviano y permitió al Imperio Alemán convertirse tempranamente en el socio exportador más importante para Bolivia.

En el capítulo referente a la extracción de materias primas se han mencionado los nombres de las casas comerciales alemanas más importantes que se establecieron en la zona oriental de Bolivia. A su vez, se ha hecho referencia a otras que abrieron sus puertas en la región andina del país. Aparte de estas se instalaron en La Paz M. Brieger \& Co., Colsmann \& Co, Luis Ernest, Federico E. Eulert, Fed. Gerder \& Co., Luis Kock \& Co., Maier \& Hagemann y Gustavo Stumpf; en Oruro J. M. Becker, Th. Bickenback \& Co., Böhme, Borgilte, Findel, Julio Martens, Reinecke, A. Wisher \& Co., Zieriacks y Zizold; en Cochabamba A. W. Barber \& Co., Guillermo Hell- 
mann y R. Krüger \& Co. y en Potosí Nicolás Jürgen Schütt. Una parte apreciable, tanto de éstas como de las casas fundadas en el oriente, contaban con sucursales en diversas ciudades del país. ${ }^{29}$

Tres factores permiten explicar la exitosa incursión de elemento de origen alemán en la esfera comercial boliviana. En primer lugar el rápido proceso de integración de Bolivia al mercado mundial a partir de 1880 aproximadamente no fue acompañado por el surgimiento de un estrato social nacional lo suficientemente preparado como para responder eficientemente a las exigencias cada vez más complejas del comercio internacional. El atraso general del país no permitió la constitución endógena de una capa de comerciantes capaces de enfrentar y de competir con un elemento foráneo que llegaba al país con una preparación lo suficientemente amplia como para adecuarse a las necesidades de un intercambio comercial en constante crecimiento. A ello se agrega que las empresas del Imperio Alemán, interesadas en promover las relaciones comerciales con Bolivia, veían en los súbditos alemanes emigrados a este país, tanto por razones idiomáticas como por motivos de afinidad general, a los intermediarios idóneos para sus negocios.

Pero no fue solamente la falta de una vigorosa capa de comerciantes nacionales la que permitió a los inmigrantes alemanes ocupar una posición preeminente en el mundo de los negocios. Ellos tampoco se vieron enfrentados - como sucedió en casi todo el resto de Suramérica - a otros grupos foráneos capaces de bloquear efectivamente su incursión en la esfera mercantil. Según Pfannenschmidt, en 1906 la población extranjera residenteen Bolivia sumaba escasamente 2.528 personas. De estas 759 eran italianos, 510 españoles, 385 alemanes, 379 franceses, 270 austríacos y 225 ingleses. ${ }^{30}$ Si bien no existen estudios sobre el rol de estos inmigrantes en la vida nacional, es evidente que ninguna de las colectividades mencionadas contó con un respaldo tan efectivo de parte de su país de origen para penetrar y afianzarse en el campo de los negocios como el respaldo que recibió la colectividad alemana. En comparación con el Imperio Alemán, ni Italia, ni España, como tampoco el Imperio Austro-Húngaro habían alcanzado un grado de desarrollo económico que hiciera perentorio el fomento consecuente de una política comercial expansionista. Esta circunstancia restó a los inmigrantes italianos, españoles y austríacos la posibilidad de convertirse en poderosos intermediarios mercantiles con su país de proveniencia. Dado a que desde là última década del siglo XIX el desarrollo de la economía alemana fue mucho más acelerado que el de la economía francesa, las posibilidades de desempeño de los inmigrantes franceses en el comercio de 
Bolivia fueron más restringi.ias que las que tuvieron inmigrados de Alemania, aunque probablemente sífueron más amplias que las de otras colectividades extranjeras.

Lo que extraña en el caso de Bolivia es la escasa presencia de súbditos británicos tanto cuantitativamente como en el campo comercial. La gran mayoría de los ingleses que llegaron al país durante y en la fase inmediatamente posterior a las guerras de la independencia, lo abandonaron nuevamente en el correr de las tres décadas siguientes. La falta de oportunidades económicas y un percance político que llevó a la ruptura de relaciones diplomáticas por parte de Gran Bretaña motivaron este repliege. Según un informe de la penúltima década del siglo XIX, en aquel entonces no residía un sólo súbdito británico en Bolivia. ${ }^{31}$ Un artículo de 1899 denota que "en Bolivia casi no se encuentran casas comerciales inglesas. ${ }^{32}$ Es muy probable que la existencia de antiguas casas de exportación eimportación británicas en ciudades portuarias chilenas y peruanas que tradicionalmente realizaban las transacciones comerciales con Bolivia, así como el reducido mercado que ofrecía este país repercutiera en un desinterés inglés por establecer negocios en él. En todo caso, un elevado porcentaje de los ciudadanos británicos que residían en Bolivia a comienzos del presente siglo era personal técnico y administrativo vinculado a la minería y a los ferrocarriles. Se puede dar por sentado que el elemento inglés no llegó a cuestionar en ningún momento las firmes posiciones que inmigrantes alemanes habían logrado alcanzar en el comercio boliviano a partir de 1880 .

El tercer factor que permite explicar la penetración alemana en la esfera comercial se remite a la falta de alternativas ocupacionales que ofrecía Bolivia. A partir de 1880 la minería se encontraba en un rápido proceso de modernización que requería vastas inversiones. Como se ha visto en el presente trabajo, fue justamente este proceso el que determinó la absorción de propiedades mineras pertenecientes a empresarios de ascendencia alemana por parte de capitales británicos y norteamericanos. Para inmigrantes con limitados recursos financieros y falta de suficientes conocimientos técni$\cos$, la expandiente minería boliviana constituía una empresa sumamente arriesgada e incluso prohibitiva. Por eso su participación en este campo se restringió al negocio del rescate y al del financiamiento de pequeños y medianos propietarios mineros. Algunos inmigrantes alemanes emplearon su capital y se sirvierion de sus conocimientos técnicos para instalar las primeras cervecerías bolivianas. ${ }^{33}$ Sin embargo, el restringido mercado interno de Bolivia no brindó hasta entrada la década del 20 mayores posibilidades para una expansión industrial relativamente importante; ni siquiera en materia de elaboración de productos alimenticios. A diferencia de países 
como, por ejemplo, Brasil o Chile donde muchos alemanes se asentaron en el campo, Bolivia tampoco ofreció suficientes alicientes para la colonización agrícola. La Ley y Reglamento referentes a la adjudicación de tierras baldías del Estado de 1905 y el Reglamento de Inmigración Libre de 1907 aseguraban a extranjeros dispuestos a trabajar en la agricultura amplias concesiones de tierras, pero tanto aquélla como éste no comprendían medidas destinadas a dar apoyo financiero a los colonos o medidas orientadas a mejorar la infraestructura de la región prevista para el asentamiento. Estas razones, así como las ventajas sobre todo de carácter geográfico y climático que ofrecían otros países suramericanos, hicieron fracasar en Bolivia hasta después de 1950 todo intento de promover una colonización rural foránea. $^{34}$

A consecuencia de los factores señalados, la abrumadora mayoría de los inmigrantes alemanes que llegaron a Bolivia en las últimas décadas del siglo XIX establecieron casas comerciales. La configuración de una colonia alemana de carácter básicamente comercial que no tuvo que enfrentarse con serios rivales y que mantenía estrechos vínculos económicos con su país de origen fue un elemento decisivo para el auge del comercio germano-boliviano.

En el correr de las dos últimas décadas del siglo XIX las colectividades alemanas establecidas en los principales centros urbanos de Bolivia fundaron organizaciones de ayuda mutua y Asociaciones Alemanas (Deutsche Vereine). Estas asociaciones, que tenían por finalidad cultivar la propia idiosincracia, se conviertieron rápidamente en los centros de la vida social y cultural alemana. Durante la Primera Guerra Mundial, casas comerciales alemanas de La Paz y Oruro, entre ellas sobre todo las de Trepp y Callerius, promovieron un proyecto para crear establecimientos escolares alemanes y manifestaron su disposición a financiarlo. Este proyecto sólo llegó a materializarse en 1923 con el amplio respaldo de las colectividades alemanas de La Paz, Oruro y Cochabamba. ${ }^{35}$ A comienzos del presente siglo inmigrantes alemanes figuraban como delegados en diversos municipios del país. ${ }^{36}$ A pesar de haber echado raíces en Bolivia, la colectividad alemana, tanto por razones de índole étnica y cultural como, sobre todo, a consecuencia de sus vínculos económicos con el Imperio Alemán, mantuvo una profunda y manifiesta lealtad a su país de procedencia. Esta no solamente se manifestó en la fundación de centros sociales para conservar y propagar normas de vida y valores propios, sino también en el activo apoyo prestado a Alemania durante la primera gran conflagración mundial. A partir de 1914 todas las colectividades alemanas desparramadas en el territorio boliviano reco- 


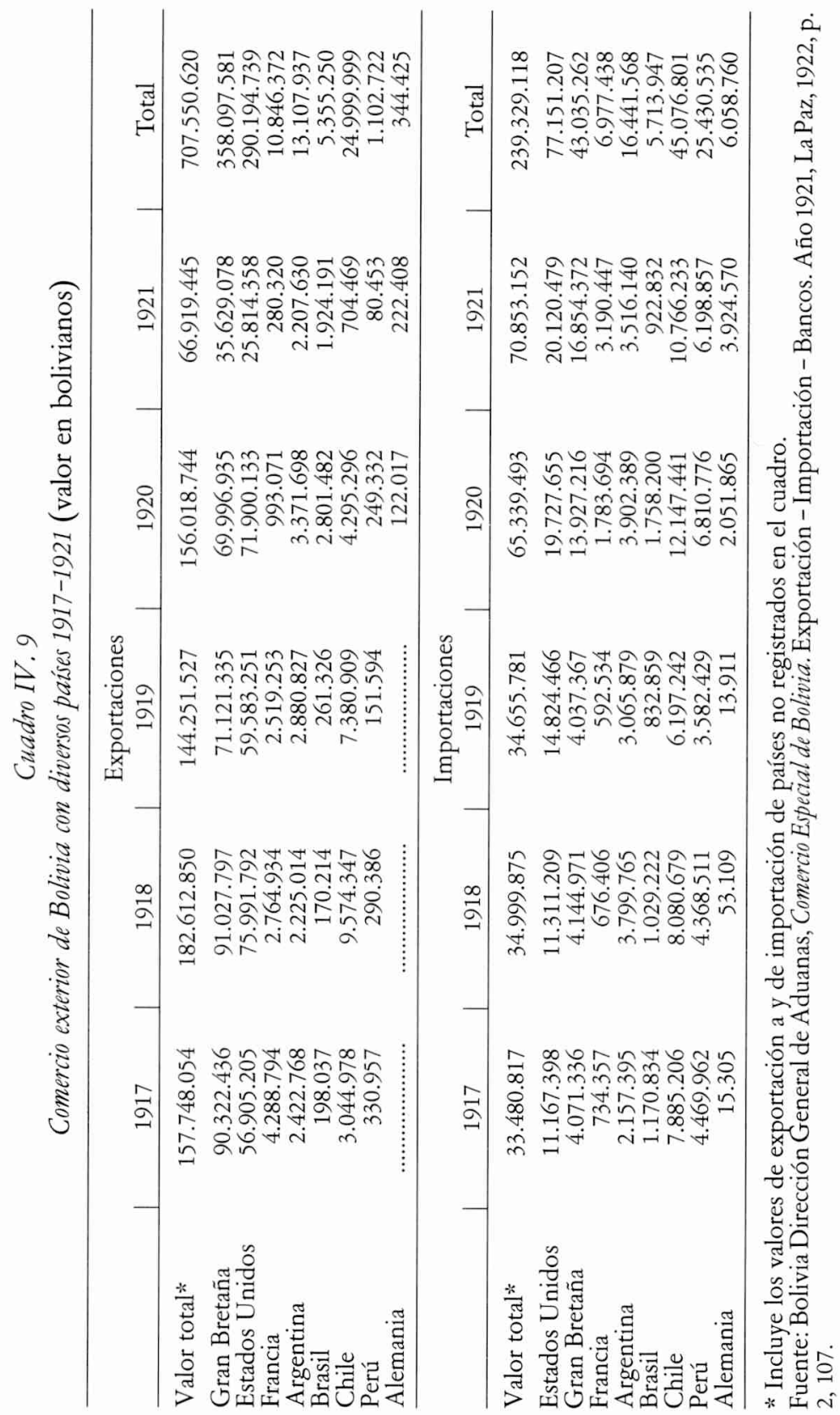


lectaron fondos destinados a amparar los fines bélicos de su país de procedencia. Las casas comerciales jugaron un rol de primera importancia tanto en la contribución, recaudación como en el envío a Berlín de los medios financieros. ${ }^{37}$ Con la finalidad de exponer y difundir las posiciones del Imperio Alemán, inmigrantes de este país publicaron en Bolivia durante la Primera Guerra Mundial el periódico Vanguardia y la revista Deutsche Blätter für Bolivien.

\section{La decadencia de la influencia de Alemania en el comercio boliviano después de 1917}

En un artículo publicado el 18 de abril de 1917, el Ministro Residente de los Estados Unidos en La Paz destacó que su país se había convertido en "the chief supplier of Bolivia's imports; until 1914 it was the fourth in importance. This great advance on the part of the United States is due to the activities displayed by American manufacturers since the breaking out of the European war, and to the necessity of effecting purchases from other than the countries at war. ${ }^{38}$ En efecto, a consecuencia de la Primera Guerra Mundial los Estados Unidos pasaron a ser el proveedor más importante de productos para Bolivia. A su vez, se convirtieron en el segundo país de importancia para las exportaciones bolivianas. El valor total de las importaciones que realizó Bolivia de 1917 a 1921 ascendió a 239.329.118 bolivianos. A este valor los Estados Unidos aportaron 77.151.207, Gran Bretaña 43.035.262 y Francia 6.977.438 bolivianos. En el mismo quinquenio Bolivia exportó por un valor de 707.550 .620 bolivianos, de los cuales 358.097.581 corresponden a Gran Bretaña, 290.194.739 a los Estados Unidos y 10.846.372 a Francia. Durante el lustro referido Alemania exportó a Bolivia mercaderías por un valor de 6.058 .760 e importó productos de este país por un valor de 344.425 bolivianos. La importancia de Alemania en el total del comercio internacional boliviano no fue solamente insignificante en comparación con la de otros países occidentales altamente industrializados, sino que también quedó muy por debajo de la que correspondió a países limítrofes como Chile, Perú y la Argentina. A pesar de la recuperación de las exportaciones alemanas en 1920 y 1921, su valor fue muy reducido en comparación con las ventas realizadas en aquellos años por los Estados Unidos, Gran Bretaña y Chile.

El desmoronamiento del intercambio comercial germano-boliviano fue producto de la conflagración mundial que estalló en 1914. El resquebraja- 
miento que se produjo a partir del primer año de guerra en los tradicionales circuitos mercantiles entre los países de la Europa Central y Suramérica llevó a una suspensión completa de las relaciones comerciales entre Alemania y Bolivia en las postrimerías de aquel conflicto. ${ }^{39}$ Cuandro en abril de 1917 el gobierno boliviano rompió las relaciones diplomáticas con Berlín, el otrora tan significativo intercambio comercial entre los dos países se encontraba ya prácticamente anulado. ${ }^{40}$

La derrota alemana en la Primera Guerra Mundial y el ascenso de los Estados Unidos a potencia hegemónica mundial fueron las causas fundamentales que no permitieron a la República de Weimar recuperar la posición que el Imperio Alemán había logrado adquirir entre 1895 y 1913 en el comercio exterior boliviano. Una estadística del año 1926 demuestra este hecho. Entre enero y noviembre de aquel año Bolivia importó de los Estados Unidos por valor de 18.834 .938 bolivianos y de Gran Bretaña por valor de 13.828.413 bolivianos, mientras que las importaciones provenientes de Alemania solamente ascendieron a 7.398 .334 bolivianos. Las exportaciones de Bolivia arrojaron los montos siguientes: a Gran Bretaña 88.042.604, a Estados Unidos 10.552.918 y a Alemania 3.803 .096 bolivianos. $^{41}$

A pesar de las repercusiones negativas que la guerra tuvo para el comercio germano-boliviano, la posición de los inmigrantes alemanes en la esfera mercantil de Bolivia no fue afectada de manera persistente. Si bien es evidente que la política de Listas Negras, impulsada a partir de 1915 por el Enemy Trading Act de los Estados Unidos, tuvo entre 1916 y 1919 consecuencias negativas para casas comerciales alemanas establecidas en el país, ella no llegó a tener el efecto devastador que le han atribuido algunos autores. ${ }^{42}$ Bolivia como país signatario del Tratado de Versalles no hizo uso del derecho que le otorgó este tratado para liquidar propiedades alemanes en su territorio. ${ }^{43}$ Una minuta oficial alemana de junio de 1920 constata que "los intereses alemanes en Bolivia no fueron afectados por la guerra ... Nunca ha existido una causa para advertencias o medidas contra el gobierno boliviano." ${ }^{44}$ En agosto de 1921 el embajador de Alemania en Santiago de Chile informó a Berlín que durante una visita suya a Bolivia él pudo cercionarse de que aún después de la ruptura de relaciones diplomáticas, los intereses alemanes en este país no fueron afectados, a no ser por efecto de las Listas Negras. ${ }^{45}$

El relativo debilitamiento del elemento alemán en el comercio boliviano a partir de 1914 fue producto tanto de las dificultades a las que él se vió enfrentado a causa del impetuoso retroceso de las relaciones comerciales germano-bolivianas como de la penetración de los Estados Unidos en la esfera 
mercantil.El establecimiento de la empresa norteamericana W. R. Grace \& Co. en Bolivia durante la Primera Guerra Mundial y su ulterior expansión a los centros de actividad económica más importantes en el país contribuyeron de manera substancial a resquebrajar la posición hegemónica de los viejos establecimientos comerciales alemanes. Sin embargo, esta competencia no llegó a destruirlos. Comerciantes de origen alemán retuvieron importantes posiciones en las grandes ciudades y, a pesar de la poderosa rivalidad de la sociedad mercantil británica Madeira-Mamore Trading Co., no llegaron a perder la supremacía que habían logrado adquirir en la región oriental del país. ${ }^{46}$

En la década posterior a la Primera Guerra Mundial la colonia alemana establecida en Bolivia afianzó su posición económica, social y cultural y logró ampliar su influencia en la vida nacional. Sin lugar a dudas ella constituía la colectividad extranjera más importante y mejor cohesionada del país. A pesar del ascendiente que llegaron a tener los Estados Unidos en la economía de Bolivia, en ella nunca se llegó a conformar una colonia norteamericana de peso e influencia semejante a la alemana. Este hecho ha tenido en décadas posteriores una notoria influencia en el conjunto de las relaciones internacionales entre Bolivia y las naciones altamente industrializadas. 


\section{$\mathrm{V} \cdot \mathrm{CONSIDERACIONES} \mathrm{FINALES}$}

Debido a su impetuoso desarrollo económico desde fines del siglo XIX, Alemania se convirtió en una nación cada vez más dependiente de la importación de materias primas a su vez que en una nación interesada por encontrar mercados de exportación para sus productos industriales y por realizar inversiones de capital. El creciente interés del Imperio Alemán por asegurarse esferas de influencia en el extranjero que respondiesen a su necesidad de expansión económica se manifiesta, por ejemplo, en el periódico "Export", órgano de la "Asociación Central para geografía comercial y fomento de intereses alemanes en el extranjero". En el marco de su ideario de nítida tendencia expansionista colonial y neocolonial, este periódico enfatizó en un artículo de mediados de 1902 la necesidad de que la política alemana prestase mayor atención a países de menor importancia relativa en América Latina: "Podría parecer cansador llamar reiteradas veces la atención sobre aquellos países latinoamericanos cuyos territorios, como los de Perú, Colombia, Bolivia, Ecuador, etc., en su mayor parte aún no están colonizados y elogiar la abundancia de sus recursos naturales; países en los cuales, por ende, todavía se puede desarrollar una enorme tarea civilizadora. Sin embargo, si la primera nación comercial e industrial del mundo, la inglesa, estudia incesantemente a fondo este tema, entonces nosotros, que para nuestra expansión comercial, industrial y emigratoria dependemos aún más que Inglaterra de aquellos países diríamos yermos, deberíamos hacer por lo menos lo mismo. Ello porque nuestras colonias son pobres en comparación con las de nuestros vecinos; solamente en escala muy reducida ellas ofrecen al espíritu empresarial alemán, si él existiera, la oportunidad de atreverse a negocios que tal vez prometan ganancia." Alemania, recalca el artículo, debería seguir el ejemplo de Inglaterra, país para el cual "ningún Estado es demasiado pequeño y demasiado insignificante como para no regalarle diplomática y comercialmente las más alta atención." ${ }^{2}$ Como pregonero de la idea que Alemania buscase esferas de influencia en "países yermos", "Export" dirigió su ojo avizor a la República de Bolivia. Las valiosas minas, las innumerables existencias de gomeros, la cantidad de plantas medicinales, de maderas finas, de cultivos tropicales y subtropicales, de corteza de quina, de coca y de lanas finas de alpaca, vicuña y oveja "conforman el cuadro seductor de una de aquellas regiones altamente favo- 
recidas la cual - debido al circuito cada vez más angosto de los territorios todavía no o escasamente colonizados - debería recibir mayor atención de nuestra parte" ${ }^{3}$, constata, sin ambages, un artículo de 1899. El interés que Alemania empezó a desarrollar por la economía boliviana a partir de fines del siglo XIX tuvo su origen en las crecientes necesidades que surgían del rápido desarrollo de sus fuerzas productivas después de 1870 . Bolivia no solamente ofrecía a la ascendiente potencia europea la posibilidad de proveerse con materias primas - entre ellas algunas de fundamental importancia - para su desenvolvimiento industrial, sino también posibilidades de exportaciones y de inversiones.

Si bien es indudable que el interés de Alemania por Bolivia en el período 1880-1914 constituye una parte integral de la política wilhelmínica de expansión imperialista, sería una burda simplificación interpretar el rol que jugó aquel país en la economía boliviana únicamente como corolario de esa política. La presencia de intereses alemanes en Bolivia fue a su vez producto del ideario y de las aspiraciones de desarrollo y modernización de las élites conservadora y liberal que gobernaron la república andina de 1880 a 1900 y de 1900 a 1920 respectivamente. Tanto ésta como aquella estaban imbuidas de la convicción que el atraso del país sólo podía ser superado si Bolivia lograba integrarse al mercado mundial en calidad de productor de materias primas con el apoyo financiero y tecnológico de las naciones industrializadas. Mariano Baptista (1832-1907), el hombre que por su talento periodístico y su oratoria política fue durante seis décadas el vocero más lúcido y el representante más conspicuo de la élite conservadora, ha delineado el leitmotiv del quehacer político de este grupo social en los términos siguientes: “... encadenar las acciones mineras a la vertiginosa circulación de Londres; movilizar esos cerros, convertirlos en valor de mercado, transformarlos ..., en billetes al portador, lanzados al centro de todas las transacciones; ieso sería fecundo, incalculable! iQué campo de ocupaciones para esos nuestros honrados cholos, tan dóciles, tan inteligentes! - iQué porvenir de trabajo para esa nuestra juventud! que no es ociosa, no; ique es desgraciada, sí! porque faltan ocasiones para su actividad." ${ }^{4}$ Esta concepción de desarrollo, que se gestó en Bolivia en el último tercio del siglo decimonónico, sobrevivió a la Revolución Federal de 1899 mediante la cual la élite liberal, vinculada al circuito productivo y comercial del noroeste, desplazó del poder al grupo conservador, ligado a los intereses mineros, básicamente argentíferos, del suroeste. Manuel Pando, el primer presidente de la época liberal, expresó al primer embajador del Imperio Alemán ante el gobierno boliviano, Michahelles, su ferviente deseo que Alemania invirtiera capitales en Bolivia. En un informe de julio de 1902 al canciller de su país, Micha- 
helles señaló que en una de sus conversaciones con Pando éste le había manifestado que en caso de concretizarse la fundación de un Banco Alemán en Bolivia, él se mostraría propenso a acordarle todo tipo de apoyo oficial. Podría otorgarle, por ejemplo, el privilegio exclusivo de emitir billetes de un boliviano y asegurarle de esta manera, desde un comienzo, un amplio radio de actividades en el país. "De cualquier manera - prosigue Michahelles - yo podría dar por sentado que él (Pando, L. B.) colaboraría en todas las medidas que tendrían por consecuencia una mayor participación del capital alemán en el desarrollo de Bolivia. ${ }^{6}$

Las relaciones económicas germano-bolivianas en las tres décadas anteriores al estallido de la Primera Guerra Mundial fueron producto de la confluencia de intereses entre una nación que por su grado de desarrollo estaba urgida de encontrar esferas de expansión y de influencia, y un país atrasado en el cual los grupos de poder implementaron una concepción de desarrollo basada en la convicción que la ayuda económica foránea constituía la vía idónea para la modernización.

Los tres capítulos anteriores permiten establecer algunas conclusiones con respecto a aquellas relaciones. Debido a las deficiencias señaladas en el Prólogo, estas conclusiones están abiertas a cuestionamiento basado en investigaciones más profundas que puedan realizarse en el futuro.

El rasgo distinctivo sobresaliente de las relaciones económicas establecidas entre Alemania y Bolivia con anterioridad a 1920 parece residir en su carácter marcadamente mercantil. Fue el intercambio comercial y no la inversión de capitales lo que caracterizó aquellas relaciones. Como potencia imperialista el Imperio Alemán encontró en Bolivia una fuente para adquirir materias primas y, sobre todo, un mercado para vender productos manufacturados. Sin embargo, Alemania no llegó a jugar ningún rol importante como inversor de capitales en el país suramericano. La expansión de la producción minera y cauchera así como la de la infraestructura boliviana no ofrecieron al Imperio Alemán posibilidades, al menos posibilidades substanciosas, para la exportación de capitales, sino la posibilidad de incrementar los flujos comerciales. En términos de la economía marxista, lo peculiar de las relaciones germano-bolivianas a nivel económico no fue la creación sino la realización de plus valía.

De la correspondencia diplomática alemana y de artículos de prensa alemanes se desprende el interés que tenían sectores de la industria y la banca del Imperio Alemán de invertir capitales en Bolivia. Diversas razones frustra- 
ron este interés. En el campo de la explotación minera parece que fue sobre todo la rivalidad británica y, posteriormente, la aún más poderosa de los Estados Unidos la que obstruyó una incursión financiera alemana. Sin embargo, al respecto son necesarias investigaciones más profundas las cuales probablemente sólo pueden realizarse a base de material documental de empresas y de la correspondencia diplomática boliviana, británica y norteamericana. En todo caso parece evidente que la presencia de capitales alemanes en la minería boliviana no provino básicamente del Imperio Alemán sino de súbditos alemanes arraigados en Bolivia. Con el proceso de modernización de la industria extractiva después de 1880, éstos perdieron posiciones frente a los capitales provenientes de Gran Bretaña y de los Estados Unidos. Debido a la propensión de los inmigrantes alemanes de mantener vínculos con su país de origen, aquel desarrollo probablemente contribuyó de manera notoria a coartar las posibilidades del capital alemán de incursionar en el sector minero del país andino.

La negativa del Deutsche Bank y de la Cancillería del Imperio Alemán en 1902 a participar en el "Bolivian Syndicate" para promover la explotación dela goma en el Acre, ponen de manifiesto diversas razones que cohibieron la presencia de capitales de Alemania en la extracción de materias primas bolivianas. Ante todo, se patentiza el temor del capital alemán frente al de los Estados Unidos. También se pone de manifiesto que los intereses económicos de Alemania en Bolivia tenían un carácter secundario frente a los existentes en países vecinos mucho más poderosos como el Brasil. En su negativa a participar en el Sindicato, el Deutsche Bank arguyó, entre otros, la falta de apoyo gubernamental. Tanto esta referencia, como la reticente actitud de Berlín a establecer relaciones diplomáticas con Bolivia y las quejas de grupos de presión económicos sobre la negligencia de la diplomacia alemana en promover las relaciones con países suramericanos atrasados, dejan presumir que la poca importancia atribuida por la política del Imperio Alemán al país andino constituyó un freno para la incursión de capitales alemanes en la economía boliviana.

A pesar de su marcado interés, Alemania no participó con una sola inversión en la construcción de la red ferroviaria de Bolivia. A diferencia de lo acontecido en el sector extractivo en el cual, por lo visto, la rivalidad de capitales británicos y estadounidenses representó un escollo demasiado poderoso, en el caso de la construcción de vías férreas la ausencia de capitales alemanes se debe a razones más diferenciadas. Como consecuencia de la forma encubierta con la cual Bolivia otorgó una gran parte de las concesiones, al Imperio Alemán le restaron opciones relativamente limitadas para intervenir con sus recursos financieros en la construcción de la red. El que 
tampoco haya llegado a aprovechar ninguna de estas opciones no se debió solamente a que otros solicitantes adquirieron el privilegio sino también al abandono de proyectos por parte del gobierno boliviano así como al propio desinterés o a la propia indecisión.

En marcado contraste con lo occurido en materia de inversiones de capital, el desarrollo del intercambio comercial entre Alemania y Bolivia hasta 1914 fue altamente significativo. Sin haber llegado a rivalizar con Gran Bretaña y con los Estados Unidos en materia de inversiones tanto en el sector extractivo como en la construcción ferroviaria, el Imperio Alemán logró convertirse en el primer suministrador de productos manufacturados de Bolivia y, después de Inglaterra, en el segundo comprador de productos bolivianos. A pesar de la influencia financiera británica en Bolivia, Alemania frustró las intenciones de la compañía Marconi de monopolizar el suministro de material para las estaciones radiotelegráficas establecidas en aquel país hasta 1925. El ascendiente del Imperio Alemán en el comercio exterior de Bolivia se explica por la posición hegemónica que llegaron a tener a partir de fines del siglo XIX casas comerciales establecidas por inmigrantes alemanes en la esferea mercantil boliviana. Estas casas fueron las correas de transmisión del flujo comercial entre ambos países. Si bien la balanza comercial germano-boliviana arrojó claros superávits para Bolivia, todo hace prever que los verdaderos beneficiarios del intercambio mercantil fueron los propietarios y socios de aquellas casas comerciales. Ello explica la marcada afinidad que ellos retuvieron hacia su país de origen. Esta afinidad, que sobrevivió en décadas posteriores, se articuló claramente en el apoyo material a los esfuerzos bélicos del Imperio Alemán durante la primera gran conflagración mundial.

En la medida en que el Imperio Alemán visualizó el desarrollo de la economía boliviana como medio para ampliar su comercio exterior y como fuente potencial de inversiones lucrativas, sus designios quedaron truncos. El interés de invertir capitales fue malogrado por la competencia primero británica y luego norteamericana, pero también por falta de intrepidez y desconfianza. Debido a ello, Alemania en sus relaciones económicas con Bolivia hasta la Primera Guera Mundial no logró transformar el maduro desarrollo mercantil en una política de clara raigambre imperialista. 
Referencia. En las notas los nombres de los archivos se abreviarán del siguiente modo:

- Bundesarchiv $=$ Bundarch.

- Bundesarchiv - Militärachiv = Militarch.

- Politisches Archiv des Auswärtigen Amtes = Polarch. d. AA

- Hauptstaatsarchiv Stuttgart $=$ Hptstarch. Stuttg.

1 Cf. Arturo Costa de la Torre, Catálogo de la Bibliografía Boliviana. Libros y Folletos 1900-1963, tomos 1 y 2, La Paz 1966 y 1973.

2 Cf. Werner Guttentag T., Bio-Bibliografía Boliviana. Han sido consultados los volúmenes correspondientes a los años que van de 1962 a 1980. Los de 1962 y 1963 fueron editados en La Paz en 1963 y 1964, los restantes en La Paz y Cochabamba entre 1965 y 1982.

3 Cf. Charles W. Arnade, The Historiography of Colonial and Modern Bolivia, en: The Hispanic American Historical Review, vol. XLII, núm. 3, Durham 1962, págs. 333-384.

4 Cf. Ch. W. Arnade, A Selected Bibliography of Bolivian Social Sciences, en: Inter-American Review of Bibliography, vol. VIII, núm. 3, Washington 1958, págs. 256-265. Los trabajos sobre relaciones económicas figuran en pág. 263.

5 Cf. Juan Siles Guevara, Bibliografía Selecta de Historia de Bolivia, La Pazl Cochabamba 1975, págs. 5-9 y 21-28.

6 Cf. R. A. Humphreys, Liberation in South America 1806-1827. The Career of James Paroissien, London 1952, págs. 142-162. Guillermo Ovando-Sanz, British Interests in Potosí, 1825-1828; Unpublished Documents from the Archivo de Potosí, en: The Hispanic American Historical Review, vol. XLV, núm. 1, Durham 1965, págs. 64-87. Enrique Tandeter, Potosí y los ingleses a fines de 1826, en: bistoria y cultura, núm. 3, La Paz 1978, págs. 125-143.

7 Cf. J. Fred Rippy, British Investments in Paraguay, Bolivia and Peru, en: Inter-American Economic Affairs, vol. 6, núm. 4, Washington, D.C. 1953, págs. 41-43.

8 Cf. Roberto Querejazu Calvo, Bolivia y los ingleses (1825-1948), La Paz/Cochabamba 1973.

9 Cf. Norman T. Ness, The Movement of Capital into Bolivia. A Backward Country (Ph. D.), Harvard University (Department of Economics) 1938. Citado en Herbert S. Klein, Orígenes de la Revolución Nacional Boliviana. La Crisis de la Generación del Chaco, La Paz 1968, pág. 438.

10 Cf. Margaret Alexander Marsh, The Bankers in Bolivia. A Study in American Foreign Investment, New York 1928. 
$11 \mathrm{Al}$ respecto se pueden consultar Cornelius H. Zondag, The Bolivian Economy, 1952-65. The Revolution and its aftermath, New York, Washington, London 1966, págs. 177-200. James W. Wilkie, The Bolivian Revolution and U.S. Aid since 1952. Financial Background and Context of Political Decisions, Los Angeles 1969, págs. 8-13 y 48-49. Richard W. Patch, Bolivia: U.S. Assistance in a Revolutionary Setting, en: Richard N. Adams y otros, Social Change in Latin America Today. Its Implications for United States Policy, New York 1960, págs. 108-176. En el contexto referido véase págs. 151-166. Richard Gordon Frederick, United States aid to Bolivia 1953-1972 (Ph. D.), University of Maryland 1977. Citado en W. Guttentag T., op. cit. correspondiente al año 1980, La Paz/Cochabamba 1982, pág. 222.

12 El libro de René Ruiz González, La Economía Boliviana y el Comercio Exterior, Oruro 1956 contiene en su primera parte un análisis del comercio exterior de Bolivia con datos a partir de 1929 y énfasis especial en la década del 40. Véase págs. 31-115.

13 Cf. Correos y Telégrafos, Informe Gestión de 1914-15, La Paz 1915, pág. 153.

14 Sobre las relaciones económicas entre Alemania y países suramericanos existen valiosas investigaciones alemanas. Al respecto véase Hermann Kellenbenz, As Relacôes Econômicas Teuto-brasileiras no Período de 1815 a 1830, en: II Colóquio de Estudos Teuto Brasileiros, Recife 1974, págs. 435-453. Gerhard Brunn, Deutschland und Brasilien (1889-1914), Köln/Wien 1971. Rolf Walter, Venezuela und Deutschland (1815-1870), Wiesbaden 1983.

El informativo libro del argentino Luis V. Sommi, Los Capitales Alemanes en la Argentina. Historia de su Expansión, Buenos Aires 1945 que analiza el período que va desde fines del siglo XIX hasta la Segunda Guerra Mundial, lamentablemente carece de referencias bibliográficas.

1 Sobre la decadencia de la producción minera en Bolivia durante las primeras décadas de vida republicana véase: Alcides Dessalines D’Orbigny, Viaje a la América Meridional, en: Viajes por América del Sur, Madrid 1958, págs. 858-861. José María Dalence, Bosquejo Estadístico de Bolivia, Chuquisaca 1851, págs. 293296. León E. Bieber, El potencial de desarrollo de los empresarios mineros bolivianos de la segunda mitad del siglo XIX, en: Revista Ciencias Sociales, vol. III, nr. 12, Quito 1981, págs. 139-141.

2 El cuadro siguiente refleja la decadencia de la producción argentífera entre 1895 y 1910

Producción de plata en Bolivia desde 1895

\begin{tabular}{l|l|l|l}
\hline Años & Marcos & Valores & Rendimientos \\
\hline
\end{tabular}

$\begin{array}{llll}1895 & 2.690 .907 & \text { Bs. } 18.431 .198 & \text { Bs. 815.659,21 } \\ 1896 & 1.337 .396 & \text { Bs. } 14.885 .498 & \text { Bs. 603.889,78 } \\ 1897 & 1.788 .122 & \text { Bs. } 15.819 .927 & \text { Bs. 675.638,47 }\end{array}$




\begin{tabular}{llll}
1898 & 1.409 .816 & Bs. 14.654 .348 & no consta \\
1899 & 1.292 .927 & Bs. 13.662 .000 & Bs. 415.790,64 \\
1900 & 1.820 .238 & Bs. 15.043 .454 & Bs. 421.540,10 \\
1901 & 1.212 .941 & Bs. 11.389 .207 & Bs. 404.235,67 \\
1902 & 1.120 .861 & Bs. 11.769 .040 & Bs. 376.147,90 \\
1903 & $745.407,62$ & Bs. 6.938 .294 & Bs. 59.632,61 \\
1904 & $432.859,62$ & Bs. 3.857 .949 & Bs. 34.628,77 \\
1905 & $385.801,87$ & Bs. 3.858.020 & Bs. 30.864,15 \\
1906 & $478.766,24$ & Bs. 4.786.752,51 & Bs. 38.301,38 \\
1907 & $648.346,39$ & Bs. $6.483 .463,90$ & Bs. 51.867,39 \\
1908 & $681.572,62$ & Bs. $6.802 .296,88$ & Bs. 54.525,81 \\
1909 & 680.907 & Bs. 8.060 .461 & Bs. 54.472,59 \\
$1910 *$ & 449.694 & Bs. 4.488 .782 & \\
\hline
\end{tabular}

* Producción durante los primeros nueve meses.

Fuente: Pedro Aniceto Blanco, Monografía de la Industria Minera en Bolivia, La Paz 1910, p. 344.

3 Cf.E.Pfannenschmidt, Boliviens Land-und Volkswirtschaft, Berlín 1916, pág. 54.

Participación de los países productores más importantes en la producción mundial de estaño (porcentajes)

\begin{tabular}{l|c|c|c}
\hline & $1851-1875$ & $1876-1900$ & $1901-1925$ \\
\hline Estados Malayos Federados & 29.45 & 41.39 & 38.13 \\
Bolivia & 0.41 & 3.12 & 18.51 \\
Indias Holandesas & 24.71 & 18.27 & 17.67 \\
Siam & 2.06 & 5.98 & 5.22 \\
Nigeria & - & - & 0.62 \\
China & 2.39 & 5.08 & 5.61 \\
Cornwall & 34.20 & 12.83 & 3.30 \\
Australia & 5.76 & 12.89 & 5.09 \\
\hline
\end{tabular}

Fuente: Josef Wollnik, Zinn. Wandlungen in der Erzeugung und Verwendung des Zinns nach dem Weltkrieg, Leipzig 1936, pág. 44.

Datos sobre la participación de los Estrechos Malayos y de Bolivia en la exportación mundial de estaño entre 1904 y 1913 trae Luis Peñaloza, Historia Económica de Bolivia, t. II, La Paz 1954, pág. 221.

5 Respecto al valor de las exportaciones bolivianas de estaño en las dos primeras décadas del presente siglo puede consultarse también Amado Canelas O., Mito y Realidad de la Corporación Minera de Bolivia, La Paz/Cochabamba 1966, pág. 25.

6 Cf. Staatsanzeiger del 23. 12. 1903, en: Admiralstab der Marine, RM 5/V, Nr. 5396, Militarch., Freiburg i.B.

7 Cf. V.L., Der Handel Boliviens, en: Die Weltwirtschaft, 1. Jg., H. 3/4, Wien, Leipzig 1905, pág. 12. 
8 Cf. Julius Uzarski, Bolivia. Natur und wirtschaftliche Verhältnisse (InauguralDissertation), Bonn 1911, pág. 77.

9 Cf. Richard Stappenbeck, Die Minerallagerstätten Südamerikas und ihre wirtschaftliche Bedeutung für das Deutsche Reich, Buenos Aires 1916, págs. 2 sigs., en: Bergwerkswesen des Auslandes, R 85, Vorl. 1194, Nr. 62, Bd. 5, Anlage 1 zu Bericht 134, Buenos Aires 18. 7. 1916, Bundarch., Koblenz.

10 Cf. Export del 16. 8. 1906, en: Admiralstab der Marine, op cit.

11 Cf. Wilhelm Sievers, Südamerika und die deutschen Interessen. Eine geographisch-politische Betrachtung, Stuttgart 1903, pág. 85.

Los valores indicados por Sievers están altamente sobreestimados. Al respecto véase Cuadro IV. 5. El aporte de los productos minerales al valor total probablemente refleja una relación correcta.

12 Cf. Export, op. cit.

13 Cf. Denkschrift zum Bericht Nr. 20025 vom 1. 12. 1909, pág. 9, en: Verträge des Deutschen Reichs mit Bolivien, Akten des K. Staatsministeriums, R 3/9, Nr. 1084, Hptstarch. Stuttg., Stuttgart.

14 Cf. J. Uzarski, op. cit., pág. 79.

15 Cf. R. Stappenbeck, op. cit., pág. 35.

16 Cf. op. cit., pág. 33.

$17 \mathrm{Al}$ respecto véase L. E. Bieber, op. cit., págs. 141-145 y Antonio Mitre, The economic and social structure of silver mining in XIX century Bolivia (PH.D., 1977), Ann Arbor 1981, págs. 135-139.

18 Cf. op. cit., págs. 111-164; L. E. Bieber, op. cit., págs. 145-155 y Guillermo Lora, Historia del Movimiento Obrero Boliviano. 1848-1900, La Paz/Cochabamba 1967, págs. 133-163, 168-175 y 191-231.

19 José Avelino Aramayo, Informe sobre los asuntos de Bolivia en Europa, Pau 1877, pág. 11.

20 Cf. J. Fred Rippy, The Peak of British Investment in Latin-American Mines, en: Inter-American Economic Affairs, vol. II, Nr. 1, Washington, D. C. 1948, pág. 47.

21 Detalles sobre el surgimiento y desarrollo de la Compañía Huanchaca en: L.E. Bieber, op. cit., págs. 146-155; G. Lora, op. cit., págs. 198-201; A. Mitre, op. cit., págs. 129, 133-135, 140-151 y 165-222; L. Peñaloza, op. cit., págs. 179-188.

22 Cf. op. cit., pág. 319.

23 Sobre las actividades mineras de José Avelino y de Félix Avelino Aramayo pueden consultarse: op. cit., págs. 316-319; L. E. Bieber, op. cit., págs. 146-155; G. Lora, op. cit., págs. 142-160 y Adolfo Costa du Rels, Félix Avelino Aramayo y su Epoca 1846-1929, Buenos Aires 1942.

24 Una amplia descripción de las inversiones realizadas por los Estados Unidos hasta la tercera década del presente siglo en la minería boliviana, básicamente en la del estaño, da Margaret A. Marsh, The Bankers in Bolivia, New York 1928, págs. 45-51.

Detalles sobre la empresa minera de Patiño dan L. Peñaloza, op. cit., págs. 4551 y Eduardo Klein Koch, Grundzüge der geschicbtlichen Entwicklung des Exportsektors und des Staates in Bolivien (1545-1952) (Inaugural-Dissertation), Marburg/Lahn 1978, págs. 214-218 y 234-236.

25 Cf. op. cit., pág. 236. 
26 M. A. Marsh, op. cit., pág. 45.

27 R. Stappenbeck, op. cit., pág. 36. (Subrayado por L.B.).

28 Op. cit., pág. 33.

29 Cf. Fritz Kübler, Deutsche in Bolivien, Stuttgart 1936, págs. 31-32.

30 Detalles sobre la personalidad de O.P. Braun y, en especial, sobre sus propiedades mineras en Corocoro pueden consultarse en Ernst Mossbach, Bolivia. Culturbilder aus einer südamerikanischen Republik in persönlichen Erlebnissen, Leipzig 1875, págs. 10-63. Mossbach fue contratado como director de las minas de cobre de Braun en 1858 y trabajó en ellas hasta su venta en 1860. Su libro contiene interesantes descripciones sobre la pujante vida de Corocoro en aquel entonces.

El papel que desempeñó Braun en Bolivia desde la época de las guerras de independencia hasta su retorno a Alemania en la década del 60 expone Alberto Crespo R., Alemanes en Bolivia, La Paz/Cochabamba 1978, págs. 133-164. Crespo sólo menciona tangencialmente la incursión de Braun en la minería.

31 Cf. M.A. Marsh, op. cit., pág. 50.

Coroco fue de la producción cuprífera boliviana. Datos sobre la producción de este centro en: Bolivia, en: Fr. Heinemann (edit.), Handels-und Wirtschaftsgeographie von Südamerika, Leipzig 1908, pág. 55; sobre la producción anual de cobre en el país entre 1885 y 1913 véase E. Pfannenschmidt, op. cit., pág. 54 y sobre volúmenes y valores de exportación de este mineral véase Cuadro II. 6 de este trabajo.

32 Máximo J. de Vacano, Bolivia, su desarrollo y progreso, Berlín 1925, pág. 191.

33 Cf. E. Mossbach, op. cit., pág. 63.

34 Las propiedades mineras de la empresa Böttiger, Trepp \& Co. en la década del 30 enumera F. Kübler, op. cit., pág. 32.

Cifras sobre el valor aproximado de la producción anual y el monto de exportación de la mina Araca (en comparación con otras minas del departamento de La Paz) en M.J. de Vacano, op. cit., pág. 193.

35 Cf. F. Kübler, op. cit., pág. 32 y M.A. Marsh, op. cit., págs. 45-46.

36 Cf. E. Klein K., op. cit., pág. 215 y Landwirtschaft, Handel und Industrie, en: Süd- und Mittel-Amerika, 6. Jg., Nr. 12, Berlin 28. 6. 1913, págs. 193-194.

37 Cf. A. Mitre, op. cit., Anexo 9, págs. 287-288.

38 El aporte de alemanes en materia de exploración mineralógica y de innovaciones tecnológicas mencionan G. Lora, op. cit., págs. 144-145; F. Kübler, op. cit., pág. 32; A. Mitre, op. cit., págs. 179-185 y M.J. de Vacano, op. cit., pág. 205. Las actividades de O. Rück en Bolivia describe A. Crespo en op. cit., págs. 189-209.

39 Cf. F. Kübler, op. cit., pág. 32 y Landwirtschaft, Handel und Industrie, en op. cit.

40 Cf. E. Klein K., op. cit., pág. 216. Detalles más amplios sobre adquisiciones realizadas por Patiño en Alemania contiene Landwirtschaft, Handel und Industrie, en op. cit.

41 R. Stappenbeck, op. cit., pág. 44.

42 F. Kübler, op. cit., pág. 30.

43 Cf. E. Klein K., op. cit., págs. 163-164, 340.

Sievers ha estimado la producción de goma en las cifras siguientes: año 1900 9.000 toneladas en el delta del Amazonas y 4.000 en la región de Purus; año 1901 
15.700 toneladas en el Estado de Amazonas, 13.400 en el Estado de Pará y 2.330 en el Acre boliviano. Cf. W. Sievers, op. cit., pág. 35.

44 Cf. E. Pfannenschmidt, op. cit., pág. 36.

45 Cf. J. Uzarski, op. cit., pág. 84.

46 Cf. E. Klein K., op. cit., págs. 158-159 y Lewis A. Tambs, Rubber, Rebels, and Rio Branco: The Contest for the Acre, en: Hispanic American Historical Review, vol. XLVI, nr. 3, Durham 1966, pág. 267.

47 Cf. Eduardo Arze Cuadros, La Economia de Bolivia. Ordenamiento territorial y dominación externa 1492-1979, La Paz/Cochabamba 1979, pág. 328.

48 Respecto a las dificultades que tuvo Bolivia por materializar su soberanía en la costa del Atacama sobre el océano Pacífico véase L.E. Bieber, op. cit., págs. 142-145.

49 Descripciones y datos sobre la situación demográfica en los llanos septentrionales de Bolivia a fines del siglo XIX dan L. Peñaloza, op. cit., págs. 196199 y J. Valerie Fifer, The Empire Builders: A History of the Bolivian Rubber Boom and the Rise of the House of Suárez, en: Journal of Latin American Studies, vol. 2, nr. 2, Cambridge 1970, págs, 117-118 y 124-127.

50 Cf. L. A. Tambs, op. cit., pág. 265. También J. V. Fifer, op. cit., pág. 130. "Long practically uninhabited and subject to the control of Bolivia, the Acre came into prominence when immigrants from Ceará finally penetrated the area and discovered enormous reserves of rubber. By 1900 the Brazilian settlers, ... formed the greater part of the population, ..." John Melby, Rubber River: An account of the rise and collapse of the Amazon boom, en: The Hispanic American Historical Review, vol. XXII, vol. XXII, nr. 3, Durham 1942, pág. 461.

51 Referencias sobre los proyectos de colonización mencionados en L. A. Tambs, op. cit., págs. 257, 260-263 y E. Klein K., op. cit., pág. 152.

52 Referencias sobre los conflictos en el Acre entre 1899 y 1903 y sobre el Tratado de Petrópolis se encuentran en L. A. Tambs, op. cit., págs. 266-273; E. Arze C., op. cit., págs. 332-335 y Augusto Guzmán, Breve Historia de Bolivia, La Paz/ Cochabamba 1969, págs. 239-242. Sobre el Tratado de Petrópolis véase también Politik, Kolonisation, Verkehr, en: Süd-und Mittel-Amerika, Nr. 9, Berlin 18. 5. 1908, págs. 213-214.

53 Informe confidencial de la Embajada del Imperio Alemán en el Brasil No. 162/J No. 872, Petrópolis 22. 6. 1900, en: Abt. A, Die inneren Zustände und Verbältnisse Boliviens, 1. 1. 1899-31. 7. 1900, Vol.3, Bolivien No. 1, Polarch.d. AA, Bonn.

54 Op. cit.

55 Anexo al Informe confidencial de la Embajada del Imperio Alemán en el Brasil No. 162/J No. 872, .., en: op. cit.

56 Op. cit.

57 Cf. op. cit.

58 El texto completo del contrato sobre el arrendamiento del Acre firmado en junio de 1901 en El Comercio, 15. 1. 1902, Lima. Una copia respectiva se encuentra en Abt. A, Die inneren Zustände und Verbältnise Boliviens, 1. 8. 190021. 6. 1902, Vol. 4, Bolivien No. 1, Polarch. d. AA, Bonn. Detalles sobre el contrato trae un artículo del periódico Die Post del 30. 3. 1902 y un artículo del periódico Frankfurter Zeitung del 6. 5. 1902 bajo el título "Eine Republik auf Aktien". Ambos artículos en op. cit. 
Véase también Informe de la Embajada del Imperio Alemán en Perú No. 10, Lima 24. 1. 1902, en: op. cit.

Este contrato era prueba evidente "que Bolivia se declaraba impotente para administrar directamente el territorio del Acre y reprimir el filibusterismo." L. Peñaloza, op. cit., pág. 202.

59 Copia de la carta de Martin Conway, Londres s/f., en: Abt. A, Die inneren Zustände ... op. cit.

Algunas referencias biográficas sobre Sir Martin Conway da J. Uzarski, op. cit., pág. 19.

60 Cf. Carta de Martin Conway, op. cit. y Export del 14. 8. 1902, en: Admiralstab der Marine, RM 5/V, Nr. 5396, Militarch., Freiburg i.B.

61 Copia de la carta de Martin Conway, op. cit.

62 "Con esta concesión se realiza el primer paso por parte de Norteamérica para poner el pie también territorialmente en Suramérica." Informe de la Embajada del Imperio Alemán en Perú No. 10, Lima 24. 1. 1902, op. cit.

63 Copia de la carta de Martin Conway, op. cit.

64 Detalles sobre las negociaciones realizadas por Sir M. Conway y Mr. Whitridge en Berlín respecto al arrendamiento del Acre se encuentran en Informe de la Embajada del Imperio Alemán en los Estados Unidos No. A. 177, Washington 6. 6. 1902, en: Abt. A. Die inneren Zustände ..., op. cit.; A 15354 del 20. 10. 1902, en: Abt. A, Die inneren Zustände und Verbältnisse Boliviens, 22. 6. 190231. 3. 1903, Vol. 5, Bolivien No. 1, Polarch. d. AA, Bonn y Zu A. 15196, Berlin 29. 10. 1902, en: op. cit.

65 Cf. Informe confidencial de la Embajada del Imperio Alemán en el Brasil No. 162/J No. 872, Petrópolis 22. 6. 1900, op. cit.

66 Op. cit.

67 Op. cit.

68 Cf. op. cit.

69 Cf. Informe del conde de Arco Valley, Petrópolis 19. 7. 1900, en: Abt. A, Die inneren Zustände..., Vol. 4.

Sobre las repercusiones del clima en la región amazónica para trabajadores alemanes véase por ejemplo III A 6164, Berlin 1. 10. 1909, en: Akten des Königl. Ministeriums der auswärtigen Angelegenbeiten, Rep. E 46, Fasz. 891, Hptstarch. Stuttg, Stuttgart.

70 An tit. Grafen Arco No. A 10, Berlin 15. 8. 1900, en: Abt. A., Die inneren Zustände..., Vol. 4.

71 Cf. Informe Graf von Arco an Reichkanzler Hohenlohe, Petrópolis 6. 9. 1900, en: op. cit.

72 A 15989, Berlin 1. 11. 1902, en: Abt. A, Die inneren Zustände ..., Vol. 5.

73 Cf. op. cit. y zu A 15989, Berlin 2. 11. 1902, en op. cit.

74 Op. cit.

75 Cf.J.V. Fifer, op. cit., pág. 132.

76 Cf. op. cit., págs. 141-142.

77 Las dos compañías estadounidenses nombradas no tenían su centro de operaciones en el Beni sino en el departamento de La Paz. The Chicago Bolivian Rubber Co. trabajó en la provincia de Yungas y The Bolivian Rubber Co. of Baltimore en la de Caupolicán. Ambas comercializaban la goma a través del puerto de Mollendo sobre el océano Pacífico. 
78 Cf. J.V. Fifer, op. cit., pág. 143; F. Kübler, pág. 24; Sammlungen der Deutschen in Bolivien, en: Liebesgaben und sonstige besondere Zuwendungen aus Bolivien an deutsches Militär, R 85, Vorl. 2516, Nr. 102a, Bundarch., Koblenz; Konsulat des Deutschen Reiches, J.N.11/C.N.4, Riberalta 31. 10. 1919, en: Die Nationalspende und andere Stiftungen für die Hinterbliebenen der im Kriege Gefallenen aus Bolivien, 1916-1924, R 85, Vorl. 2564, Nr. 102 b, Bundarch., Koblenz; Anlage zu Ber. der Gesandtschaft Rio de Janeiro, Rio de Janeiro 21. 8. 1923, en: op. cit y V S 2165, Berlin 3. 4. 1924, en: op. cit.

79 Cf. Sammlungen der Deutschen in Bolivien, en op. cit.

1 Respecto a proyectos ferroviarios en la región de Atacama con anterioridad a 1879 cf. Luis Peñaloza, Historia Económica de Bolivia, t. II, La Paz 1954, págs. 129-144, 329-343; Cesáreo Aramayo Avila, Ferrocarriles Bolivianos. Pasado Presente Futuro, La Paz 1959, págs. 40-46.

2 Cf. The Pan American Union, Bolivia. General descriptive data, Washington, D.C. 1921, pág. 21.

Edwin B. Karnopp en su trabajo de 1920 "Bolivia, sus ferrocarriles y su posición económica en Sud América" señala que en aquel entonces el país contaba con 1.635 kilómetros de vías férreas en operación y 616 kilómetros en construcción. Cf. C. Aramayo A., op. cit., pág. 170.

3 Descripciones sobre la construcción de los ferrocarriles Antofagasta-Oruro, Guaqui-La Paz y Arica-El Alto de La Paz se encuentran en op. cit., págs. 50-61, 130-138; L. Peñaloza, op. cit., págs. 347-353, 379-385. Exposiciones más resumidas se encuentran en Juan Muñoz Reyes, El desarrollo de los ferrocarriles en Bolivia, en: Bolivia en el Primer Centenario de su Independencia, La Paz 1925, págs. 539, 542, 544; The Pan American Union, op. cit., págs. 21, 23, 25; International Bureau of the American Republics, Bolivia. Geographical sketch, natural resources, laws, economic conditions, actual development, prospects of future growth, Washington, D. C. 1904, págs. 174-177 (incluye sólo los ferrocarriles Antofagasta-Oruro y Guaqui-La Paz). Sobre la inauguración del ramal a Corocoro véase también Verkehr. Eröffnung einer neuen Eisenbahnlinie in Bolivien, en: Süd-und Mittel-Amerika, 7. Jg., Nr. 3, Berlin 16. 2. 1914, pág. 45.

Los datos que dan los trabajos señalados sobre los años de construcción y sobre la extensión de las vías en muchos casos difieren los unos de los otros.

4 Cf. Antonio Mitre, The economic and social structure of silver mining in XIX century Bolivia (PH. D., 1977), Ann Arbor 1981, págs. 242-243.

5 Cf. W.L. Sisson, Informe del Reconocimiento sobre el Proyectado Sistema de Ferrocarriles Bolivianos, La Paz 1905, págs. 71-72.

6 Cf. Nachrichten- und Archivdienst des Ibero-Amerikanischen Instituts Hamburg, informe No. 1948 del 2. 10. 1918, en: Eisenbahnen in Bolivien, 1913-1919, R 85, Vorl. 126, Bundarch., Koblenz.

7 Cf. Julius Uzarski, Bolivia. Natur und wirtschaftliche Verbältnisse (InauguralDissertation), Bonn 1911, pág. 95. 
8 Sobre la construcción del ferrocarril Uyuni-frontera Argentina véase L. Peñaloza, op. cit., págs. 389-392 y J. Muñoz Reyes, op. cit., págs. 542-543. La construcción del tramo Villazón-Atocha describe C. Aramayo A., op. cit., págs. $148-164$.

Detalles respecto a la reducción de tiempo y costos a consecuencia de la vía férrea en consideración, en J. Uzarski, op. cit., pág. 97 e International Bureau of the American Republics, op. cit., pág. 172.

9 Cf. C. Aramayo A., op. cit., págs. 32-37; L. Peñaloza, op. cit., págs. 343-347 y J. Valerie Fifer, The Empire Builders: A History of the Bolivian Rubber Boom and the Rise of the House of Suárez, en: Journal of Latin American Studies, vol. 2, no. 2, Cambridge 1970, págs. 120-121.

10 "Según datos oficiales la obra costó - 306,485 kilómetros - algo así como 5.985.400 libras esterlinas, 14.614 vidas humanas e invalidó a 38.500 trabajadores, desde 1872 hasta 1912." C. Aramayo A., op. cit., pág. 37.

Los saltos de agua en el Madera, entre Guajaramerím y San Antonio describe Quintín Quevedo en su aporte The Madeira and its Head-Waters, en: Georg Earl Church (compilador), Explorations made in the Valley of the River Madeira, from 1749 to 1860, (London 1875) reprint Ann Arbor/London 1980, págs. 167-188. En este contexto sobre todo págs. 179-183.

11 Cf. E. Pfannenschmidt, Boliviens Land- und Volkswirtschaft, Berlin 1916, pág. 47.

12 Cf. C. Aramayo A., op. cit., págs. 253-254.

13 Cf. op. cit., págs. 55-61 y Ferrocarril de Guaqui a La Paz. Contrato de anticipo de fondos para la terminación de esta obra (edición oficial), La Paz 1904.

14 La literatura consultada para establecer el aporte de capitales a la construcción de la red ferroviaria boliviana contiene una multiplicidad de contradicciones. El Cuadro III. 2, elaborado en base a las obras y las fuentes que se citan en este capítulo, constituye un intento, obviamente sujeto a errores, de sintetizar el problema del financiamento de esta red.

15 Cf. Informe de la Embajada del Imperio Alemán en Santiago de Chile al príncipe von Bismarck del 25. 5. 1888, en: Abt. IA, Die inneren Zustände und Verbältnisse Boliviens, 23. 3. 1880-25. 5. 1889, Vol. 1, Bolivien No. 1, Polarch. d. AA, Bonn.

16 Op. cit.

17 Export, XXIV. Jg., Nr. 26, Berlin 26. 6. 1902, en: Admiralstab der Marine, RM 5/V, Nr. 5396, Militarch, Freiburg i.B.

18 Anexo al informe Nr. 73 del 20. 5. 1913, Embajada del Imperio Alemán en La Paz, 4. 8. 1913, en: Eisenbahnen in Bolivien: 1913-1919, op. cit.

19 Op. cit.

20 Cf. Staatsanzeiger del 25. 1. 1904 y del 8. 3. 1904, en: Admiralstab der Marine, op. cit.

21 Informe G. Nr. 547/K. 82, Embajada Alemana en La Paz, 26. 5. 1922, en: Abt. III, Eisenbabnwesen in Bolivien, 19. 9. 1920-20. 10. 1926, E. 2, Bolivien, Bd. 1, Polarch. d. AA, Bonn.

22 Si bien una ley dictada el 27 de noviembre de 1905 preveía el llamado a propuestas públicas para otorgar la construcción de los tramos mencionados en último término, este llamado no se realizó. Al respecto C. Aramayo A., op. cit., págs. 67-74 y Seferino Chulver Romero, Bolivia y el Contrato Speyer. Estu- 
dio Sintético, en: Revista de la Facultad de Economía, Año XIV, No. 21, Oruro 1966, pág. 67. "Aunque un modesto proyecto para la construcción de siete líneas ferroviarias en abierta propuesta había sido aprobado por el Congreso, Montes (entonces presidente de Bolivia, L.B.) con su acostumbrada manera de obrar por sí mismo, había procedido a negociar su propio proyecto en contrato cerrado con el consorcio de banqueros de Nueva York, el First National City Bank y Speyer \& Company." Herbert S. Klein, Origenes de la Revolución Nacional Boliviana. La Crisis de la Generación del Chaco, La Paz 1968, pág. 48.

23 Cf. C. Aramayo A., op. cit., págs. 132-134; Verkehrswege. Eisenbahn von Arica nach La Paz, en: Süd-und Mittelamerika, Nr. 1, Berlin 6. 1. 1908, pág. 70 y Verkehr. Eisenbahn Arica-La Paz, en: op. cit., 5. Jg., Nr. 6, Berlin 29. 3. 1912, pág. 98.

24 Cf. Informe K. Nr. 111 de la Embajada del Imperio Alemán en Bolivia, La Paz 26. 8. 1913, en: Eisenbahnen in Bolivien, 1913-1919, op. cit.

25 Cf. II E 347, Berlin 17. 2. 1914, en op. cit.

En cuanto al interés de la Firma Lenz \& Co. por arrendar la sección boliviana del ferrocarril Arica-La Paz cf. C. Aramayo A., op. cit., págs. 140-141.

26 Cf. Orenstein Koppel-Arthur Koppel Aktiengesellschaft, Berlin 9. 10. 1913, en: Eisenbahnen in Bolivien, 1913-1919, op. cit.

27 Informe K. Nr. 147 de la Embajada del Imperio Alemán en Bolivia, La Paz 7. 12. 1913, en op. cit.

28 Cf. Informe B. 48 de la Embajada Alemana en La Paz, La Paz 8. 4. 1926, en: Eisenbahnwesen in Bolivien, 19. 9. 1920-20. 10. 1926, op. cit.

29 Gabriel Gosálvez T., La Administración de Saavedra, en: Bolivia en el Primer Centenario ..., op. cit., pág. 165.

30 Anexo al Informe G. Nr. 298/K. 28 de la Embajada Alemana en La Paz, La Paz 29. 3. 1922, en: Eisenbabnwesen in Bolivien 19. 9. 1920-20. 10. 1926, op. cit.

31 Op. cit.

32 Cf. Informe G. Nr. 824/K. Nr. 126 de la Embajada Alemana en La Paz, La Paz 11. 8. 1922, en op. cit.

33 Cf. Anexo a III W A 2258, Berlin 9. 10. 1922, en op. cit.

$34 \mathrm{Al}$ respecto C. Aramayo A., op. cit., pág. 171.

35 Cf. Moisés Ascarrunz, El Partido Liberal en el Poder, t. I, La Paz 1917, pág. 418; Frankfurter Zeitung del 9. 10. 1902, en: Admiralstab der Marine, op. cit y Staatsanzeiger del 15. 9. 1906, en op. cit.

36 Sobre el Sindicato Fomento del Oriente véase Estudio de la Propuesta del Sindicato "Fomento del Oriente Boliviano", La Paz 1907, págs. 6 sigs.; L. Peñaloza, op. cit. págs. 392-393; E. Pfannenschmidt, op. cit., págs. 46-47 y J. Uzarski, op. cit., págs. 99-100.

37 Cf. Staatsanzeiger del 15. 9. 1906 op. cit.

38 Copia de la carta de C. Offermann, Mar del Plata 1. 2. 1921, anexo a B. Nr. 201, en: Eisenbabnwesen in Bolivien 19. 9. 1920-20. 10. 1926, op. cit.

39 Op. cit.

40 Cf. op. cit.

41 Sobre la concesión otorgada a la Bolivian Development and Colonization Company y sobre las modalidades de la concesión véase Daily Consular Reports, No. 194 del 20. 8. 1913, en: Eisenbahnen in Bolivien, 1913-1919, op. 
cit. y L. Peñaloza, op. cit., págs. 393-394.

Sobre el abandano del proyecto por parte de la Compañía de Desarrollo y Colonización véase Informe K. Nr. 142 de la Embajada del Imperio Alemán en Bolivia, La Paz 25. 11. 1913, en: Eisenbabnen in Bolivien, 1913-1919, op. cit.

42 Op. cit.

43 Cf. II E 69, Berlin 14. 1. 1914, en op. cit. así como Orenstein \& KoppelArthur Koppel AG, Berlin 23. 1. 1914, en: Eisenbahnen in Bolivien (Empfangsbestätigungen und Dankschreiben) - Pressestimmen, 1914, R 85, Vorl. 127, Nr. 151 adh., Bundarch., Koblenz y Staudt \& Co, Berlin 16. 1. 1914, en op. cit.

44 Informe Nr. Z. 8 de la Embajada del Imperio Alemán en Argentina, Buenos Aires 16. 2. 1914, en: Eisenbabnen in Bolivien, 1913-1919, op. cit.

45 La falta de datos pertinentes hace imposible desarrollar este particular con amplitud.

46 Cf. Export del 16. 8. 1906, en: Admiralstab der Marine, op. cit.

47 Cf. Deutscher Handel mit Bolivien, en: Abt. III, Handelsvertragsverbältnis zu Deutschland, 1920-1927, Nr. H. 13, Bd. 1, Bolivien, Polarch. d. AA, Bonn. El pésimo confeccionamiento del material estadístico citado no permite calcular el aporte porcentual de las mercaderías enumeradas en relación con el valor total de las importaciones que Bolivia realizó de Alemania en aquel año.

48 Cf. op. cit.

49 Cf. Anlage 3 der Denkschrift zum Entwurf eines Gesetzes über die Wiederinkraftsetzung des Freundschafts- und Handelsvertrags zwischen Deutschland und Bolivien vom 22. Juli 1908, en: Verträge des Deutschen Reichs mit Bolivien, Akten des K. Staatsministeriums, R 3/9, Nr. 1084, Hptstarch. Stuttg., Stuttgart.

50 Cf. Hans Bredow, Denkschrift über funkentelegrafische Weltprojekte, Berlin 1916, pág. 2, en: Die drabtlose (Funken-)Telegraphie, 1914-1917, R 85, Vorl. 753, Bundarch., Koblenz. Sobre la hegemonía mundial que a comienzos del siglo XX tenía Gran Bretaña en el campo de la telegrafía alámbrica véase R. Hertlein, Internationale Kabelpolitik, en: Die Weltwirtschaft, 1.Jg., H. 10, Wien/Leipzig 1905, págs. 9-15 y Ernst H. Nickel, Von der Zukunft der Kabeltelegraphie, en op. cit. IV. Jg., Nr. 2, Wien/Leipzig 1908, págs. 37-40.

51 Detalles sobre el desarrollo de la radiotelegrafía por parte de Alemania en $\mathrm{H}$. Bredow, op. cit., págs. 1-5, 7, 9-10. Respecto a las estaciones radiotelegráficas que la Telefunken estableció hasta 1914 en países latinoamericanos véase Fritz Pauli, Telefunken im lateinischen Amerika, en: Süd- und MittelAmerika, 7. Jg., Nr. 5, Berlin 18. 3. 1914, págs. 65-86.

52 Citado en H. Bredow, op. cit., pág. 5.

53 Citado en op. cit., págs. 5-6.

54 Cf. op. cit., pág. 6.

55 Cf. International Bureau of the American Republics, op. cit., pág. 182.

56 Cf. Information about Bolivia, Washington 1912, en: Die Postverbältnisse mit Bolivien 1908-1915, R 85, Vorl. 669, Nr. 6, Bundarch., Koblenz.

57 Cf. Dirección General de Telégrafos, Informe del Director Sr. Rosendo Villalobos, 1911-1912, pág. 6, en: Die Telegraphen Verhältnisse in Südamerika, 1908-1919, R 85, Vorl. 838, Nr. 55, Bundarch., Koblenz.

58 Sobre el elevado costo de instalación y mantenimiento de una estación radiotelegráfica véase H. Bredow, op. cit., pág. 6. 
59 Cf. Abschrift II.E.758, Kais. Deutsche Ministerresidentur, La Paz 8. 1. 1912, en: Admiralstab der Marine, op. cit.

60 Cf. Dirección General de Telégrafos, op. cit., Anexos, pág. 9.

Un informe de la Embajada del Imperio Alemán en Bolivia menciona que también la Compagnie Genurate Radiotélégraphique presentó una solicitud. Cf. Abschrift II E 5541, Kaiserlich Deutsche Ministerresidentur, La Paz 21. 8.1912, en: Admiralstab der Marine, op. cit.

61 Cf. Dirección General de Telégrafos, op. cit., Anexos págs. 10-11.

El Informe de la Dirección de Telégrafos señala que la libra esterlina en aquel momento se cotizaba a 18.75 bolivianos (Anexos, pág. 10). Ello es incorrecto. Los cálculos hechos en el propio informe muestran que la cotización fluctuaba entre 12.50 y 12.75 bolivianos por libra esterlina. Los equivalentes señalados en este trabajo toman por base esta última valoración.

62 Cf. op. cit., Anexos, pág. 19.

63 Cf. op. cit., Anexos, pág. 26.

64 Cf. Abschrift von II E 4819, Kaiserlich Deutsche Ministerresidentur, La Paz 17. 7. 1912, en: Admiralstab der Marine, op. cit.

65 Dirección General de Telégrafos, op. cit., Anexos, pág. 31. Al respecto también op. cit., Anexos, pág. 15. En cuanto a la opinión del general Ampuero cf. Abschrift II. E. 758, op. cit.

66 Cf. Dirección General de Telégrafos, op. cit., Anexos, págs. 23-26 y 45-48.

67 Op. cit., Anexos, págs. 49-51.

68 Cf. op. cit., Anexos, pág. 50.

69 La ventaja que el sistema Telefunken ofrecía a Bolivia (en comparación con el sistema Marconi) debido a su posibilidad de vincular las estaciones radiotelegráficas del país tanto por la vía del Pacífico como por la vía del Atlántico, la realzó el gerente de esta empresa en una carta dirigida al Ministerio de Relaciones Exteriores en Berlín. Cf. Gesellschaft für drahtlose Telegraphie m.b.H., Berlin 4. 3. 1912, en: Admiralstab der Marine, op. cit.

70 Abschrift II.E.758, op. cit.

71 Op. cit. También Abschrift Nr. 83, Kaiserlich Deutsche Ministerresidentur, La Paz 12. 11. 1911, en: op. cit.

72 Abschrift von II E 4819, op. cit.

73 Op. cit.

74 Cf. op. cit.

75 Op. cit.

76 Sobre el particular op. cit.; Abschrift von II E 5471, Kaiserlich Deutsche Ministerresidentur, La Paz 16. 9. 1913, en: op. cit.; Informe K. Nr. 119, Kaiserlich Deutsche Ministerresidentur, La Paz 16. 9. 1913, en: Drabtlose (Funken-) Telegraphie in Südamerika, 1913-1915, R 85, Vorl. 810, Bundarch., Koblenz.

77 Op. cit.

El informe contiene detalles sobre el convenio firmado entre el gobierno de Bolivia y la empresa Marconi. Al respecte véase también Abschrift von II E 5471, op. cit.

78 Informe K. Nr. 119, op. cit.

79 Informe A 4697, Kaiserlich Deutsche Ministerresidentur, La Paz 26. 1. 1914, en: Abt. IA, Die inneren Zustände und Verbältnisse Boliviens, 16. 12. 1913-19. 10. 1920, Bd. 16, No. 1, Polarch. d. AA., Bonn. 
80 Cf. Informe K. No. 22, Kaiserlich Deutsche Ministerresidentur, La Paz 18. 2. 1915, en:Drabtlose (Funken-)Telegraphie in Südamerika, 1913-1915, op. cit.

81 Cf. Abschrift von II.E.758, op. cit.

82 Op. cit.

83 Cf. Abschrift Nr. 83, op. cit.

84 Cf. Abschrift von Nr. II E 4819, op. cit.

85 Op. cit.

86 Cf. op. cit. y Abschrift von II E 5136, Kaiserlich Deutsche Ministerresidentur, La Paz 26. 7. 1912, en: Admiralstab der Marine, op. cit.

87 Cf. op. cit.

88 Respecto a la presión ejercida por los agentes de la Telefunken en el Congreso y en la prensa de Bolivia véase Abschrift von Bericht von Sanden, La Paz 9. 9. 1912, en: Admiralstab der Marine, op. cit.; Abschrift Gust. Hinke u. Co., Oruro 3. 10. 1912, en op. cit. y Abschrift II E 110, Kaiserlich Deutsche Ministerresidentur, La Paz 23. 11. 1912, en op. cit.

89 Informe K. No. 22, op. cit.

90 Cf. Dirección General de Telégrafos, op. cit., págs. 61 y 92 sigs.

91 Cf. Abschrift von II E 5471, op. cit. y Verkehr. Telefunkenapparate für den bolivianischen Chaco und Paraguay, en: Süd-und Mittel-Amerika, 6.Jg., Nr. 21, Berlin 15. 11. 1913, pág. 338.

92 Informe Nr. A 23, Kaiserlich Deutsche Ministerresidentur, La Paz 1. 11. 1911, en: Abt. IA, Die inneren Zustände und Verbältnisse Boliviens, 1911, Bd. 13, Bolivien No. 1, Polarch. d. AA, Bonn.

1 Cf. Julius Uzarski, Bolivia. Natur und wirtschaftliche Verhältnisse, Bonn (Inaugural-Dissertation) 1911, pág. 73.

2 Cf. op. cit., pág. 73.

3 Al respecto Vicente Mendoza López, Las Finanzas Públicas de la República de Bolivia, en: Bolivia en el Primer Centenario de su Independencia, La Paz 1925, pág. 471 e Informe No. 94, Kaiserlich Deutsche Gesandtschaft in Lima, Lima 1. 11. 1901, en: Abt. IA, Die inneren Zustände und Verbältnisse Boliviens, 1. 8.1900 -21. 6. 1902, Vol. 4, Bolivien No. 1, Polarch. d. AA., Bonn.

4 Para establecer estas discrepancias pueden compararse por ejemplo E. Pfannenschmidt, Boliviens Land-und Volkswirtschaft, Berlin 1916, pág. 48; Herbert S. Klein, Orígenes de la Revolución Nacional Boliviana. La crisis de la generación del Chaco, La Paz 1968, págs. 40, 50-51, 64, 72; J. Uzarski, op. cit, pág. 74; Bolivia, en: Fr. Heinemann y otros, Handels- und Wirtschaftsgeographie von Südamerika, 2da. edición, Leipzig 1908, pág. 59; Staatsanzeiger del 12. 22. 1904, en: Admiralstab der Marine, RM 5/V, Nr. 5396, Militarch., Freiburg i.B.; Export del 28. 3. 1907, en op. cit.

Obviamente también se pueden establecer discrepancias entre la literatura señalada y las cifras del Cuadro IV. 2 del presente trabajo.

5 Cf. J. Uzarski, op. cit., pág. 76.

6 Cf. The Pan American Union, Bolivia. General descriptive Data, Washington, D.C. 1921, pág. 2. 
$7 \mathrm{Al}$ respecto Eduardo Klein Koch, Grundzüge der geschicbtlichen Entwicklung des Exportsektors und des Staates in Bolivien (1545-1952), Marburg/Lahn (Inaugural-Dissertation) 1978, pág. 213; Informe de von Stengel, Deutsche Gesandtschaft La Paz, La Paz 11. 4. 1922, en: Abt. III, Handelsvertragsverbältnis zu Deutscbland, 1920-1927, Bd. 1, Bolivien Handel 13, Polarch. d. AA, Bonn y Denkschrift zum Entwurf eines Gesetzes über die Wiederinkraftsetzung des Freundschafts- und Handelsvertrags zwischen Deutschland und Bolivien vom 22. Juli 1908, pág. 5, en: Verträge des Deutschen Reichs mit Bolivien, 1909-1927, Akten des König. Staatsministeriums, R 3/9, Nr. 1084, Hptstarch. Stuttg., Stuttgart.

8 Los valores totales indicados han sido calculados a base de las cifras parciales tomadas de Wilhelm Sievers, Südamerika und die deutschen Interessen. Eine geographisch-politische Betrachtung, Stuttgart 1903, págs. 53-54.

9 Para 1904 cf. Bolivia, en Fr. Heinemann y otros, op. cit., pág. 60 y Export del 16. 8. 1906, en: Admiralstab der Marine, op. cit. Para 1908 cf. Denkschrift zum Entwurf eines Gesetzes über die ..., op. cit., pág. 9.

10 Porcentajes calculados a base de las cifras en E. Klein K., op. cit., pág. 212.

11 La ganadería boliviana "comprende ... miles de llamas y ovejas y permite la exportación de lana, pero como los campos de pastoreo de la Puna no se explotan suficientemente esta posibilidad no es aprovechada seriamente; ..." W. Sievers, op. cit., pág. 45.

Sobre el reducido cultivo de algodón con anterioridad a 1950 en Bolivia véase E. Pfannenschmidt, op. cit., pág. 26 y Augusto Guzmán, Breve Historia de Bolivia, La Paz/Cochabamba 1969, pág. 270.

12 Cf. E. Pfannenschmidt, op. cit., págs. 49-50.

13 Cf. Informe No. 94, Kaiserlich Deutsche Gesandtschaft in Lima, op. cit.

14 Cf. Fritz Kübler, Deutsche in Bolivien, Stuttgart 1936, pág. 11.

15 Export del 23. 11. 1899, en: Admiralstab der Marine, op. cit.

16 Informe No. 168/J No. 855, Kaiserlich Deutsche Gesandtschaft in Brasilien, Petropolis 26. 6. 1900, en: Abt. IA, Die inneren Zustände und Verhältnisse Boliviens, 1. 1. 1899-31. 7. 1900, Vol. 3, Bolivien No. 1, Polarch. d. AA., Bonn. Anexo al informe se encuentra la nómina de las casas comerciales alemanas.

17 Cf. Informe del Conde von Arco, Kaiserlich Deutsche Gesandtschaft in Brasilien, Petropolis 19. 7. 1900, en: Die inneren Zustände und Verbältnisse Boliviens, 1. 8. 1900-21. 7. 1902, Vol. 4, Bolivien No. 1, Polarch. d. AA., Bonn.

18 Informe No. 94, Kaiserlich Deutsche Gesandtschaft in Lima, op. cit.

19 Op. cit.

20 Op. cit.

21 Auswärtiges Amt in Berlin, 28. 2. 1902 an den Kaiserlichen Gesandten in Lima, en: Die inneren Zustände und ..., op. cit., Vol. 4.

22 Citado en F. Kübler, op. cit., pág. 29.

23 Cf. Informe de la Kaiserliche Deutsche Gesandtschaft in Chile al príncipe von Bülow, Santiago 8. 11. 1888, en: Abt. IA, Die inneren Zustände und Verbältnisse Boliviens, 23. 3. 1880-25. 5. 1889, Vol. 1, Bolivien No. 1, Polarch. d. AA., Bonn y Export del 23. 11. 1899, op. cit.

24 Op. cit.

25 El texto completo del Tratado de Amistad y Comercio firmado en julio de 1908 entre el Imperio Alemán y la República de Bolivia se encuentra en Verträge 
des Deutschen Reichs mit Bolivien, 1909-1927, op. cit., págs. 3-8.

26 Export del 23. 11. 1899, op. cit.

27 Export del 14. 8. 1902, en: Admiralstab der Marine, op. cit.

28 Export del 22. 6. 1905, en op. cit.

29 La lista de nombres de casas comerciales alemanas ha sido elaborada en base a las referencias de F. Kübler, op. cit., págs. 23-24 y el anexo al Informe No. 168/J No. 855, Kaiserlich Deutsche Gesandtschaft in Brasilien, Petropolis 26. 6. 1900 , op. cit.

30 Cf. E. Pfannenschmidt, op. cit., pág. 5.

El autor estima que la inmigración a Bolivia en la década siguiente no fue significativa. Véase op. cit., pág. 6.

31 Cf. F. Kübler, op. cit., pág. 30.

32 Export del 23. 11. 1899, op. cit.

33 Cf. F. Kübler, op. cit., págs. 23-24.

34 Referencias a las leyes nombradas en The Pan American Union, op. cit., págs. 29-30. Sobre el Reglamento de Inmigración Libre véase también V. L., Das Gesetz betreffend die freie Einwanderung in Bolivien, en: Die Weltwirtschaft, IV. Jg., Nr. 4/5, Wien/Leipzig 1908, págs. 78-82. Para una evaluación crítica de ambas leyes cf. E. Pfannenschmidt, op. cit., págs. 6-10.

35 Aspectos relativos a la vida social y cultural de las colectividades alemanas en Bolivia describen F. Kübler, op. cit., págs. 38-39, 43-46, 55; Reinhard Wolff/Hartmut Fröschle, Die Deutschen in Bolivien, en: Hartmut Fröschle (edit.), Die Deutschen in Lateinamerika. Schicksal und Leistung, Tübingen/ Basel 1979, págs. 155-157 y Federico Nielsen-Reyes, Boliviens Aufbauwille, Berlin 1937, págs. 41, 45.

36 Cf. Denkschrift zum Entwurf eines Gesetzes über die Wiederinkraftsetzung des Freundschafts- und Handelsvertrags zwischen Deutschland und Bolivien vom 22. Juli 1908, op. cit., pág. 11.

37 Extractos sobre fondos reunidos por las colectividades alemanas para apoyar al Imperio Alemán durante la Primera Guerra Mundial así como detalles sobre la participación de casas comerciales en la recolección de estos fondos se encuentran en Liebesgaben und sonstige besondere Zuwendungen aus Bolivien an deutsches Militär, R 85, Vorl. 2516, Nr. 102 a y Die Nationalspende und andere Stiftungen für die Hinterbliebenen der im Kriege Gefallenen aus Bolivien, 1916-1924, R 85, Vorl. 2564, Nr. 102 b. Ambas actas en Bundarch., Koblenz.

38 John D. O'Rear, Bolivia, en: Supplement to Commerce Reports, No. 39a, Washington, D.C. 18. 4. 1917, pág. 1.

39 "A partir de 1916 se suspendió la exportación entre ambos países (Alemania y Bolivia, L.B.)." Anexo al Informe G. Nr. 682/K. 107 de von Stengel al Ministerio de Relaciones Exteriores de Alemania, La Paz 4. 7. 1922, en: Abt. III, Politische Beziebungen zwischen fremden Staaten, 1921-1934, Bolivien Politik 3, Polarch. d. AA., Bonn.

40 Sobre la ruptura de relaciones diplomáticas entre el Imperio Alemán y Bolivia y para una evaloración de este acontecimiento por parte del gobierno alemán véase Abschrift A 54524 del 1. 2. 1919 e Informe Deutsche Gesandtschaft in Brasilien del 21. 4. 1921, en: Abt. III, Politische Beziebungen Boliviens zu Deutschland, 1920-1935, Bolivien Politik 3, Polarch. d. AA., Bonn. También Abschrift von A 14207, Consulado General de Bolivia en Alemania, Zürich 27. 4. 1917 
y Abschrift A 21512, No. 537, ambos documentos en: Die Haltung der Neutralen im europäischen Kriege, 1914-1916. Bolivien, R 85, Vorl. 6676, Nr. 77, Bundarch., Koblenz.

41 Cf. Foreign Trade of Bolivia from January to November, Inclusive, 1926, en: Bolivia. Industry Commerce Banking Travel Statistics, Vol. 1, No. 6, New York 1927, págs. 20-21.

42 Así por ejemplo F. Kübler, op. cit., págs. 30-31 y todavía más radical E. Klein K., op. cit., págs. 231-232.

43 Al respecto B III 9164/22/44440, Reichsminister für Wiederaufbau, Berlin 13. 12. 1922, en: AA VIII J, Güter, Rechte, Interessen. Allgemeines, 1922-1923, Bd. 3, Polarch. d. AA., Bonn.

44 Aufzeichnung, Berlin 27. 6. 1920, en: Abt. III, Deutsche diplomatische und konsularische Vertretungen in Bolivien, 1920-1935, Bolivien Politik 10, Polarch. d. AA., Bonn.

45 Informe Erckert, Deutsche Gesandtschaft Santiago de Chile 4. 8. 1921, en op. cit.

46 Cf. F. Kübler, op. cit., pág. 33; R. Wolff/H. Fröschle, op. cit., págs. 150-151 y F. Nielsen-Reyes, op. cit., pág. 40.

1 Export del 26. 6. 1902, en: Admiralstab der Marine, RM 5/V, Nr. 5396, Militarch., Freiburg i. B.

2 Op. cit.

3 Export del 23. 11. 1899, en: op. cit.

4 Citado conforme a Guillermo Lora, Historia del Movimiento Obrero Boliviano 1848-1900, La Paz/Cochabamba 1967, pág. 141.

5 Cf. Informe Michahelles al Canciller von Bülow, Lima 1. 7. 1902, en: Abt. IA, Die inneren Zustände und Verbältnisse Boliviens, 22. 6. 1902-31. 3. 1903, Vol. 5, Bolivien No. 1, Polarch. d. AA, Bonn.

6 Op. cit. 


\section{BIBLIOGRAFÍA}

\section{BIBLIOGRAFIAS}

Arnade, Charles W., A Selected Bibliography of Bolivian Social Sciences, en: Inter-American Review of Bibliography, 8, 3, Washington 1958.

Arnade, Ch. W., The Historiography of Colonial and Modern Bolivia, en: The Hispanic American Historical Review, 42, 3, Durham 1962.

Costa de la Torre, Arturo, Catálogo de la Bibliografía Boliviana. Libros y Folletos 1900-1963, t. 1 y 2, La Paz (Universidad Mayor de San Andrés) 1966 y 1973.

Guttentag T., Werner, Bio-Bibliografía Boliviana, vols. de 1962 a 1980, La Paz y La Paz/Cochabamba (Los Amigos del Libro) de 1963 a 1982.

Siles Guevara, Juan, Bibliografía Selecta de Historia de Bolivia, La Paz/Cochabamba (Los Amigos del Libro) 1975.

\section{DOCUMENTOS}

Abreviaciones de los nombres de los archivos:

- Bundesarchiv (Koblenz) = Bundarch.

- Bundesarchiv-Militärarchiv (Freiburg i.B.) = Militarch.

- Hauptstaatsarchiv Stuttgart (Stuttgart) = Hptstarch. Stuttg.

- Politisches Archiv des Auswärtigen Amtes (Bonn) = Polarch. d. AA.

Admiralstab der Marine, RM 5/V, 5396, Militarch.

Akten des Königl. Ministeriums der auswärtigen Angelegenbeiten, Rep. E 46, Fasz. 891, Hptstarch. Stuttg.

Bergwerkswesen des Auslandes, R 85, Vorl. 1194, Bd. 5, Nr. 62, Bundarch.

Deutsche diplomatische und konsularische Vertretungen in Bolivien, 1920-1935, Abt. III, Bolivien Politik 10, Polarch. d. AA.

Die drabtlose (Funken-)Telegrapbie, 1914-1917, R 85, Vorl. 753, Bundarch.

Drabtlose (Funken-) Telegrapbie in Südamerika, 1913-1915, R 85, Vorl. 810, Bundarch. Eisenbabnen in Bolivien, 1913-1919, R 85, Vorl. 126, Bundarch.

Eisenbabnen in Bolivien (Empfangsbestätigungen und Dankschreiben) - Preßstimmen, 1914, R 85, Vorl. 127, Nr. 151 adh., Bundarch.

Eisenbabnwesen Bolivien, 1920-1926, Abt. III, E 2, Bolivien, Bd. 1, Polarch. d. AA. Güter, Rechte, Interessen. Allgemeines, 1922-1923, AA VIII J, Bd. 3, Polarch. d. AA. Die Haltung der Neutralen im europäischen Kriege, 1914-1916. Bolivien, R 85, Vorl. 6676, Nr. 77, Bundarch.

Handelsvertragsverhältnis zu Deutschland, 1920-1927, Abt. III, Nr. H 13, Bd. 1, Bolivien, Polarch. d. AA.

Die inneren Zustände und Verbältnisse Boliviens, Abt. IA, Vol. 1, Bolivien No. 1; Abt. A, Vol. 3, Bolivien No. 1; Abt. A, Vol. 4, Bolivien No. 1; Abt. A, Vol. 5 , Bolivien No. 1; Abt. IA, Bd. 13, Bolivien No. 1; Abt. IA, Bd. 16, Bolivien No. 1, Polarch. d. AA. 
Liebesgaben und sonstige besondere Zuwendungen aus Bolivien an deutsches Militär, R 85, Vorl. 2516, Nr. 102a, Bundarch.

Die Nationalspende und andere Stifungen für die Hinterbliebenen der im Kriege Gefallenen aus Bolivien, 1916-1924, R 85, Vorl. 2564, Nr. 102 b, Bundarch.

Politische Beziebungen Bolivuis zu Deutschland, 1920-1935, Abt. III, Bolivien Politik 3, Polarch. d. AA.

Politische Beziebungen zwischen fremden Staaten, 1921-1934, Abt. III, Bolivien Politik 3, Polarch. d. AA.

Die Postverhältnisse mit Bolivien, 1908-1915, R 85, Vorl. 669, Nr. 6, Bundarch.

Die Telegraphen Verbälmisse in Südamerika, 1908-1919, R 85, Vorl. 838, Nr. 55, Bundarch.

Verträge des Deutschen Reichs mit Bolivien, 1909-1927, R $3 / 9$ o R VI 69, Nr. 1084, Hptstarch. Stuttg.

\section{INFORMES}

Bolivia. Dirección General de Aduanas, Comercio Especial de Bolivia. ExportaciónImportación-Bancos. Año 1921, La Paz (Escuela Tipográfica Salesiana) 1922. Correos y Telégrafos, Informe Gestión de 1914-15, La Paz (La Prensa) 1915.

Estudio de la Propuesta del Sindicato "Fomento del Oriente Boliviano", La Paz (Artística Castillo y Co.) 1907.

Sisson, W. L., Informe del Reconocimiento sobre el Proyectado Sistema de Ferrocarriles Bolivianos, La Paz (Heitmann y Cornejo) 1905.

\section{TESIS DE GRADO}

Klein Koch, Eduardo, Grundzüge dergeschichtlichen Entwicklung des Exportsektors und des Staates in Bolivien (1545-1952) (Inaugural-Dissertation), Marburg/Lahn 1978.

Mitre, Antonio, The economic and social structure of silver mining in XIX century Bolivia (Ph. D., 1977), Ann Arbor (University Microfilm International) 1981.

Ness, Norman T., The Movement of Capital into Bolivia. A Backward Country (Ph.D.) Harvard University 1938.

Uzarski, Julius, Bolivia. Natur und wirtschaftliche Verbältnisse (Inaugural-Dissertation), Bonn (Emil Eisele) 1911.

\section{LIBROS}

Aramayo, José Avelino, Informe sobre los asuntos de Bolivia en Europa, Pau (Veronese) 1877.

Aramayo Avila, Cesáreo, Ferrocarriles Bolivianos. Pasado Presente Futuro, La Paz (Nacional) 1959.

Arze Cuadros, Eduardo, La Economia Boliviana. Ordenamiento territorial y dominación externa 1492-1979, La Paz/Cochabamba (Los Amigos del Libro) 1979.

Ascarrunz, Moisés, El Partido Liberal en el Poder, t. 1, La Paz (Marinoni) 1917. 
Blanco, Pedro Aniceto, Monografía de la Industria Minera de Bolivia, La Paz (J. Miguel Gamarra) 1910.

Bolivia en el Primer Centenario de su Independencia, La Paz (Renacimiento) 1925.

Brunn, Gerhard, Deutschland und Brasilien (1889-1914), Köln/Wien (Böhlau) 1971.

Canelas O., Amado, Mito y Realidad de la Corporación Minera de Bolivia, La Pazl Cochabamba (Los Amigos del Libro) 1966.

Costa du Rels, Adolfo, Félix Avelino Aramayo y su Epoca. 1846-1929, Buenos Aires (Viau) 1942.

Crespo R., Alberto, Alemanes en Bolivia, La Paz/Cochabamba (Los Amigos del Libro) 1978.

Dalence, José María, Bosquejo Estadístico de Bolivia, Chuquisaca (Imprenta Sucre) 1851.

Ferrocarril de Guaqui a la Paz. Contrato de anticipo de fondos para la terminación de esta obra, La Paz (Impr. del Estado) 1904.

Gosálvez T., Gabriel, La Administración de Saavedra, en: Bolivia en el Primer Centenario de su Independencia, La Paz (Renacimiento) 1925.

Guzmán, Augusto, Breve Historia de Bolivia, La Paz/Cochabamba(Los Amigos del Libro) 1969.

Heinemann, Fr., Handels- und Wirtschaftsgeograpbie von Südamerika, Leipzig (List \& von Bressensdorf) 1908.

Humphreys, R. A., Liberation in South America 1806-1827. The Career of James Paroissien, London (The Athlone Press) 1952.

International Bureau of the American Republics, Bolivia. Geographical sketch, natural resources, laws, economic conditions, actual development, prospects of the future growth, Washington, D. C. (Government Printing Office) 1904.

Kellenbenz, Hermann, As Relações econômicas Teuto-brasileiras no Período de 1815 a 1830, en: II Colóquio de Estudos Teuto Brasileiros, Recife (Universitária) 1974.

Klein, Herbert S., Orígenes de la Revolución Nacional Boliviana. La Crisis de la Generación del Chaco, La Paz (Juventud) 1968.

Kübler, Fritz, Deutsche in Bolivien, Stuttgart (Strecker und Schröder) 1936.

Lora, Guillermo, Historia del Movimiento Obrero Boliviano. 1848-1900, La Paz/Cochabamba (Los Amigos del Libro) 1967.

Marsh, Margaret Alexander, The Bankers in Bolivia. A Study in American Foreign Investment, New York (Vanguard Press) 1928.

Mendoza López, Vicente, Las Finanzas Públicas de la República de Bolivia, en: Bolivia en el Primer Centenario de su Independencia, La Paz (Renacimiento) 1925.

Mossbach, Ernst, Bolivia. Culturbilder aus einer südamerikanischen Republik in persönlichen Erlebnissen, Leipzig (J. Ambrosius Barth) 1875.

Muñoz Reyes, Juan, El desarrollo de los ferrocarriles en Bolivia, en: Bolivia en el Primer Centenario de su Independencia, La Paz (Renacimiento) 1925.

Nielsen-Reyes, Federico, Boliviens Aufbauwille, Berlin (Verlag für Auswärtige Politik) 1937.

Orbigny, Alcides d', Viaje a la América Meridional, en: Viajes por América del Sur, Madrid (Aguilar) 1958. 
The Panamerican Union, Bolivia. General descriptive data, Washington, D.C. (s./d.) 1921.

Patch, Richard W., Bolivia: U.S. Assistance in a Revolutionary Setting, en: Adams, Richard N. y otros, Social Change in Latin America Today. Its Implications for United States Policy, New York (Harper \& Brothers) 1960.

Peñaloza, Luis, Historia Económica de Bolivia, t. 2, La Paz (Fénix) 1954.

Pfannenschmidt, E., Boliviens Land- und Volkswirtschaft, Berlin (Paul Parey) 1916. Querejazu Calvo, Roberto, Bolivia y los ingleses (1825-1948), La Paz/Cochabamba (Los Amigos del Libro) 1973.

Quevedo, Quintín, The Madeira and its Head-Waters, en: Church, George Earl (compil.), Explorations made in the Valley of the River Madeira, from 1749 to 1860, Ann Arbor/London (University Microfilms International) 1980.

Ruiz González, René, La Economía Boliviana y el Comercio Exterior, Oruro (Universitaria) 1956.

Sievers, Wilhelm, Südamerika und die deutschen Interessen. Eine geographisch-politische Betrachtung, Stuttgart (Strecker \& Schröder) 1903.

Sommi, Luis V., Los Capitales Alemanes en la Argentina. Historia de su Expansión, Buenos Aires (Claridad) 1945.

Vacano, Máximo J. de, Bolivia, su desarrollo y progreso, Berlín (D. Reimer/E. Vohsen) 1925.

Walter, Rolf, Venezuela und Deutschland (1815-1870), Wiesbaden (Franz Steiner) 1983.

Wilkie, James W., The Bolivian Revolution and U.S. Aid since 1952. Financial Background and Context of Political Decisions, Los Angeles (University of California) 1969.

Wolff, Reinhard/Fröschle, Hartmut, Die Deutschen in Bolivien, en: Fröschle, Hartmut (edit.), Die Deutschen in Lateinamerika. Schicksal und Leistung, Tübingen/Basel (Horst Erdmann) 1979.

Wollnik, Josef, Zinn. Wandlungen in der Erzeugung und Verwendung des Zinns nach dem Weltkrieg, Leipzig (Bibliographisches Institut AG) 1936.

Zondag, Cornelius H., The Bolivian Economy, 1952-65. The Revolution and its aftermath, New York/Washington/London (Frederick A. Praeger) 1966.

\section{ARTÍCULOS}

Bieber, León E., El potencial de desarrollo de los empresarios mineros bolivianos de la segunda mitad del siglo XIX, en: Revista Ciencias Sociales, 3, 12, Quito 1981.

Chulver Romero, Seferino, Bolivia y el Contrato Speyer. Estudio Sintético, en: Revista de la Facultad de Economia, 14, 21, Oruro 1966.

Fifer, J. Valerie, The Empire Builders: A History of the Bolivian Rubber Boom and the Rise of the House of Suárez, en: Journal of Latin American Studies, 2, 2, Cambridge 1970.

Foreign Trade of Bolivia from January to November, Inclusive, 1926, en: Bolivia. Industry Commerce Banking Travel Statistics, 1, 6, New York 1927.

Das Gesetz betreffend die freie Einwanderung in Bolivien, en: Die Weltwirtschaft, 4, 4/5, Wien/Leipzig 1908. 
Der Handel Boliviens, en: Die Weltwirtschaft, 1, 3/4, Wien/Leipzig 1905.

Hertlein, R., Internationale Kabelpolitik, en: Die Weltwirtschaft, 1, 10, Wien/ Leipzig 1905.

Landwirtschaft, Handel und Industrie, en: Süd-und Mittel-Amerika, 6, 12, Berlin 1913.

Melby, John, Rubber River: An Account of the rise and collapse of the Amazon boom, en: The Hispanic American Historical Review, 22, 3, Durham 1942.

Nickel, Ernst H., Von der Zukunft der Kabeltelegraphie, en: Die Weltwirtschaft, 4, 2, Wien/Leipzig 1908.

O'Rear, John D., Bolivia, en: Supplement to Commerce Reports, 39a, Washington, D.C. 1917.

Ovando-Sanz, Guillermo, British Interests in Potosí, 1825-1828; Unpublished Documents from the Archivo de Potosí, en: The Hispanic American Historical Review, 45, 1, Durham 1965.

Pauli, Fritz, Telefunken im lateinischen Amerika, en: Süd- und Mittel-Amerika, 7, 5, Berlin 1914.

Politik, Kolonisation, Verkehr, en: Süd- und Mittel-Amerika, 9, Berlin 1908.

Rippy, J. Fred, The Peak of British Investment in Latin-American Mines, en: Inter-American Economic Affairs, 2, 1, Washington, D.C. 1948.

Rippy, J. Fred, British Investments in Paraguay, Bolivia and Peru, en: Inter-American Economic Affairs, 6, 4, Washington, D.C. 1953.

Tambs, Lewis, A., Rubber, Rebels, and Rio Branco: The Contest for the Acre, en: Hispanic American Historical Review, 46, 3, Durham 1966.

Tandeter, Enrique, Potosí y los ingleses a fines de 1826, en: bistoria y cultura, 3, La Paz 1978.

Verkehr. Eisenbahn Arica-La Paz, en: Süd-und Mittel-Amerika, 5, 6, Berlin 1912.

Verkehr. Eröffnung einer neuen Eisenbahnlinie in Bolivien, en: Süd-und MittelAmerika, 7, 3, Berlin 1914.

Verkehr. Telefunkenapparate für den bolivianischen Chaco und Paraguay, en: Süd- und Mittel-Amerika, 6, 21, Berlin 1913.

Verkehrswege. Eisenbahn von Arica nach La Paz, en: Süd- und Mittel-Amerika, 1, Berlin 1908. 

Abuna (río) 37

Acre

río 35, 37 41; territorio 31, 33, 35-41, 103

Alemania 11, 28, 36, 38-40, 44, 46, 58, 60-61, 72-74, 95, 97-98, 100-101, 104 y aviación boliviana 76 ; Cancillería 38-40, 60, 63, 90, 103; capitales (inversiones) en Bolivia 9-10, 23, 2729, 40-43, 60-63, 77-78, 101-104; y casas (empresas) comerciales en Bolivia 9, 27-28, 42-43, 58, 61, 90, 92-93, 95, 97-98, 104; comercio exterior 78, 83; dependencia externa 22-23; desarrollo 12, 93, 100-101; y desarrollo ferroviario en Bolivia 10, 46-47, 57-64, 76-77, 85, 103; desarrollo (industria pesada) 77 (radiotelegráfico) 65-67, 77; y estaciones radiotelegráficas de Bolivia 46, 65, 71, 76-77; exportaciones a Bolivia $10,29,42,64,75,85,87$, 97; y extracción de goma boliviana 9, 40-44, 76, 103; importaciones de Bolivia 22-23, 85, 87-88, 97-98; interés por Bolivia 10, 13, 27, 89, 91-92, 98, 101, 104; intereses en el Brasil 39-40, 103; Nacional-Socialismo 11; relaciones (con América Latina) 11 (comerciales con Bolivia) 12, 44, 58, $75,78,82-83,85,87-93,97-98,104$ (comerciales con Suramérica) 82, 91 (diplomáticas con Bolivia) 12, 64, 85, 89, 90-92, 98, 103 (económicas con Bolivia) 8, 10, 29, 76, 78, 102; rivalidad (con Estados Unidos en América Latina) 43 (con Estados Unidos en Boliva) 29-30, 43, 76-77, 97-104 (con Gran Bretaña) 65-67, 100 (con Gran Bretaña en Bolivia) 29-30, 65, 76-77, 104 (con intereses franceses) 77; y sector minero de Bolivia 9, 13, 22-23, 27-29, 42-44, $76,85,103$; vinculaciones con Bolivia 8

Allgemeine Elektrizitätsgesellschaft (AEG) 65

Amazonas (río) 33, 36, 46, 52

Amazonía 30-31

América 91

América del Norte 89

América Latina

y Estados Unidos 7, 43; relaciones con Alemania 11, 66, 100

Ampuero (General) 70

Ancken von \& Co. 41

Andes Tin Corporation 26

Anglo-Bolivian Rubber Estates 41

Antofagasta

ferrocarril 50-51, 57; puerto 50

Antofagasta and Bolivia Railway Co. 59

Araca (mina) 28

Aramayo, Félix 25-26, 37

Aramayo, José Avelino 24-26, 29

Aramayo Avila, C. 54

Arani (tranvía eléctrico) 60-61

Arce, Aniceto 45, 57

Arco Valley d' (conde) 36-37, 39, 89-90

Argentina 40, 50-51, 62, 66, 71 comercio exterior 78,97 ; comunicación ferroviaria con Bolivia 47, 51, 62 ; inversiones británicas 24

Arica 50, 58

Armand, Luciano 23

Arnade, Ch. W. 7

Asia Oriental 30, 33, 39

Asociación Alemana de Ingenieros 22

Asociaciones Alemanas (Deutsche Vereine) 95

Atacama (región del) 46

Atlántico (océano) 33, 52, 62, 71

Avebury (lord) 38 
Bahía Negra 62

Ballivián (estación radiotelegráfica) 10 Ballivián, José 35

Banco Alemán Transatlántico 10,59-60, 63

Baptista, Mariano 101

Barber, Alfredo W. \& Co. 41, 92

Barber y Julow 41

Becker, J. M. 92

Becks von \& Co. 41

Bélgica 35, 38

relaciones (comerciales con Bolivia) 82 ; (diplomáticas con Bolivia) 89

Belmont, August 38

Beni

departamento 35; llanos del 33; río 33, 41-42; casas comerciales alemanas 42

Berenguela Tin Mines Ltd. 26

Berlín 5, 10, 36, 39-40, 58, 60-61, 63, 68, 89-91, 97-98, 103

Bermejo (río) 35

Bickenback, Th. \& Co. 92

Bismarck von 8, 57

Böhme 92

Böttiger, Trepp \& Co. 27-28, 43

Bolivia 7, 9, 11, 23-24, 33, 35-37, 39, 41 $57-58,60-63,72,74-75,77,87,89-$ 90, 95, 98-101

aviación civil 46; Banco Alemán 102; bibliografía 7; Cámara de Diputados 61; capitales (empréstitos) alemanes 10, 43, 102-103; colonia alemana 46, 93, 95, 99; comercio exterior 9, 20, 33, 50, 78-80, 89-90; Congreso 73-74; correspondencia consular 8; desarrollo 8, 11-13, 18, 45, 80, 93-94, 101 (ferroviario) 10, 45-47, 50-55, 57-64, 68, 103; estaciones radiotelegráficas 9-11, 46, 65, 68-76, 104; exportaciones 79, 85, 87, 97 (goma) 30, 33, 81 (minerales) 18, 20, 27, 81; goma 31, 41, 45, 54; importaciones 79, 81, 87, 97 (de Alemania) 63-64, 81, 85, 87-88, 98 (de Estados Unidos) 81, 98 (de Gran Bretaña) 81, 98; Informes Anuales de la Dirección General de Correos y Telégrafos 10; inmigrantes (alemanes) 27-29, 41, 43, 60, 90, 92-95, 97-98, 103-104 (británicos) 94; inversiones 9, 23, 26-27 (de Estados Unidos) 7, 26 (inglesas) 7, 24; minería 13, 17-18, 20-21, 25-27, 30, 45, 51, 94; poblacion foránea 93-94; radiotelegrafiá 46; región amazónica 35-36, 39; relaciones comerciales 7-8, 75, 85 (con Alemania) 12, 2223, 27, 58, 78, 82-83, 85, 89-91, 93, 97-98, 104 (con Bélgica) 82 (con Estados Unidos) 7-8, 97-98 (con Francia) 82 (con Gran Bretaña) 7-8, 78, 82, 94, 98 (con Japón) 82; relaciones diplomática (con Alemania) 12, 64, 85, 89-92, 98, 103 (con Gran Bretaña) 7, 94; relaciones económicas 7 (con Alemania) 8, 10, 78, 102 (con Estados Unidos) 7; teléfonos 46; telegrafía 46, 67-68, 75

Bolivia Tin Corporation 26

Bolivian Development and Colonization Co. 63

Borgilte 92

Borsig 29

Brasil 33, 35-40, 47, 55, 66, 71, 89, 103 comercio exterior 78; comunicación ferroviaria con Bolivia 51; estaciones radiotelegráficas 70-71, 74; inmigrantes alemanes 95

Braun 90

Braun, Otto Philipp 27-28

Brieger 41

Brieger, M. \& Co. 92

British United Copper Mines 27

Brown Brothers \& Co. 38

Bülow von 90

Buenos Aires 22, 40, 51, 62, 73

Cachuela Esperanza 41

Callerius 95

Caracoles 46

Caracoles Tin Co. 26

Cartagena 66

Carvalho, José 36 
Cary 38

Casa Ernesto Tornquist \& Co. 63

Casa J. H. Schroeder 24

Casa Suárez 41

Casares, Vicente 62

Caupolicán (provincia) 29, 33, 50

Ceará (estado) 33, 36

Central Trust Co. 38

Centroamérica 66

Cintra da Silva, J. A. 36

Clausthal-Zellerfeld (Escuela de Minería) 29

Cobija (estación radiotelegráfica) 68

Cochabamba 55, 95 ciudad 45, 52, 60, 92; tranvía eléctrico 60-61; valle de 10, 55, 60

Colombia 66, 78, 100

Colonization and Commercial Company of Bolivia 35

Colsmann \& Co. 92

Comercio germano-boliviano 10, 12, 58, $64,77,83,85,90,92,95,97-98,104$

Compagnie Aramayo de Mines en Bolivie 26

Compagnie de télégraphie sans fils 68 , 73

Compañía de Salitres y Ferrocarril de Antofagasta 23

Compañía del Real Socavón 25

Compañía General de Minas en Bolivia 26

Compañía Huanchaca 24-26, 50, 54-55, 59

Confederación de Industrias Alemanas 61

Congreso Argentino 57

Conway, Martin (Sir) 37-38, 40

Corocoro 27; (ferrocarril) 50, 55

Costa de la Torre, A. 7

Cotaigata 25

Crédit Mobilier Français 60

Cross, S. W. 38

Cuba 66

Cuenca Amazónica 30

Chaco 35, 75

Chambres 74

Chichas (provincia) 25
Chile 23, 46-47, 50, 55, 66, 71

comercio exterior 78, 97 ; comunicación ferroviaria con Bolivia 47, 50, 59-60; estaciones radiotelegráficas 71 ; inmigrantes alemanes 95; inversiones en ferrocarriles bolivianos 59

Chimoré 62

Chorolque (cerro) 25

Chuquiaguillo 28

D’Orbigni (estación radiotelegráfica) 10

Delaware 26

Delegación del Purus 36, 39

Demag (empresa) 29

Demont, René 71-72

Deutsch-Südwest-Afrika 22

Deutsche Bank 38, 40, 58-59, 61, 63, 103

Deutsche Blätter für Bolivien (órgano de prensa) 97

Deutsche Überseeische Bank 28

Devoto 62

Dézert du, B. 70

Direccción de Obras Públicas (Bolivia) 70

Dirección General de Telégrafos (Bolivia) $67-68,70$

Diskonto-Gesellschaft 61

Duarte Muñoz 35

Ecuador 82, 100

Edimburgo 30

Elisabeth 5

Equitable Trust Co. 55

Ernest, Luis 92

España 93

Estados Unidos 26, 38, 40, 43, 54, 66, 98

Enemy Trading Act 98; expansión en América Latina 7, 43, 82, 90; y ferrocarriles bolivianos 54-55, 59$60,62-63,77$; intereses en minería de Bolivia 23, 26, 28-29; inversiones en Bolivia (goma) 41, 43 (minería) 43, 59, 103; producción de plata 17; relaciones (comerciales con Bolivia) 7-8, 85, 97-99 (diplomáticas 
con Bolivia) 89; rivalidad con intereses alemanes (en América Latina) 43 (en Bolivia) 29-30, 43, 5960, 97-98, 103-104; y territorio del Acre 38

Estanco de Alcoholes y Aguardientes (Bolivia) 54

Eulert, Federico E. 92

Europa 28-29, 41, 51, 61-62, 98

Export (órgano de prensa) 57, 89, 91-92, 100

\section{Faquhar, Parcifall (sindicato) 55, 63}

Ferrocarril

Antofagasta-Oruro 47, 52, 57; Antofagasta-Salar del Carmen 4647; Arica-La Paz 10, 50, 54, 58-60, 64, 76; Ascotán-Uyuni 46, 54, 59; Atocha-Uyuni 51, 54-55, 60; Atocha-Villazón 60, 76; Beni-La Paz 52; Cochabamba-Oruro 54-55, 59; Cochabamba-río Ichilo 52, 55, 59, 76; Cochabamba-Santa Cruz 61, 76; Corumbá-Santa Cruz 51; CharañaEl Alto de La Paz 50; Guaqui-La Paz 47, 52, 54-55, 59; La Paz-Viacha 52, 54, 59; La Paz-Yungas 55, 58-59, 62, 76; La Quiaca-Jujuy 60; La QuiacaTupiza 73; Machacamarca-Uncía 26, 52, 55, 59, 64; Madera-Mamoré 52, 55, 63; Mollendo-ArequipaPuno 54-55; Oruro-Viacha 52, 5455, 59; Potosí-río Mulato 52, 54-55, 59; Potosí-Sucre 52-53, 55, 59, 62, 76; río Paraguay-Santa Cruz 76; San Antonio-Guajaramerím 51-52; San Antonio-Guajaramerím-Villa Bella 36; Santa Cruz-Yacuiba 53; TupizaVillazón 51, 55, 60; Uyuni-Pulacayo-Huanchaca 47, 55, 59; UyuniVillazón 51, 55, 59

Findel 92

Firma Ed. Weber \& Co. (Hamburgo) 42

Firma Gmo. Demmer 41-42

Francia 41, 67, 89

créditos ferroviarios a Bolivia 60 , 73 ; inversiones en goma boliviana
41, 55; y radiotelegrafía en Bolivia 68; relaciones (comerciales con Bolivia) 82, 97 (comerciales con Suramérica) 82 (diplomáticas con Bolivia) 89

Francke, Carlos 29

Francke, Ernesto 29

Francoforte 59

Fricke, Germán \& Co. 28

Fundación del Patrimonio Cultural Prusiano 5

Gasser 42

Gedlmayr 27-28

Gerder, Fed. \& Co. 92

Germany 38

Gesellschaft für Drahtlose Telegraphie 68-74

Gildemeister \& Co. 61

Ginebra 26

Goodyear, Charles 30

Goudge 62

Grace, W. R. \& Co. 26, 54, 99

Gran Bretaña 41-42, 59, 62, 67, 100

Cámaras Unidas de Comercio 38; comercio (con Suramérica) 82 (exterior) 78; intereses (en goma boliviana) 41 (en minería boliviana) 23 , 26, 59; inversiones (en Bolivia) 24, 29, 41, 43, 54, 59, 63, 103 (en Latinoamérica) 24; radiotelegrafía 65; relaciones (comerciales con Bolivia) 7-8, 78, 82-83, 87-88, 94, 97-98 (diplomáticas con Bolivia) 7, 94; rivalidad (con Alemania en el campo de la radiotelegrafía) 65-67 (con intereses alemanes en Bolivia) 65, 97, 104

Grande (río) 42

Great Britain 38

Grether, Hans 61-62

Guaqui 50, 92

Guajaramerím 52

Guerra del Pacífico 23, 46

Guggenheim Brothers 25-26

Guttentag, W. 7

Haase, Benno 41 
Hamburg American Line 38

Hamburgo 92

Harden, E. B. 36

Hay 38

Heath, Edwin 33

Heidinger 58

Hellmann, Guillermo 93

Heluan (estación radiotelegráfica) 73

Hengartner \& Giebler 41

Hinke, Gustavo 68, 73; (casa comercial) 61

Hochschild, Moritz 27-28

Huanchaca ferrocarril 47, 57; empresa 57; mina 29

Humphreys, R. A. 7

Ichilo (río) 55, 61

Imperio Alemán (véase Alemania)

Imperio Austro-Húngaro 93

Informes Anuales de la Dirección General de Correos y Telégrafos (Bolivia) 10

Inglaterra (véase Gran Bretaña)

Instituto Ibero-Americano 5, 10

International Mining Co. 26

Iquitos (estación radiotelegráfica) 71

Iselin, Adrian jr. 38

Italia 67, 93

Itenes (río) 42

Japón

relaciones comerciales con Bolivia 82

Jujuy 57

Kade 63

Kahler, A. 30

Kock, Luis \& Co. 92

Kosmos (vapor) 73

Krüger, R. \& Co. 93

Krupp 29

Kübler 27, 29-30

L'Africaine (compañía belga) 62

Lagunillas 62

La Paz

ciudad $10,28,35,45,47,52,58$,
60-61, 70-71, 75, 89-92, 95, 97;

departamento 27-29, 33, 50, 54;

estación radiotelegráfica $68,70,74$

La Quiaca (ferrocarril) 51

La Salvadora (mina) 28

Lenz \& Co. 60

Leopoldo I 35

Lima 40, 90; (estación radiotelegráfica) 71

Listas Negras 98

Litoral (costa de Bolivia) 23

Londres 24-26, 35, 37-38, 41, 54, 72-73, 101

López Gama, Pedro 23

López Netto, F. 35

Lorenz (empresa) interés en radiotelegrafía de Bolivia 68-69

Lubbock (banco británico) 38

Llallagua (minas) 26

Madeira-Mamoré Trading Co. 99

Madera (río) 33, 36, 42, 51-52

Madidi (río) 33

Madre de Dios (río) 33, 37, 41-42

Maier \& Hagemann 92

Mamoré (río) 33, 35-36, 41-42, 51-52

Manaos 71

estación radiotelegráfica 71

MAN-Dieselmotoren 29

Mannesmann 75

Manuripi (río) 33

Marconi Wireless Telegraph Co. 65-67, $69,73,75$

instalación de estaciones radiotelegráficas en Bolivia 10, 68, 70-75, 104; rivalidad con la compañía Telefunken 11, 65, 67-74, 77

Marsh, M. A. 7, 26

Martens, Julio 92

Melbourne Clark and Co. 23

Melgarejo 23, 35

Mendoza López, V. 79

Mercedes Benz 29

Metropolitan Life Insurance Co. 38

México

producción de plata 17 
Michahelles, Gustav 90, 101-102

Ministerio de Gobierno y Fomento (Bolivia) 70

Mitre, Antonio 50

Mollendo (puerto) 50, 70

Montes, Ismael 70-73, 76

Moreno, Francisco 62

Morton Bliss \& Co. 38

Mossbach, E. 28

Mozer 42

Münchner Allgemeine Zeitung 91

Musini 62

Nacional Socialismo 11

National Bolivian Navigation Co. 35

Nauen (estación radiotelegráfica) 66-67

Ness, N. 7

New York 38

Nueva York 25

Offermann, C. 62-63

Oficina Imperial de Patentes (Alemania) 69

Orenstein \& Koppel A.G. 28-29, 60, 63-64

Orton (río) 33, 37, 41-42

Oruro 28, 95

ciudad 45, 52, 59, 61, 92; departamento 50; Escuela de Minas 29

Ovando-Sanz 7

Pacífico costa del 50-51, 57; océano 33, 71

Pando, Manuel 90, 101-102

Pará (estación radiotelegráfica) 71

Paraguay 82; (río) 46, 53, 62

París 70, 72-73

Partido Liberal (Bolivia) 72

Patiño Mines and Enterprises Consolidated Inc. 26, 55

Patiño, Simón 26, 28, 30, 43 construcción de ferrocarril 55; vinculación financiera (con Alemania) 9, 28-29, 43 (con los Estados Unidos) 26,28

Perú 38-40, 54-55, 66, 89-90, 92, 100 comercio (con Alemania) 82 (con
Bolivia) 97; comunicación ferroviaria con Bolivia 47, 50

Peruvian Corporation Limited 54-55, 59

Petrópolis 36, 39-40, 90

Pfannenschmidt 13, 30-31, 93

Philipp Holzmann \& Co. Ltda. 59-60

Pholig (empresa) 29

Pinilla, Claudio 71

Piray (río) 42

Porto Velho (estación radiotelegráfica) 74

Portugalete 25

Potosí 28

Cerro Rico 25 ; ciudad 52, 93; departamento 25, 45, 50-51; Escuela de Minas 29; inversión británica 7, 23

Primera Guerra Mundial 10, 12, 66-67, 77-79, 83, 87, 91, 95, 97-99, 102, 104

Puerto Alonso 35-36

Puerto Suárez 41 estación radiotelegráfica 68

Pulacayo (ferrocarril) 47

Puno 45, 50

Purus (río) 33

Querejazu Calvo, R. 7

Reck, Hugo 29

Reglamento de Inmigración Libre (Bolivia) 95

Reinecke 92

Reintgen, P. 30-31

República de Weimar 46, 57, 77, 98

República Federal de Alemania archivos 8, 65

República Independiente del Acre 36

Revolución Federal (Bolivia) 101

Reyes (ciudad) 41

Rhodesia 38

Riberalta 41 estación radiotelegráfica 68,70 ; ferrocarril 52

Richter, Otto 28

Rio Branco (barón) 40

Rio de Janeiro 36

Rippy, J. F. 7

Risler, André 72 
Rivero Torres, Juan 54

Rößer 41

Roosevelt, Emlen 38

Rosario (puerto) 50-51, 70

Rosenbluth, Enrique 28

Rothschild 38

Rück, Otto 29

Salinas Vega 36-37, 39, 89

San Antonio 52 estación radiotelegráfica 71

Sanden von $72-74$

Santa Cruz casas comerciales alemanas 42 ; ciudad 41-42, 52, 55, 61-62; departamento 33, 62; estación radiotelegráfica 68

Santarem (estación radiotelegráfica) 71 Santiago de Chile 57, 71, 91, 98

Sayville (estación radiotelegráfica) 66

Schnack 41

Schütt, Nicolás Jürgen 93

Schweitzer 42

Siemens 75

Siemens \& Halske 65-66

Siemens-Schuckert 28-29

Sievers 22, 31

Siles Guevara, J. 7

Sindicato Fomento del Oriente Boliviano 62-63

Sociedad Anónima Luz y Fuerza Eléctrica 55, 60

Sociedad Explotadora del Desierto de Atacama 23

Sociedad Minera de Oro 27-28

Sociedad Minera y Mercantil Aramayo y Co. 26

Sociedad Sir John Jackson Limited 59

Societé Picollet 41

Speyer and Co. 54, 59

Staatsanzeiger (órgano de prensa) 58

Stappenbeck, R. 22, 27, 29

Staudt \& Co. 63

Stegmann, Wilhelm 5

Stifel, Nicolaus 55

Stösen 41

Stricker 62

Stumpf, Augusto 29
Stumpf, Gustavo 92

Suárez

familia 41; Hermanos 41; Hermanos \& Co. 41; Hermanos \& Co. Ltd. 41; R. \& Co. 41

Sucre (ciudad) 52

Suramérica 30, 38, 40, 66, 82, 93, 98

Tahuamanu (río) 33

Tambs 31, 35

Tandeter 7

Telefunken 66-67, 74, 76 instalación de estaciones radiotelegráficas en Bolivia 10, 68, 70-77; rivalidad von la compañía Marconi $11,65,67-71,73-74,77$

Tesoro Nacional (del Estado de Bolivia) 55

The American Fund for Public Service 7

The Antofagasta and Bolivia Railway Co. 54-55

The Bolivian Rubber Co. of Baltimore 41

The Bolivian Syndicate 37-40, 103

The Chicago-Bolivian Rubber Co. 41

The National City Bank 54, 49

The Orton (Bolivia) Rubber Co. Ltd. 41

The Royal Silver Mines of Potosi, Bolivia Limited 25

Thomson 30

Titicaca (lago) 45, 47

Togo (radiotelegrafía) 67

Torrico, Carlos 73

Tratado de Amistad y Comercio (Alemania-Bolivia) 91

Tratado de Petrópolis 36, 51

Tratado de Versalles 98

Tratado Muñoz-Netto 35

Trepp (casa comercial) 95

Trinidad ciudad 41-42; estación radiotelegráfica 68

Twombly, K. 38

Ule, E. 30

Ulen Contracting Co. 55

Uncía (minas) 26 
United States (véase Estados Unidos)

Universidad Mayor de San Andrés (Biblioteca) 10

Uruguay 66,82

Uyuni (ferrocarril) 45, 47, 51-52, 54

Uzarski 31

Vaca Diez, Antonio 41

vinculación con (capital alemán) 10, 41 (finanzas británicas y francesas) 40-41

Vacano, M. J. 28

Valparaiso (estación radiotelegráfica) 73

Vanderbilt (familia) 38

Vanguardia (órgano de prensa) 97

Velasco y Henicke 41

Venezuela 78,82

Vermilye Co. 38

Villa Bella estación radiotelegráfica 68, 70; Zieriacks 92 ferrocarril 51-52
Villa Montes 62

Villalobos, Rosendo 70-71

Villinger 41

Vinto (tranvía eléctrico) 60

Voß y Müller 41

Weber 62

Whitridge Willingford, Federico 3738,40

Windhuk (radiotelegrafía) 67

Wisher, A. \& Co. 92

Yacuiba 62 estación radiotelegráfica 68 Yacuma (río) 42

Yungas

extracción de plata 27-28; ferrocarril 52; goma 33, 50

Zeller 41

Zizold 92 
Palabras de Agradecimiento 5

I. PRÓLOGO 7

II. LA EXPLOTACIÓN DE MATERIAS PRIMAS

EN BOLIVIA Y EL IMPERIO ALEMÁN 13

$\begin{array}{ll}\text { 1. El caso de la producción minera } & 13\end{array}$

2. El caso de la goma natural $\quad 30$

3. Evaluación de la influencia del Imperio Alemán
en el sector extractivo de Bolivia

III. ALEMANIA Y EL DESARROLLO DEL SISTEMA DE
TRANSPORTES Y COMUNICACIONES EN BOLIVIA

1. El desarrollo ferroviario 46

2. El establecimiento de estaciones radiotelegráficas 64

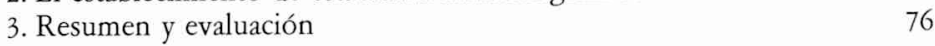

IV. LAS RELACIONES COMERCIALES GERMANO-BOLIVIANAS 78

1. La expansión del comercio exterior de Bolivia 78

2. La importancia de Alemania en el comercio exterior

3. Factores determinantes de la influencia

del Imperio Alemán $\quad 91$

4. La decadencia de la influencia de Alemania
en el comercio boliviano después de 1917

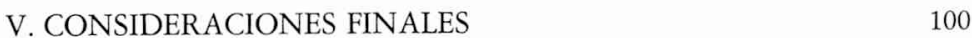

$\begin{array}{ll}\text { Notas } & 105\end{array}$

$\begin{array}{ll}\text { Bibliografía } & 121\end{array}$

$\begin{array}{lr}\text { Indice } & 127\end{array}$ 


\section{INDICE DE MAPAS}

Mapa II. 1 Bolivia. Depósitos Minerales en el Macizo Boliviano

Mapa II. 2 Bolivia: Región Norte y Central

Mapa III. 1

Ferrocarriles en Bolivia. Desarrollo en 1925

Mapa III. 2 Proyecto del gobierno de Bolivia para instalar estaciones radiotelegráficas. 1911

\section{INDICE DE GRAFICOS}

Gráfico II. 1 Participación por países en la producción mundial de la plata (1811-1910)

Gráfico II. 2 Producción del estaño en Bolivia (1890-1940)

\section{INDICE DE CUADROS}

Cuadro II. 1 Producción de plata en Bolivia (1870-1904)

Cuadro II. 2 Participación por países en la producción mundial de la plata (1861-1910)

Cuadro II. 3 Producción del estaño en Bolivia (1892-1908)

Cuadro II. 4 Exportación de estaño de Bolivia (1900-1920)

Cuadro II. 5

Bolivia: Participación porcentual del estaño y de la plata en el total de las exportaciones (1900-1920)

Cuadro II. 6 Bolivia: Exportación de minerales en el quinquenio anterior a la Primera Guerra Mundial

Cuadro II. 7 List of Shareholders of the Huanchaca Company, 1874

Cuadro II. 8 Volumen y valor de las exportaciones agrícolas de Bolivia (1909-1913)

Cuadro II. 9 Producción de goma boliviana (1890-1913)

Cuadro II. 10 Participación porcentual de la goma en el total de las exportaciones bolivianas (1900-1920) 32

Cuadro III. 1 Red ferroviaria de Bolivia en 1925. Extensión y costo

Cuadro III. 2 Financiamiento del sistema ferroviario de Bolivia. $1887-1925$

Cuadro III. 3 Distancias de los enlaces radiotelegráficos de Alemania y de Gran Bretaña en 1914

Cuadro III. 4 Presupuestos para la instalación de 7 estaciones radiotelegráficas en Bolivia. 1911

Cuadro III. 5 Estaciones radiotelegráficas de Bolivia. 1925 
Cuadro IV. 1 Participación de países suramericanos en el total del comercio exterior de la región. 1907

Cuadro IV. 2 Desarrollo del comercio exterior de Bolivia 1895-1920 80

Cuadro IV. 3 Bolivia. Importaciones (1902-1903) 81

Cuadro IV. 4 Intercambio comercial de países desarrollados con Suramérica (1890 y 1900) 83

Cuadro IV.5 Desarrollo del comercio germano-boliviano. 1895-1913 84

Cuadro IV. 6 Exportaciones de Bolivia a Alemania (1904 y 1908) 86

Cuadro IV. 6a Exportaciones de Alemania a Bolivia en $1900 \quad 86$

Cuadro IV. 7 Participación del Imperio Alemán en el comercio exterior de Bolivia (1895-1913) 87

Cuadro IV. 8 Participación del Imperio Alemán y de Gran Bretaña en el comercio exterior de Bolivia (1898-1905) 88

Cuadro IV. 9 Comercio exterior de Bolivia con diversos países $1917-1921$

Cuadro en nota Producción de plata en Bolivia desde 1895

Capítulo II. 2

106

Cuadro en nota Participación de los países productores más importantes Capítulo II. 4 en la producción mundial de estaño (1851-1925) 



\section{BIBLIOTHECA IBERO-AMERICANA}

Veröffentlichungen des Ibero-Amerikanischen Instituts

Preußischer Kulturbesitz

Herausgegeben von Wilhelm Stegmann

Max Uhle

Wesen und Ordnung der altperuanischen Kulturen

Aus dem Nachlaß herausgegeben von Gerdt Kutscher

Band $1 \cdot 132$ Seiten, 2 Tafeln, 7 Abb. (vergriffen)

Hans Horkheimer

Nabrung und Nabrungsgewinnung im vorspanischen Peru

Band $2 \cdot 160$ Seiten, 8 Tafeln, 7 Abb. ISBN 3767800705

Miguel de Ferdinandy

En torno al pensar mítico

Nueve variaciones sobre el tema del mito en folklore, arte, poesía e historia

Band $3 \cdot 260$ Seiten (vergriffen)

Peter A. Schmitt

Paraguay und Europa

Die diplomatischen Beziehungen unter Carlos Antonio López

und Francisco Solano López 1841-1870

Band $4 \cdot 368$ Seiten ISBN 3767801213

Rudolf Geske

Góngoras Warnrede im Zeichen der Hekate

Band $5 \cdot 135$ Seiten ISBN 3767801434

Cary Hector

Der Staatsstreich als Mittel der politischen Entwicklung in Südamerika

Band $6 \cdot 226$ Seiten ISBN 376781485

Fritz Hoppe

Portugiesisch-Ostafrika in der Zeit des Marquês der Pombal (1750-1777)

Band $7 \cdot 360$ Seiten ISBN 376781604

Juan Carlos Agulla

Soziale Strukturen und soziale Wandlungen in Argentinien

Band 8 280 Seiten, zahlr. Tab. und graph. Darstellungen ISBN 3767801957

Friedel Maurer-Rothenberger

Die Mitteilungen des Guzmán de Alfarache

Band 9 $\cdot 131$ Seiten ISBN 3767801973

Georg Thomas

Die portugiesische Indianerpolitik in Brasilien 1500-1640

Band $10 \cdot 244$ Seiten ISBN 3767802058 
Ulrich Fleischmann

Ideologie und Wirklichkeit in der Literatur Haitis

Band $11 \cdot 312$ Seiten ISBN 376782449

Ronald Daus

Der epische Zyklus der Cangaceiros

in der Volkspoesie Nordostbrasiliens

Band $12 \cdot 156$ Seiten ISBN 3767802457

Martin Gerbert

Religionen in Brasilien

Band $13 \cdot 128$ Seiten ISBN 3767802678

Käte Harms-Baltzer

Die Nationalisierung der deutschen Einwanderer und ibrer Nachkommen in Brasilien als Problem der deutsch-brasilianischen Beziebungen

Band $14 \cdot 248$ Seiten ISBN 3767802732

Thomas Baecker

Die deutsche Mexikopolitik 1913/1914

Band $15 \cdot 352$ Seiten ISBN 3767802945

Klaus Rother

Wirtschaft und Berufserziebung in Venezuela

Band 16 200 Seiten ISBN 3767803194

Gustav Siebenmann

Die neuere Literatur Lateinamerikas

und ibre Rezeption im deutschen Sprachraum

Band $17 \cdot 96$ Seiten ISBN 3767803259

Reinhard Peterwerth

Das Vertragswerk des Zentralamerikanischen Gemeinsamen Marktes

Band $18 \cdot 134$ Seiten ISBN $376780333 \mathrm{X}$

Armando Abad Franco

Parteiensystem und Oligarchie in Ecuador

Band $19 \cdot 292$ Seiten ISBN 3767803631

Renate Garcia y Más

Die Biblioteca Nacional in Madrid

Band $20 \cdot 128$ Seiten ISBN 3767803763

Konrad Tyrakowski

Ländliche Siedlungen im Becken von Puebla Tlaxcala

(Mexiko) und ibre Entwicklung im 19. und 20. Jabrbundert

Band $21 \cdot 120$ Seiten mit zahlr. Abb. ISBN 3767803852 
Waldo Ross

Problemática de la literatura bispanoamericana

Band $22 \cdot 76$ Seiten ISBN 3767803968

Richard A. Cardwell

Juan R. Jiménez: The Modernist Apprenticeship 1895-1900

Band $23 \cdot 329$ Seiten ISBN 3767804277

Arnold Spitta

Paul Zech im südamerikanischen Exil 1933-1946

Ein Beitrag zur Geschichte der deutschen Emigration in Argentinien

Band $24 \cdot 296$ Seiten ISBN 3767804506

Hans Haufe

Funktion und Wandel christlicher Themen in der mexikanischen Malerei des 20. Jh.

Band $25 \cdot$ Textteil 232 Seiten, Bildteil 130 Seiten (323 Abb.)

ISBN 3767804492

La emigración europea a la América Latina: Fuentes y estado de investigación

(IV. Reunión de Historiadores Latinoamericanistas Europeos)

Band $26 \cdot 272$ Seiten ISBN 3767804514

Gerónimo de Vivar: Crónica y relación copiosa y verdadera de los Reinos de Chile (1558)

Edición de Leopoldo Sáez-Godoy

Band $27 \cdot 368$ Seiten ISBN $376780462 \mathrm{X}$

Nicolas de Valenzuela: Conquista del Lacandón y conquista del Cbol

Relación sobre la expedición de 1695 contra los Lacandones e Itzá según el "Manuscrito de Berlin"

Edición y comentario de Götz Freiherr von Houwald

Band 28 - Tomo I: Texto 510 Seiten - Tomo II: Comentario 200 Seiten

ISBN 3767804859

Evelyn Fishburn

The Portrayal of Immigration in Nineteenth Century Argentine Fiction (1845-1902)

Band $29 \cdot 264$ Seiten ISBN 3767805235

León Enrique Bieber

En torno al origen bistórico e ideológico

del ideario Nacionalista Populista Latinoamericano

Gestación, elaboración y vigencia de la concepción aprista de Haya de la Torre Band $30 \cdot 88$ Seiten ISBN 3767805766

León Enrique Bieber

Las relaciones económicas de Bolivia con Alemania 1880-1920

Band $31 \cdot 144$ Seiten ISBN 3767806053 





influencia, y un país en el cual los grupos de poder buscaron ayuda económica foránea como medio para promover la modernización. 2da) El rasgo sobresaliente de aquellas relaciones fue el intercambio comercial y no la inversión de capitales; vale decir que ellas tuvieron un carácter marcadamente mercantil. 3ra) En sus relaciones económicas con Bolivia, Alemania no logró transformar el maduro desarrollo mercantil en una política de clara raigambre imperialista.

León Enrique Bieber nació en La Paz (Bolivia) en 1943. En 1968 obtuvo el título de licenciatura en Ciencias Políticas y en 1978 el de Dr. phil. de la Universidad Libre de Berlín. Fue docente en el Instituto Latinoamericano de esa Universidad, en la Pontificia Universidad Católica del Ecuador, en la Facultad Latinoamericana de Ciencias Sociales en Quito y en la Universidad Mayor de San Andrés de La Paz. Desde mediados de 1981 hasta fines de 1983 trabajó como investigador adjunto en el Instituto Ibero-Americano de Berlín. Ha publicado una serie de trabajos sobre diversos aspectos del desarrollo económico, social y político de la Argentina, Bolivia y Ecuador. En 1982 el "Colloquium Verlag" editó como publicación de la Bibliotheca Ibero-Americana su libro "En torno al origen histórico e ideológico del ideario nacionalista populista latinoamericano". 
